\title{
Variational inequalities and fixed point problems : a survey
}

\author{
Renu Chugh and Rekha Rani * \\ Department of Mathematics, Maharshi Dayanand University, Rohtak (INDIA)- 124001 \\ *Corresponding author E-mail: rekhadalal93@gmail.com
}

Copyright () 2014 Renu Chugh and Rekha Rani. This is an open access article distributed under the Creative Commons Attribution License, which permits unrestricted use, distribution, and reproduction in any medium, provided the original work is properly cited.

\begin{abstract}
The variational inequality problem provides a broad unifying setting for the study of optimization, equilibrium and related problems and serves as a useful computational framework for the solution of a host of problems in very diverse applications. Variational inequalities have been a classical subject in mathematical physics, particularly in the calculus of variations associated with the minimization of infinite-dimensional functionals. This paper presents a survey of main results related to variational inequalities and fixed point problems defined on real Hilbert spaces and Banach spaces.
\end{abstract}

Keywords: Fixed Point Problem, Inverse-Strongly-Monotone Mappings, Monotone Mappings, Projection Mappings, Variational Inequality Problem.

\section{Introduction}

Variational inequalities were formulated between the end of 60' and the beginning of 70' of previous century by the italian mathematician G. Stampacchia [16]. In recent years, variational inequality theory has been extended and generalized in several directions, using new and powerful methods, to study a wide class of unrelated problems in a unified and general framework. The theory of variational inequalities represents, in fact, a very natural generalization of the theory of boundary value problems and allows us to consider new problems arising from many fields of applied mathematics, such as mechanics, physics, engineering, the theory of convex programming and the theory of control. While the variational theory of boundary value problems has its starting point in the method of orthogonal projection, the theory of variational inequalities has its starting point in the projection on a convex set. They provide a very general framework for a wide range of mathematical problems among which, rather under general hypotheses, optimization ones. Moreover, they have shown to be important models in the study of equilibrium problems [40], in the engineering sciences (equilibrium problems in a traffic network) and in the economic sciences (oligopolistic market equilibrium problems) [7], [10], [6]. Such problems, in fact, play a crucial role in the theory of complex systems and for this reason, recently, has been presented many variational formulations of these problems. It is well known that the classical variational inequality is equivalent to a fixed point problem. This alternative equivalent formulation has played a major role in variational inequalities. In particular, the solution of the variational inequalities can be computed using iterative algorithms; see [1], [32], [46], [45], [44], [38], [59], [57], and [63]. Indeed, many well-known problems arising in various branches of science can be studied by using algorithms which are iterative in their nature. As an example, in computer tomography with limited data, each piece of information implies the existence of a convex set $C_{m}$ in which the required solution lies. The problem of finding a point in the intersection $\bigcap_{m=1}^{N} C_{m}$ is then of crucial interest but cannot be usually solved directly. Therefore, an iterative algorithm must be used to approximate such a point. One of the most important and difficult problems in this theory is the development of an efficient and implementable iterative algorithm for solving variational inequalities. As a result of interaction between different branches of mathematical and engineering sciences, we now have a variety of techniques to suggest and analyze various

Numerical methods including projection technique and its variant forms, auxiliary principle, and Wiener-Hopf equations for solving variational inequalities and related optimization problems. Related to the variational inequalities, we have the problem of finding the fixed points of the nonexpansive mappings, which is the subject of current interest in functional analysis. It is natural to consider a unified approach to these two different problems. 
The development of the finite-dimensional variational inequalities also began in the mid-1960s but followed a different path. Unlike its infinite-dimensional counterpart, which was conceived in the area of partial differential systems, the finite-dimensional variational inequality was born in the domain of Mathematical Programming. The developments include a rich mathematical theory, a host of effective solution algorithms and a multitude of interesting connections to numerous disciplines. The variational inequality problem is considered within optimization theory as a natural extension of minimization problems, see [45].

\section{Definitions}

Let $\mathrm{H}$ be a real Hilbert space with inner product $\langle.,$.$\rangle and norm \|$.$\| , respectively. Let \mathrm{C}$ be a closed convex subset of $\mathrm{H}$.

The variational inequality problem is to find $\mathrm{u} \in \mathrm{C}$ such that $\langle\mathrm{Au}, \mathrm{v}-\mathrm{u}\rangle \geq 0, \forall \mathrm{v} \in \mathrm{C}$.

The set of solutions of variational inequality problem $\operatorname{VI}(\mathrm{C}, \mathrm{A})$ is denoted by $\Omega$. The variational inequality problem has been extensively studied in literature; see, for example, [7], [10], [6] and references therein.

Definitions: Let $\mathrm{A}: \mathrm{C} \rightarrow \mathrm{H}$ be a mapping of $\mathrm{C}$ into $\mathrm{H}$.

1) A is called monotone if $\langle A u-A v, u-v\rangle \geq 0 \forall u, v \in C$.

Monotone operators are the key ingredient of monotone variational inequalities.

2) $\mathrm{A}$ is called $\alpha$-inverse-strongly-monotone [12], [13] if there exists a positive real number $\alpha$ such that $<\mathrm{Au}-\mathrm{Av}, \mathrm{u}-\mathrm{v}>\geq \alpha\|\mathrm{Au}-\mathrm{Av}\|^{2} \forall \mathrm{u}, \mathrm{v} \in \mathrm{C}$.

It is easy to see that a $\alpha$-inverse-strongly mapping $\mathrm{A}$ is monotone and Lipschitz continuous but converse is not true.

3) $\mathrm{A}$ is called $\beta$-strongly-monotone if there exists a positive real number $\alpha$ such that $\langle\mathrm{Au}-\mathrm{Av}, \mathrm{u}-\mathrm{v}\rangle$ $\geq \beta\|\mathrm{u}-\mathrm{v}\|^{2} \forall \mathrm{u}, \mathrm{v} \in \mathrm{C}$.

4) A mapping $\mathrm{S}: \mathrm{C} \rightarrow \mathrm{C}$ is called nonexpansive [55-56] if $\|\mathrm{Su}-\mathrm{Sv}\| \leq\|\mathrm{u}-\mathrm{v}\| \forall \mathrm{u}, \mathrm{v} \in \mathrm{C}$.

We denote by $F(S)$ the set of fixed points of $S$.

5) A mapping $\mathrm{S}: \mathrm{C} \rightarrow \mathrm{C}$ is called Lipschitz continuous if there exists a real number $\mathrm{L}>0$ such that $\|\mathrm{Su}-\mathrm{Sv}\| \leq \mathrm{L}$ $\|\mathrm{u}-\mathrm{v}\| \forall \mathrm{u}, \mathrm{v} \in \mathrm{C}$

6) A mapping $\mathrm{S}: \mathrm{C} \rightarrow \mathrm{C}$ is called contraction if there exists a real number $\alpha \in(0,1)$ such that $\|\mathrm{Su}-\mathrm{Sv}\|$ $\leq \alpha\|\mathrm{u}-\mathrm{v}\| \forall \mathrm{u}, \mathrm{v} \in \mathrm{C}$.

7) A mapping $\mathrm{S}: \mathrm{C} \rightarrow \mathrm{C}$ is called strictly pseudo-contractive with the coefficient $\mathrm{k} \epsilon(0,1)$ if $\|\mathrm{Su}-\mathrm{Sv}\|^{2}$ $\leq\|\mathrm{u}-\mathrm{v}\|^{2}+\mathrm{k}\|(\mathrm{I}-\mathrm{S}) \mathrm{u}-(\mathrm{I}-\mathrm{S}) \mathrm{v}\|^{2} \forall \mathrm{u}, \mathrm{v} \in \mathrm{C}$.

For such a case, $\mathrm{S}$ is also said to be a k-strict pseudo-contraction.

8) A mapping $\mathrm{S}: \mathrm{C} \rightarrow \mathrm{C}$ is called pseudo-contractive if $\langle\mathrm{Su}-\mathrm{Sv}, \mathrm{u}-\mathrm{v}\rangle \leq\|\mathrm{u}-\mathrm{v}\|^{2} \forall \mathrm{u}, \mathrm{v} \in \mathrm{C}$.

9) A mapping $\mathrm{S}: \mathrm{C} \rightarrow \mathrm{C}$ is called asymptotically nonexpansive [28] if there exists a sequence $\left\{\mathrm{k}_{\mathrm{n}}\right\}$ of positive numbers such that limn $\rightarrow \infty \mathrm{k}_{\mathrm{n}}=1$ and $\left\|\mathrm{S}^{\mathrm{n}} \mathrm{u}-\mathrm{S}^{\mathrm{n}} \mathrm{v}\right\| \leq \mathrm{k}_{\mathrm{n}}\|\mathrm{u}-\mathrm{v}\| \forall \mathrm{u}, \mathrm{v} \in \mathrm{C}, \forall \mathrm{n} \geq 1$.

10) A mapping $\mathrm{S}: \mathrm{C} \rightarrow \mathrm{C}$ is called asymptotically nonexpansive [47] in the intermediate sense provided $\mathrm{S}$ is uniformly continuous and $\lim _{n \rightarrow \infty} \sup _{\mathrm{u}, \mathrm{v} \varepsilon \mathrm{C}}^{\sup }\left(\left\|S^{\mathrm{n}} \mathrm{u}-\mathrm{S}^{\mathrm{n}} \mathrm{v}\right\|-\|\mathrm{u}-\mathrm{v}\|\right) \leq 0$.

11) A mapping $\mathrm{S}: \mathrm{C} \rightarrow \mathrm{C}$ is called uniformly Lipschitzian if there exists a real number $\mathrm{L}>0$ such that $\left\|\mathrm{S}^{\mathrm{n}} \mathrm{u}-\mathrm{S}^{\mathrm{n}} \mathrm{v}\right\|$ $\leq \mathrm{L}\|\mathrm{u}-\mathrm{v}\| \forall \mathrm{u}, \mathrm{v} \in \mathrm{C}, \forall \mathrm{n} \geq 1$.

Let $\mathrm{A}$ be an inverse strongly monotone mapping. Then, in the context of the variational inequality problem, it is easy to see that

$\mathrm{u} \in \Omega \Leftrightarrow \mathrm{u}=\mathrm{P}_{\mathrm{C}}(\mathrm{u}-\lambda \mathrm{Au})$, for any $\lambda>0$.

So to find the solutions of variational inequality problem, we shall use projection mappings. Now we describe some properties of projection mappings.

Some Properties of Projection Mapping:

Let $\mathrm{H}$ be a real Hilbert space with inner product $\langle.$, . $\rangle$ and norm $\|$.$\| . Let \mathrm{C}$ be a closed convex subset of $\mathrm{H}$. We shall write $x_{n} \rightarrow x$ to indicate that the sequence $\left\{x_{n}\right\}$ converges weakly to $x . x_{n} \rightarrow x$ implies that $\left\{x_{n}\right\}$ converges strongly to $x$. It is well known that for any $x \in H$, there exists a unique nearest point in $C$, such that $\left\|u-P_{C} x\right\|=\inf \{\|u-y\|: y \in C\}$ $\mathrm{P}_{\mathrm{C}}$ is called the metric projection of $\mathrm{H}$ onto $\mathrm{C}$. The metric projection $\mathrm{P}_{\mathrm{C}}$ of $\mathrm{H}$ onto $\mathrm{C}$ satisfies

$<\mathrm{x}-\mathrm{y}, \mathrm{P}_{\mathrm{C}} \mathrm{x}-\mathrm{P}_{\mathrm{C}} \mathrm{y}>\geq\left\|\mathrm{P}_{\mathrm{C}} \mathrm{x}-\mathrm{P}_{\mathrm{C}} \mathrm{y}\right\|^{2}$, for every $\mathrm{x}, \mathrm{y} \in \mathrm{H}$,

$\mathrm{P}_{\mathrm{C}}$ is characterized by the properties: $\mathrm{P}_{\mathrm{C}} \mathrm{X} \in \mathrm{C}$,

$<\mathrm{x}-\mathrm{P}_{\mathrm{C}} \mathrm{x}, \mathrm{y}-\mathrm{P}_{\mathrm{C}} \mathrm{x}>\leq 0$, for all $\mathrm{x} \in \mathrm{H}, \mathrm{y} \in \mathrm{C}$,

$\|\mathrm{x}-\mathrm{y}\|^{2} \geq\left\|\mathrm{x}-\mathrm{P}_{\mathrm{C}} \mathrm{x}\right\|^{2}+\left\|\mathrm{y}-\mathrm{P}_{\mathrm{C}} \mathrm{x}\right\|^{2}$, for all $\mathrm{x} \in \mathrm{H}, \mathrm{y} \in \mathrm{C}$.

It is known that $\mathrm{H}$ satisfies the Opial condition [68], that is, for any sequence $\left\{\mathrm{x}_{\mathrm{n}}\right\}$ with $\mathrm{x}_{\mathrm{n}} \rightarrow \mathrm{x}$, the inequality,

$\lim _{n \rightarrow \infty} \inf \left\|x_{n}-x\right\|<\lim _{n \rightarrow \infty} \inf \left\|x_{n}-y\right\|$

holds for every $\mathrm{y} \in \mathrm{H}$ with $\mathrm{y} \neq \mathrm{x}$. We also know that, if $\left\{\mathrm{x}_{\mathrm{n}}\right\}$ is sequence of $\mathrm{H}$ with $\mathrm{x}_{\mathrm{n}} \rightarrow \mathrm{x}$ and $\left\|\mathrm{x}_{\mathrm{n}}\right\| \rightarrow\|\mathrm{x}\|$, then there holds that $\mathrm{x}_{\mathrm{n}} \rightarrow \mathrm{x}$.

A set valued mapping $\mathrm{T}: \mathrm{H} \rightarrow 2^{\mathrm{H}}$ is called monotone if for all $\mathrm{x}, \mathrm{y} \in \mathrm{H}, \mathrm{f} \in \mathrm{Tx}$ and $\mathrm{g} \in \mathrm{Ty}$ imply $\langle\mathrm{x}-\mathrm{y}, \mathrm{f}-\mathrm{g}\rangle \geq 0$. A monotone mapping $\mathrm{T}: \mathrm{H} \rightarrow 2^{\mathrm{H}}$ is maximal if its graph $\mathrm{G}(\mathrm{T})$ is not properly contained in the graph of any other monotone mapping. It is known that a monotone mapping $\mathrm{T}$ is maximal if and only if for ( $\mathrm{x}, \mathrm{f}) \in \mathrm{H} \times \mathrm{H},\langle\mathrm{x}-\mathrm{y}, \mathrm{f}-\mathrm{g}>\geq 0$ for every $(y, g) \in G(T)$ implies $f \in T x$.

Let $\mathrm{A}: \mathrm{C} \rightarrow \mathrm{H}$ be a monotone, $\mathrm{k}$ - Lipschitz continuous mapping and $\mathrm{N}_{\mathrm{C}} \mathrm{v}$ be the normal cone to $\mathrm{C}$ at $\mathrm{v} \in \mathrm{C}$, that is, 
$\mathrm{N}_{\mathrm{C}} \mathrm{v}=\{\mathrm{w} \in \mathrm{H}:\langle\mathrm{v}-\mathrm{u}, \mathrm{w}>\geq 0, \forall \mathrm{u} \in \mathrm{C}\}$

Define, $\mathrm{Tv}= \begin{cases}A v+\mathrm{N}_{\mathrm{C}} \mathrm{v}, & \text { if } \mathrm{v} \in \mathrm{C} \\ \phi, & \text { if } \mathrm{v} \notin \mathrm{C}\end{cases}$

Then, $\mathrm{T}$ is maximal monotone [49-50] and $0 \in \mathrm{Tv}$ if and only if $\mathrm{v} \in \mathrm{VI}(\mathrm{C}, \mathrm{A})$

If $\mathrm{A}$ is a $\alpha$-inverse-strongly-monotone mapping of $\mathrm{C}$ into $\mathrm{H}$, then it is obvious that $\mathrm{A}$ is $1 / \alpha$-Lipschitz continuous. We also have that for all $\mathrm{x}, \mathrm{y} \in \mathrm{C}$ and $\lambda>0$,

$\|(\mathrm{I}-\lambda \mathrm{A}) \mathrm{x}-(\mathrm{I}-\lambda \mathrm{A}) \mathrm{y}\|^{2}=\|(\mathrm{x}-\mathrm{y})-\lambda(\mathrm{Ax}-\mathrm{Ay})\|^{2}$

$=\|\mathrm{x}-\mathrm{y}\|^{2}-2 \lambda<\mathrm{x}-\mathrm{y}, \mathrm{Ax}-\mathrm{Ay}>+\lambda^{2}\|\mathrm{Ax}-\mathrm{Ay}\|^{2}$

$\leq\|\mathrm{x}-\mathrm{y}\|^{2}+\lambda(\lambda-2 \alpha)\|\mathrm{Ax}-\mathrm{Ay}\|^{2}$

So, if $\lambda \leq \alpha$, then $\mathrm{I}-\lambda \mathrm{A}$ is a nonexpansive mapping of $\mathrm{C}$ into $\mathrm{H}$.

\section{Main results}

Let $\mathrm{H}$ be a real Hilbert space with inner product $\langle.,$.$\rangle and norm \|$.$\| , respectively. Let \mathrm{C}$ be a closed convex subset of $\mathrm{H}$. Let $\mathrm{A}: \mathrm{C} \rightarrow \mathrm{H}$ be a nonlinear mapping.

The classical variational inequality problem is to find $\mathrm{u} \in \mathrm{C}$ such that

$<\mathrm{Au}, \mathrm{v}-\mathrm{u}>\geq 0, \forall \mathrm{v} \in \mathrm{C}$,

which is introduced and studied by Stampacchia [16].

The set of solutions of variational inequality problem $\operatorname{VI}(\mathrm{C}, \mathrm{A})$ is denoted by $\Omega$. The variational inequality problem has been extensively studied in literature, see, for example,[7], [10], [6] and references therein.

A first geometric interpretation of $\operatorname{VIP}(C, A)$, defined by inequality (3.1), is that $u$ in $C$ is a solution of $\operatorname{VIP}(C, A)$ if and only if there exists Au which forms a non-obtuse angle with every vector of the form $\mathrm{v}-\mathrm{u}$ with $\mathrm{v} \in \mathrm{C}$.

\subsection{Results regarding solution of variational inequalities and fixed point problems in Hilbert spaces}

The following result was given by Takahashi and Toyoda [57], for the existence of solutions of the variational inequality problem for $\alpha$-inverse-strongly-monotone mappings.

Proposition [57]. Let $\mathrm{C}$ be a bounded closed convex subset of a real Hilbert space $\mathrm{H}$ and let $\mathrm{A}$ be an $\alpha$-inverse-stronglymonotone mapping of $\mathrm{C}$ into $\mathrm{H}$. Then, $\mathrm{VI}(\mathrm{C}, \mathrm{A})$ is nonempty.

In 2003, W. Takahashi and M. Toyoda [57] introduced an iteration process for finding a common element of the set of fixed points of a nonexpansive mapping and the set of solutions of a variational inequality problem for an inverse strongly-monotone mapping and then obtained a weak convergence theorem.

Theorem.3.1.1. [57] Let $\mathrm{K}$ be a closed convex subset of a real Hilbert space H. Let $\alpha>0$. Let $\mathrm{A}$ be an $\alpha$-inversestrongly-monotone mapping of $\mathrm{K}$ into $\mathrm{H}$ and let $\mathrm{S}$ be a nonexpansive mapping of $\mathrm{K}$ into itself such that $\mathrm{F}(\mathrm{S}) \cap \mathrm{VI}(\mathrm{K}, \mathrm{A})$ $\neq \phi$. Let $\left\{\mathrm{x}_{\mathrm{n}}\right\}$ be a sequence generated by

$\mathrm{x}_{0}=\mathrm{x} \in \mathrm{K}$,

$\mathrm{x}_{\mathrm{n}+1}=\alpha_{\mathrm{n}} \mathrm{x}_{\mathrm{n}}+\left(1-\alpha_{\mathrm{n}}\right) \mathrm{SP}_{\mathrm{K}}\left(\mathrm{x}_{\mathrm{n}}-\lambda_{\mathrm{n}} \mathrm{A} \mathrm{x}_{\mathrm{n}}\right)$,

for every $n=0,1,2, \ldots \ldots \ldots$, where $\left\{\lambda_{n}\right\} \subset[a, b]$ for some $a, b \in(0,2 \alpha)$ and $\left\{\alpha_{n}\right\} \subset[c, d]$ for some $c, d \in(0,1)$. Then, $\left\{x_{n}\right\}$ converges weakly to $z \in F(S) \cap$ VI $(K, A)$, where $z=\lim _{n \rightarrow \infty} P_{F(S) \cap V I(C, A)} x_{n}$.

Lemma [52] Let $C$ be a closed convex subset of a real Hilbert space H. Let $S$ be a nonexpansive mapping of $C$ into itself such that $F(S) \neq \phi$. Then $F(S)=F\left(P_{C} S\right)$.

In 2004, using above lemma given by S. Matsushita and D. Kuroiwa [52] and motivated by the result given by W. Takahashi and M. Toyoda [57], Hideaki Iiduka and Wataru Takahashi [18], introduced an iterative scheme for finding a common element of the set of fixed points of a nonexpansive nonself-mapping and the set of solutions of the variational inequality for an inverse-strongly-monotone mapping in a Hilbert space. Then they showed that the sequence converges strongly to a common element of two sets.

Theorem.3.1.2: [18] Let $C$ be a closed convex subset of a real Hilbert space $H$. Let $A$ be an $\alpha$-inverse-stronglymonotone mapping of $C$ into $H$ and let $S$ be a nonexpansive mapping of $C$ into itself such that $F(S) \cap V I(C, A) \neq \phi$. Let $\left\{x_{n}\right\}$ be a sequence generated by $x_{0}=x \in C$,

$\mathrm{x}_{\mathrm{n}+1}=\mathrm{P}_{\mathrm{C}}\left(\alpha_{\mathrm{n}} \mathrm{x}+\left(1-\alpha_{\mathrm{n}}\right) \mathrm{SP}_{\mathrm{C}}\left(\mathrm{x}_{\mathrm{n}}-\lambda_{\mathrm{n}} \mathrm{A} \mathrm{x}_{\mathrm{n}}\right)\right)$,

for every $n=0,1,2, \ldots \ldots \ldots$, where $\left\{\lambda_{n}\right\}$ is a sequence in $[0,2 \alpha]$. If $\left\{\alpha_{n}\right\}$ and $\left\{\lambda_{n}\right\}$ are chosen so that $\lambda_{n} \in[a, b]$ for some a, b with $0<\mathrm{a}<\mathrm{b}<2 \alpha$,

$$
\lim _{n \rightarrow 0} \alpha_{n}=0, \sum_{n=0}^{\infty} \alpha_{n}=\infty, \sum_{n=0}^{\infty}\left|\alpha_{n+1}-\alpha_{n}\right|<\infty, \sum_{n=0}^{\infty}\left|\lambda_{n+1}-\lambda_{n}\right|<\infty .
$$


Then $\left\{\mathrm{x}_{\mathrm{n}}\right\}$ converges strongly to $\mathrm{P}_{\mathrm{F}(\mathrm{S}) \cap \mathrm{VI}(\mathrm{C}, \mathrm{A}) \mathrm{X}}$.

After that in 2005, Iiduka and Takahashi [17] proposed a Halpern-like iterative scheme and obtained a strong convergence theorem in Hilbert space.

Theorem.3.1.3: [17] Let $C$ be a closed convex subset of a real Hilbert space $H$. Let $A$ be an $\alpha$-inverse-stronglymonotone mapping of $C$ into $H$ and let $S$ be a nonexpansive mapping of $C$ into itself such that $F(S) \cap V I(C, A) \neq \phi$. Let $\left\{x_{n}\right\}$ be a sequence generated by $x_{1}=x \in C$,

$\mathrm{x}_{\mathrm{n}+1}=\alpha_{\mathrm{n}} \mathrm{x}+\left(1-\alpha_{\mathrm{n}}\right) \mathrm{SP}_{\mathrm{C}}\left(\mathrm{x}_{\mathrm{n}}-\lambda_{\mathrm{n}} \mathrm{A} \mathrm{x}_{\mathrm{n}}\right)$,

for every $n=1,2, \ldots \ldots \ldots$, where $\left\{\alpha_{n}\right\}$ is a sequence in $[0,1)$ and $\left\{\lambda_{n}\right\}$ is a sequence in $[0,2 \alpha]$. If $\left\{\alpha_{n}\right\}$ and $\left\{\lambda_{n}\right\}$ are chosen so that $\lambda_{\mathrm{n}} \in[\mathrm{a}, \mathrm{b}]$ for some $\mathrm{a}, \mathrm{b}$ with $0<\mathrm{a}<\mathrm{b}<2 \alpha$,

$\lim _{n \rightarrow 0} \alpha_{n}=0, \sum_{n=0}^{\infty} \alpha_{n}=\infty, \sum_{n=0}^{\infty}\left|\alpha_{n+1}-\alpha_{n}\right|<\infty, \sum_{n=0}^{\infty}\left|\lambda_{n+1}-\lambda_{n}\right|<\infty$

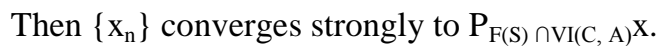

On the other hand, for solving the variational inequality problem in a finite dimensional Euclidean space $\mathrm{R}^{\mathrm{n}}$ under the assumption that a set $\mathrm{C} \subset \mathrm{R}^{\mathrm{n}}$ is nonempty, closed and convex, a mapping $\mathrm{A}: \mathrm{C} \rightarrow \mathrm{R}^{\mathrm{n}}$ is monotone and k-Lipschitz continuous and $\Omega$ is nonempty, Korpelevich [10] introduced the following so-called extragradient method:

$\mathrm{x}_{0}=\mathrm{x} \in \mathrm{R}^{\mathrm{n}}$

$\mathrm{y}_{\mathrm{n}}=\mathrm{P}_{\mathrm{C}}\left(\mathrm{x}_{\mathrm{n}}-\lambda A \mathrm{x}_{\mathrm{n}}\right)$

$\mathrm{x}_{\mathrm{n}+1}=\mathrm{P}_{\mathrm{C}}\left(\mathrm{x}_{\mathrm{n}}-\lambda \mathrm{A} \mathrm{y}_{\mathrm{n}}\right), \forall \mathrm{n} \geq 0$,

where $\lambda \in(0,1 / k)$. He showed that the sequences $\left\{x_{n}\right\}$ and $\left\{y_{n}\right\}$ generated by above algorithm converge to the same point $\mathrm{z} \in \Omega$.

In 2006, motivated by the idea of Korpelevich's extragradient method [15], N. Nadezhkina and W. Takahashi [42], introduced the following iterative process for finding the common element of the set of fixed points of a nonexpansive mapping and the set of solutions of the variational inequality problem for a monotone, Lipschitz-continuous mapping. The proposed iterative process was based on the so-called extragradient method. They obtained a weak convergence theorem for two sequences generated by this process.

Theorem.3.1.4: [42] Let $C$ be a closed convex subset of a real Hilbert space H. Let $A$ be a monotone and $k$-Lipschitz continuous mapping of $C$ into $H$ and let $S$ be a nonexpansive mapping of $C$ into itself such that $F(S) \cap V I(C, A) \neq \phi$. Let $\left\{x_{n}\right\},\left\{y_{n}\right\}$ be sequences generated by

$\mathrm{x}_{0}=\mathrm{x} \in \mathrm{C}$,

$\mathrm{y}_{\mathrm{n}}=\mathrm{P}_{\mathrm{c}}\left(\mathrm{x}_{\mathrm{n}}-\lambda_{\mathrm{n}} \mathrm{A} \mathrm{x}_{\mathrm{n}}\right)$

$\mathrm{x}_{\mathrm{n}+1}=\alpha_{\mathrm{n}} \mathrm{x}_{\mathrm{n}}+\left(1-\alpha_{\mathrm{n}}\right) \mathrm{SP}_{\mathrm{c}}\left(\mathrm{x}_{\mathrm{n}}-\lambda_{\mathrm{n}} \mathrm{A} \mathrm{y}_{\mathrm{n}}\right), \forall \mathrm{n} \geq 0$,

where $\left\{\lambda_{n}\right\} \subset[a, b]$ for some $a, b \in(0,1 / k)$ and $\left\{\alpha_{n}\right\} \subset[c, d]$ for some $c, d \in(0,1)$. Then the sequences $\left\{x_{n}\right\},\left\{y_{n}\right\}$

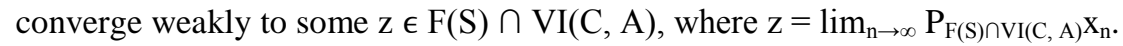

Further in 2006, inspired by Nadezhkina and Takahashi's iterative process Lu-Chuan Zeng and Jen-Chih Yao [36], introduced an iterative process for finding the common element of the set of fixed points of a nonexpansive mapping and the set of solutions of the variational inequality problem for a monotone, Lipschitz-continuous mapping. The proposed iterative process was based on the so-called extragradient method. They obtained a strong convergence theorem for two sequences generated by this process.

Theorem.3.1.5: [36] Let $C$ be a closed convex subset of a real Hilbert space H. Let $A$ be a monotone and $k$-Lipschitz continuous mapping of $C$ into $H$ and let $S$ be a nonexpansive mapping of $C$ into itself such that $F(S) \cap V I(C, A) \neq \phi$. Let $\left\{x_{n}\right\},\left\{y_{n}\right\}$ be sequences generated by $x_{0}=x \in C$,

$\mathrm{y}_{\mathrm{n}}=\mathrm{P}_{\mathrm{c}}\left(\mathrm{x}_{\mathrm{n}}-\lambda_{\mathrm{n}} \mathrm{Ax}\right)$,

$\mathrm{x}_{\mathrm{n}+1}=\alpha_{\mathrm{n}} \mathrm{x}_{0}+\left(1-\alpha_{\mathrm{n}}\right) \mathrm{SP}_{\mathrm{c}}\left(\mathrm{x}_{\mathrm{n}}-\lambda_{\mathrm{n}} \mathrm{A} \mathrm{y}_{\mathrm{n}}\right), \forall \mathrm{n} \geq 0$,

where $\left\{\lambda_{n}\right\}$ and $\left\{\alpha_{n}\right\}$ satisfy the conditions:

a) $\quad\left\{\lambda_{\mathrm{n}} \mathrm{k}\right\} \subset(0,1-\delta)$ for some $\delta \in(0,1)$;

b) $\quad\left\{\alpha_{n}\right\} \subset(0,1), \lim _{n \rightarrow 0} \alpha_{n}=0, \sum_{n=0}^{\infty} \alpha_{n}=\infty$.

Then the sequences $\left\{\mathrm{x}_{\mathrm{n}}\right\},\left\{\mathrm{y}_{\mathrm{n}}\right\}$ converge strongly to same point $\mathrm{P}_{\mathrm{F}(\mathrm{S}) \cap \mathrm{VI}(\mathrm{C}, \mathrm{A})} \mathrm{x}_{0}$, provided,

$\lim _{n \rightarrow \infty}\left\|x_{n}-x_{n+1}\right\|=0$

Remark. The iterative scheme (3.6) in theorem 3.1.4 has only weak convergence. The iterative scheme (3.7) in theorem 3.1.5 has strong convergence but imposed condition (3.8) on the sequence $\left\{x_{n}\right\}$.

Further, inspired by iterative schemes (3.6) and (3.7), in 2006, Yonghong Yao, Yeong-Cheng Liou and Jen-Chih Yao [67], presented an extragradient method for fixed point problems and variational inequality problems. Using this method, they found the common element of the set of fixed points of a nonexpansive mapping and the set of solutions of the variational inequality for monotone mapping. They obtained a strong convergence theorem under some mild conditions. 
Theorem.3.1.6: [67] Let $C$ be a closed convex subset of a real Hilbert space H. Let A be a monotone and k-Lipschitz continuous mapping of $C$ into $H$ and let $S$ be a nonexpansive mapping of $C$ into itself such that $F(S) \cap \Omega \neq \phi$. For fixed $u \in H$ and given $x_{0} \in H$ arbitrary, let $\left\{x_{n}\right\},\left\{y_{n}\right\}$ be sequences generated by

$\mathrm{y}_{\mathrm{n}}=\mathrm{P}_{\mathrm{c}}\left(\mathrm{x}_{\mathrm{n}}-\lambda_{\mathrm{n}} A \mathrm{x}_{\mathrm{n}}\right)$,

$\mathrm{x}_{\mathrm{n}+1}=\alpha_{\mathrm{n}} \mathrm{u}+\beta_{\mathrm{n}} \mathrm{x}_{\mathrm{n}}+\gamma_{\mathrm{n}} \operatorname{SPc}\left(\mathrm{x}_{\mathrm{n}}-\lambda_{\mathrm{n}} A y_{\mathrm{n}}\right), \forall \mathrm{n} \geq 0$,

where $\left\{\alpha_{n}\right\},\left\{\beta_{n}\right\},\left\{\gamma_{n}\right\}$ are three sequences in $[0,1]$ satisfying the conditions:

$\left(\mathrm{C}_{1}\right) \cdot \alpha_{\mathrm{n}}+\beta_{\mathrm{n}}+\gamma_{\mathrm{n}}=1$,

$\left(C_{2}\right) . \lim _{n \rightarrow 0} \alpha_{n}=0, \sum_{n=0}^{\infty} \alpha_{n}=\infty$,

$\left(C_{3}\right) .0<\liminf _{n \rightarrow \infty} \beta_{n} \leq \limsup _{n \rightarrow \infty} \beta_{n}<1$,

$\left(\mathrm{C}_{4}\right) . \lim _{\mathrm{n} \rightarrow \infty} \lambda_{\mathrm{n}}=0$.

Then $\left\{\mathrm{x}_{\mathrm{n}}\right\}$ converges strongly to $\mathrm{P}_{\mathrm{F}(\mathrm{S}) \cap \Omega} \mathrm{u}$.

Definition: Generalized variational inequality problem is defined as follows:

Let $\mathrm{C}$ be closed, convex subset of a real Hilbert space H. Find $\mathrm{u} \in \mathrm{C}$ such that $<\mathrm{u}-\mathrm{Au}-\lambda \mathrm{Bu}, \mathrm{v}-\mathrm{u}>\geq 0, \forall \mathrm{v} \in \mathrm{C}, \lambda>0$.

Remark. The generalized variational inequality problem (3.10) is reduced to classical variational inequality (3.1) if $\mathrm{A}=$ I, the identity mapping.

In 2010, motivated by the results obtained by Iiduka, Takahashi, Toyoda [18] and Iiduka, Takahashi [17], Sun Young Cho [53], considered a generalized variational inequality problem by a Halpern-type iterative method. A strong convergence theorem was established in a real Hilbert space.

Theorem.3.1.7: [53] Let $C$ be a closed convex subset of a real Hilbert space H. Let $A$ be an $\alpha$-strongly-monotone and $L$-Lipschitz continuous mapping of $C$ into $H$ and $B$ be an $\beta$-strongly-monotone and $K$-Lipschitz continuous mapping of $C$ into $H$ such that $V I(C, B, A) \neq \phi$. Let $\left\{x_{n}\right\}$ be sequence generated by

$\mathrm{x}_{0} \in \mathrm{C}$,

$x_{n+1}=\alpha_{n} u+\beta_{n} x_{n}+\gamma_{n} \operatorname{Pc}\left(A x_{n}-\lambda B x_{n}\right), \forall n \geq 0$,

where $u$ is fixed element in $C, \lambda$ is a positive constant and $\left\{\alpha_{n}\right\},\left\{\beta_{n}\right\},\left\{\gamma_{n}\right\}$ are three sequences in $(0,1)$. Assume that above control sequences satisfy the following restrictions:

$\left(\mathrm{C}_{1}\right) \cdot \alpha_{\mathrm{n}}+\beta_{\mathrm{n}}+\gamma_{\mathrm{n}}=1, \mathrm{n} \geq 0$

$\left(C_{2}\right) . \lim _{n \rightarrow 0} \alpha_{n}=0, \sum_{n=0}^{\infty} \alpha_{n}=\infty$,

$\left(C_{3}\right) .0<\liminf _{n \rightarrow \infty} \beta_{n} \leq \limsup _{n \rightarrow \infty} \beta_{n}<1$,

$\left(\mathrm{C}_{4}\right) \cdot \sqrt{1-2 \mathrm{a}+\mathrm{L}^{2}}+\sqrt{1-2 \lambda \beta+\lambda^{2} \mathrm{~K}^{2}} \leq 1$.

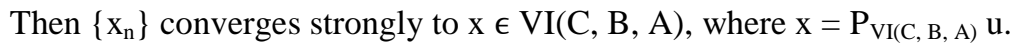

In 2011, Wang H. and Song Y. [20] introduced an iterative method for finding a common element of the set of fixed points of a nonexpansive mapping and the set of solutions of some variational inequality in a Hilbert space.

Theorem 3.1.8: [20] Let $K$ be a nonempty closed convex subset of a Hilbert space $H$. Assume that $A: K \rightarrow H$ is an $\alpha$ inverse strongly monotone mapping and $T: K \rightarrow K$ is a nonexpansive self-mapping with $V I(K, A) \cap F(T) \neq \phi$. For an anchor point $u \in K$ and an initial value $x_{0} \in K$ and a constant $\lambda \in(0,2 \alpha)$, the sequence $\left\{x_{n}\right\}$ be defined iteratively by

$\mathrm{x}_{\mathrm{n}+1}=\alpha_{\mathrm{n}} \mathrm{u}+\beta_{\mathrm{n}} \mathrm{x}_{\mathrm{n}}+\left(1-\alpha_{\mathrm{n}}-\beta_{\mathrm{n}}\right) \mathrm{TP}_{\mathrm{K}}\left(\mathrm{x}_{\mathrm{n}}-\lambda \mathrm{Ax}_{\mathrm{n}}\right)$.

Suppose that $\left\{\alpha_{n}\right\} \subset(0,1)$ and $\left\{\beta_{n}\right\} \subset(0,1)$ satisfy the following conditions:

(C1). $\operatorname{Lim}_{\mathrm{n} \rightarrow \infty} \alpha_{\mathrm{n}}=0$,

(C2). $\sum_{\mathrm{n}=0}^{\infty} \alpha_{\mathrm{n}}=\infty$,

(C2). $0<\liminf _{n \rightarrow \infty} \beta_{n} \leq \lim \sup _{n \rightarrow \infty} \beta_{n}<1$,

Then $\left\{\mathrm{x}_{\mathrm{n}}\right\}$ converges strongly to $\mathrm{x}=\mathrm{P}_{\mathrm{VI}(\mathrm{K}, \mathrm{A}) \cap \mathrm{F}(\mathrm{T})} \mathrm{u}$.

Moreover, there exist a subsequence $\left\{\mathrm{x}_{\mathrm{n}_{\mathrm{k}}}\right\} \subset\left\{\mathrm{x}_{\mathrm{n}}\right\}$ and $\left\{\epsilon_{\mathrm{n}}\right\} \subset(0, \infty)$ with $\lim _{\mathrm{n} \rightarrow \infty} \in_{\mathrm{n}}=0$ such that

$\left\|x_{n_{k}}-x^{*}\right\|^{2} \leq \frac{1}{\sum_{m=0}^{n_{k}} \alpha_{m}}+2 \epsilon_{n_{k}}$,
$\left\|x_{n_{k}+1}-x^{*}\right\|^{2} \leq \frac{1}{\sum_{m=0}^{n_{k}} \alpha_{m}}+\left(1+2 \alpha_{n_{k}}\right) \epsilon_{n_{k}}$, 


$$
\begin{aligned}
& \left\|x_{n}-x^{*}\right\|^{2} \leq\left\|x_{n_{k}+1}-P u\right\|^{2}-\sum_{m=n_{k}+1}^{n-1} \frac{\alpha_{m}}{\theta_{m}}, n_{k}+1<n<n_{k+1}, \theta_{m}=\sum_{i=0}^{m} \alpha_{i}, \\
& \left\|x_{n+1}-x^{*}\right\|^{2} \leq\left\|x_{0}-x^{*}\right\|^{2}-\sum_{m=0}^{n} \frac{\alpha_{m}}{\theta_{m}} \leq\left\|x_{0}-x^{*}\right\|^{2}, 1 \leq n \leq n_{k}-1, \\
& 1 \leq n_{k} \leq s_{\max }=\max \left\{s ; \sum_{m=0}^{s} \frac{\alpha_{m}}{\theta_{m}} \leq\left\|x_{0}-x^{*}\right\|^{2}\right\} .
\end{aligned}
$$

Using above theorem, they proved some corollaries.

Corollary (i): [20] Let $\mathrm{H}, \mathrm{T}, \mathrm{A}, \mathrm{K}, \lambda$ be as in theorem3.1.8. For an anchor point $\mathrm{u} \in \mathrm{K}$ and an initial value $\mathrm{x}_{0} \in \mathrm{K}$ and a constant $\delta \in(0,1)$, the sequence $\left\{\mathrm{x}_{\mathrm{n}}\right\}$ be defined iteratively by

$\mathrm{x}_{\mathrm{n}+1}=\alpha_{\mathrm{n}} \mathrm{u}+\left(1-\alpha_{\mathrm{n}}\right)\left[\delta \mathrm{x}_{\mathrm{n}}+(1-\delta) \mathrm{TP}_{\mathrm{K}}\left(\mathrm{x}_{\mathrm{n}}-\lambda \mathrm{Ax}_{\mathrm{n}}\right)\right]$.

Suppose that $\left\{\alpha_{n}\right\} \subset(0,1)$ satisfies the following conditions:

(C1). $\operatorname{Lim}_{n \rightarrow \infty} \alpha_{n}=0$,

(C2). $\sum_{n=0}^{\infty} \alpha_{n}=\infty$,

Then $\left\{x_{n}\right\}$ converges strongly to $x=P_{V I(K, A)} \cap \mathrm{F}(\mathrm{T}) \mathrm{u}$.

Corollary (ii): [20] Let $\mathrm{H}, \mathrm{T}, \mathrm{A}, \mathrm{K}, \lambda$ be as in theorem3.1.8. For an anchor point $\mathrm{u} \in \mathrm{K}$ and an initial value $\mathrm{x}_{0} \in \mathrm{K}$ and a constant $\delta \in(0,1)$, the sequence $\left\{\mathrm{x}_{\mathrm{n}}\right\}$ be defined iteratively by

$\mathrm{x}_{\mathrm{n}+1}=\delta\left(\alpha_{\mathrm{n}} \mathrm{u}+\left(1-\alpha_{\mathrm{n}}\right) \mathrm{x}_{\mathrm{n}}\right)+(1-\delta) \mathrm{TP}_{\mathrm{K}}\left(\mathrm{x}_{\mathrm{n}}-\lambda \mathrm{Ax}_{\mathrm{n}}\right)$.

Suppose that $\left\{\alpha_{n}\right\} \subset(0,1)$ satisfies the following conditions:

(C1). $\operatorname{Lim}_{\mathrm{n} \rightarrow \infty} \alpha_{\mathrm{n}}=0$,

(C2). $\sum_{n=0}^{\infty} \alpha_{n}=\infty$,

Then $\left\{\mathrm{x}_{\mathrm{n}}\right\}$ converges strongly to $\mathrm{x}=\mathrm{P}_{\mathrm{VI}(\mathrm{K}, \mathrm{A}) \cap \mathrm{F}(\mathrm{T})} \mathrm{u}$.

Corollary (iii): [20] Let $\mathrm{H}, \mathrm{T},\left\{\alpha_{\mathrm{n}}\right\},\left\{\beta_{\mathrm{n}}\right\}$ be as in theorem3.1.8. Assume that $\mathrm{A}: \mathrm{K} \rightarrow \mathrm{H}$ is an $\alpha$-inverse-strongly monotone mapping with VI $(\mathrm{K}, \mathrm{A}) \neq \phi$. For an anchor point $\mathrm{u} \in \mathrm{K}$ and an initial value $\mathrm{x}_{0} \in \mathrm{K}$ and a constant $\lambda \in(0,2 \alpha)$, the sequence $\left\{x_{n}\right\}$ be defined iteratively by $x_{n+1}=\alpha_{n} u+\beta_{n} x_{n}+\left(1-\alpha_{n}-\beta_{n}\right) P_{K}\left(x_{n}-\lambda A x_{n}\right)$.

Then $\left\{x_{n}\right\}$ converges strongly to $P_{V I}(K, A) u$.

The viscosity approximation method for finding a fixed point of a given nonexpansive mapping was proposed by Moudafi [52] in 2000. He proved the strong convergence of the sequence generated by both the implicit and explicit methods to a unique solution of some variational inequality.

In 2014, Chugh R and Rani R [46], motivated by Takahashi and Toyoda [57], S. Matsushita and D. Kuroiwa [52], Iiduka and Takahashi [17] and the research going in this direction, introduced a new iterative scheme for finding a common element of the set of fixed points of a nonexpansive mapping and the set of solutions of a variational inequality problem for an $\alpha$-inverse-strongly-monotone mapping and then obtained a weak convergence theorem.

Theorem 3.1.9: [17] Let $C$ be a closed convex subset of a real Hilbert space. Let $A$ be an $\alpha$-inverse-strongly monotone mapping of $C$ into $H$ and let $S$ be a nonexpansive mapping of $C$ into itself such that $F(S) \cap V I(C, A) \neq \phi$. Let $\left\{x_{n}\right\},\left\{y_{n}\right\}$ be sequences generated by

$\mathrm{x}_{0}=\mathrm{x} \in \mathrm{C}$,

$y_{n}=\alpha_{n} x_{n}+\left(1-\alpha_{n}\right) S P_{c}\left(x_{n}-\lambda_{n} A x_{n}\right)$,

$\mathrm{x}_{\mathrm{n}+1}=\beta_{\mathrm{n}} \mathrm{y}_{\mathrm{n}}+\left(1-\beta_{\mathrm{n}}\right) \operatorname{SP}_{\mathrm{c}}\left(\mathrm{y}_{\mathrm{n}}-\lambda_{\mathrm{n}} \mathrm{A} \mathrm{y}_{\mathrm{n}}\right)$,

Where $\left\{\lambda_{n}\right\} \subset[0,2 \alpha],\left\{\alpha_{n}\right\} \subset[0,1]$ and $\left\{\beta_{n}\right\} \subset[0,1]$ if $\left\{\alpha_{n}\right\},\left\{\lambda_{n}\right\}$ and $\left\{\beta_{n}\right\}$ satisfy the following conditions

1) $\lim _{n \rightarrow 0} \alpha_{n}=0, \sum_{n=0}^{\infty} \alpha_{n}=\infty$.

2) $\beta_{\mathrm{n}} \in[0, \mathrm{a}) \forall \mathrm{n} \geq 0$ and for some $\mathrm{a} \in(0,1)$.

3) $\left\{\lambda_{\mathrm{n}}\right\} \subset[\mathrm{c}, \mathrm{d}]$ for some c,d with $0<\mathrm{c}<\mathrm{d}<2 \alpha$.

4) $\quad \sum_{n=0}^{\infty}\left|\alpha_{n+1}-\alpha_{n}\right|<\infty, \sum_{n=0}^{\infty}\left|\beta_{n+1}-\beta_{n}\right|<\infty, \sum_{n=0}^{\infty}\left|\lambda_{n+1}-\lambda_{n}\right|<\infty$.

Then, the sequences $\left\{x_{n}\right\},\left\{y_{n}\right\}$ converge weakly to the same point $z \in F(S) \cap \operatorname{VI}(C, A)$, where $z=\lim _{n \rightarrow \infty} P_{F(S)} \cap \operatorname{VI}(C, A) x_{n}$.

Theorem 3.1.10: [5] In a Hilbert space, define $\left\{x_{n}\right\}$ by implicit way

$\mathrm{x}_{\mathrm{n}}=\frac{1}{1+\varepsilon_{\mathrm{n}}} \mathrm{Tx}_{\mathrm{n}}+\frac{\varepsilon_{\mathrm{n}}}{1+\varepsilon_{\mathrm{n}}} \mathrm{f}\left(\mathrm{x}_{\mathrm{n}}\right)$, 
where $\epsilon_{\mathrm{n}}$ is a in sequence $(0,1)$ tending to zero, where $\mathrm{f}: \mathrm{C} \rightarrow \mathrm{C}$ is a contraction and $\mathrm{T}: \mathrm{C} \rightarrow \mathrm{C}$ is a nonexpansive mapping. Then $\left\{x_{n}\right\}$ converges strongly to the unique solution $\mathrm{x} \in \mathrm{C}$ of the variational inequality

$<(\mathrm{I}-\mathrm{f}) \mathrm{x}, \mathrm{x}-\mathrm{y}>\leq 0$.

In other words, $x$ is the unique fixed point of $\mathrm{P}_{\mathrm{Fix}(\mathrm{T})} \mathrm{f}$.

Theorem 3.1.11: [5] In a Hilbert space, define $\left\{x_{n}\right\}$ by ( $x_{0} \in C$ is arbitrary)

$\mathrm{x}_{\mathrm{n}+1}=\frac{1}{1+\varepsilon_{\mathrm{n}}} \mathrm{Tx}_{\mathrm{n}}+\frac{\varepsilon_{\mathrm{n}}}{1+\varepsilon_{\mathrm{n}}} \mathrm{f}\left(\mathrm{x}_{\mathrm{n}}\right)$

Suppose that $\left\{\epsilon_{\mathrm{n}}\right\}$ satisfies the conditions

$\lim _{\mathrm{n} \rightarrow \infty} \in_{\mathrm{n}}=0, \sum_{\mathrm{n}=0}^{\infty} \varepsilon_{\mathrm{n}}=\infty, \lim _{\mathrm{n} \rightarrow \infty}\left|\frac{1}{\varepsilon_{\mathrm{n}}}-\frac{1}{\varepsilon_{\mathrm{n}-1}}\right|=0$.

Then $\left\{\mathrm{x}_{\mathrm{n}}\right\}$ converges strongly to the unique solution $\mathrm{x} \in \mathrm{C}$ of the variational inequality

$<(\mathrm{I}-\mathrm{f}) \mathrm{x}, \mathrm{x}-\mathrm{y}>\leq 0$.

In other words, $\mathrm{x}$ is the unique fixed point of $\mathrm{P}_{\mathrm{Fix}(\mathrm{T})} \mathrm{f}$.

In 2004, Xu [19] extended the results of [5] to more general version. He proved the following theorems:

Theorem 3.1.12: [19] Let $H$ be a Hilbert space, $C$ be a closed convex subset of $H$ and $T: C \rightarrow C$ be a nonexpansive mapping with Fix $(T) \neq \phi$ and $f$ is a contraction on $C$. Let $\left\{x_{t}\right\}$ be given by

$\mathrm{x}_{\mathrm{t}}=\mathrm{tf}\left(\mathrm{x}_{\mathrm{t}}\right)+(1-\mathrm{t}) \mathrm{T} \mathrm{x}_{\mathrm{t}}, \mathrm{t} \in(0,1)$.

Then:

i) $\quad \mathrm{s}-\lim _{\mathrm{t} \rightarrow 0} \mathrm{X}_{\mathrm{t}}=\mathrm{x}$ exists;

ii) $x=P_{S} f(x)$ or equivalently, $x$ is the unique solution in $F(T)$ to the variational inequality

$<(\mathrm{I}-\mathrm{f}) \mathrm{x}, \mathrm{x}-\mathrm{y}>\leq 0, \mathrm{y} \in \mathrm{S}$,

where $S=F(T)$ and $P_{S}$ is the metric projection from $H$ to $S$.

Theorem 3.1.13: [19] Let $H$ be a Hilbert space, $C$ be a closed convex subset of $H$ and $T: C \rightarrow C$ be a nonexpansive mapping with $\operatorname{Fix}(T) \neq \phi$ and $f$ is a contraction on $C$. Let $\left\{x_{n}\right\}$ be given by

$\mathrm{x}_{\mathrm{n}+1}=\alpha_{\mathrm{n}} \mathrm{f}\left(\mathrm{x}_{\mathrm{n}}\right)+\left(1-\alpha_{\mathrm{n}}\right) \mathrm{Tx}_{\mathrm{n}}, \mathrm{n} \geq 0$.

Then under the following hypotheses

(H1). $\operatorname{Lim}_{n \rightarrow \infty} \alpha_{n}=0$,

(H2). $\sum_{n=0}^{\infty} \alpha_{n}=\infty$,

(H3). Either $\sum_{n=0}^{\infty}\left|\alpha_{n+1}-\alpha_{n}\right|<\infty$ or $\lim _{n \rightarrow \infty} \frac{\alpha_{n+1}}{\alpha_{n}}=1$,

$\mathrm{x}_{\mathrm{n}} \rightarrow \mathrm{x}$, where $\mathrm{x}$ is the unique solution of the variational inequality

$<(\mathrm{I}-\mathrm{f}) \mathrm{x}, \mathrm{x}-\mathrm{y}>\leq 0, \mathrm{y} \in \mathrm{S}$.

In 2007, motivated by the results in [5] and [9], Junmin Chen, Lijuan Zhang and Tiegang Fan [23] studied viscosity approximation methods for nonexpansive mappings. They showed that the sequence generated by proposed scheme converges strongly to a common element of the set of fixed points of a nonexpansive nonself-mapping and the set of solutions of the variational inequality for an inverse-strongly-monotone mapping in a Hilbert space.

Theorem 3.1.14: [23] Let $C$ be a closed convex subset of a real Hilbert space H. Let $f: C \rightarrow C$ be a contracton with coefficient $k(0<k<1)$. Let $A$ be a $\alpha$-inverse-strongly-monotone mapping of $C$ into $H$ and let $S$ be a nonexpansive mapping of $C$ into itself such that $F(S) \cap V I(C, A) \neq \phi$. Let $\left\{x_{n}\right\}$ be a sequence generated by

$\mathrm{x}_{0}=\mathrm{x} \in \mathrm{C}$,

$\mathrm{x}_{\mathrm{n}+1}=\alpha_{\mathrm{n}} \mathrm{f}\left(\mathrm{x}_{\mathrm{n}}\right)+\left(1-\alpha_{\mathrm{n}}\right) S \mathrm{SP}_{\mathrm{C}}\left(\mathrm{x}_{\mathrm{n}}-\lambda_{\mathrm{n}} \mathrm{Ax} \mathrm{x}_{\mathrm{n}}\right)$

for every $n=0,1,2, \ldots \ldots \ldots$, where $\left\{\lambda_{n}\right\} \subset[a, b]$ and $\left\{\alpha_{n}\right\}$ is a sequence in $(0,1)$. If $\left\{\alpha_{n}\right\}$ and $\left\{\lambda_{n}\right\}$ are chosen so that $\lambda_{n} \epsilon$ [a,b] for some a, b with $0<\mathrm{a}<\mathrm{b}<2 \alpha$,

$\lim _{n \rightarrow 0} \alpha_{n}=0, \sum_{n=0}^{\infty} \alpha_{n}=\infty, \sum_{n=0}^{\infty}\left|\alpha_{n+1}-\alpha_{n}\right|<\infty, \sum_{n=0}^{\infty}\left|\lambda_{n+1}-\lambda_{n}\right|<\infty$

Then $\left\{x_{n}\right\}$ converges strongly to $q \in F(S) \cap V I(C, A)$, which is the unique solution in the $F(S) \cap V I(C, A)$ to the following variational inequality $<(I-f) q, q-p>\leq 0, p \in F(S) \cap \operatorname{VI}(C, A)$.

Inspired by the results given by Nadezhkina and Takahashi [42], Zeng and Yao [36], Zeng and Yao [37] again introduced an extragradient-like approximation method basing on the extragradient method and viscosity approximation method and obtained the very interesting result. 
Theorem 3.1.15: [37] Let $C$ be a closed convex subset of a real Hilbert space $H$. Let $f: C \rightarrow C$ be a contracton mapping, let $A: C \rightarrow H$ be a monotone, L-Lipschitz continuous mapping and let $S$ be a nonexpansive mapping of $C$ into itself such that $F(S) \cap \operatorname{VI}(C, A) \neq \phi$. Let $\left\{x_{n}\right\},\left\{y_{n}\right\}$ be the sequences generated by

$\mathrm{x}_{0}=\mathrm{x} \in \mathrm{C}$,

$\mathrm{y}_{\mathrm{n}}=\left(1-\gamma_{\mathrm{n}}\right) \mathrm{x}_{\mathrm{n}}+\mathrm{P}_{\mathrm{C}}\left(\mathrm{x}_{\mathrm{n}}-\lambda_{\mathrm{n}} \mathrm{Ax} \mathrm{x}_{\mathrm{n}}\right)$

$x_{n+1}=\left(1-\alpha_{n}-\beta_{n}\right) x_{n}+\alpha_{n} f\left(y_{n}\right)+\beta_{n} S P_{C}\left(x_{n}-\lambda_{n} A y_{n}\right)$,

where $\left\{\lambda_{n}\right\}$ is a sequence in $(0,1)$ with $\sum_{n=0}^{\infty} \lambda_{n}<\infty$ and $\left\{\alpha_{n}\right\},\left\{\beta_{n}\right\}\left\{\gamma_{n}\right\}$ are three sequences in [0, 1] satisfying the conditions:

i) $\quad \alpha_{n}+\beta_{n} \leq 1$ for all $n \geq 0$;

ii) $\lim _{\mathrm{n} \rightarrow 0} \alpha_{\mathrm{n}}=0, \sum_{\mathrm{n}=0}^{\infty} \alpha_{\mathrm{n}}=\infty$;

iii) $\quad 0<\liminf _{n \rightarrow \infty} \beta_{n} \leq \lim \sup _{n \rightarrow \infty} \beta_{n}<1$,

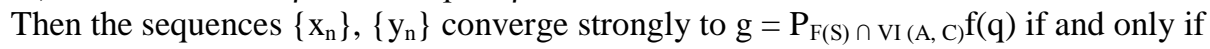

$\left\{\mathrm{Ax}_{\mathrm{n}}\right\}$ is bounded and $\lim _{\mathrm{inf}} \rightarrow \infty<\mathrm{Ax}_{\mathrm{n}}, \mathrm{y}-\mathrm{x}_{\mathrm{n}}>\geq 0, \forall \mathrm{y} \in \mathrm{C}$

Remark. The iterative scheme (3.6) in theorem 3.1.4 has only weak convergence. The iterative scheme (3.7) in theorem 3.1.5 has strong convergence but imposed the condition (3.8) on the sequence $\left\{x_{n}\right\}$. The iterative scheme (3.19) in theorem 3.1.15 has strong convergence but imposed condition (3.20) on the sequence $\left\{\mathrm{x}_{\mathrm{n}}\right\}$. So there is a natural question-

Could we construct an iterative scheme to approximate the common element of the set of fixed points of a nonexpansive mapping and the set of solutions of the variational inequality for monotone mapping without any assumption on the sequence $\left\{x_{n}\right\}$ ?

In 2007, Muhammad Aslam Noor, YonghongYao, Rudong Chen and Yeong-Cheng Loiu [39], tried to answer the question and presented an iterative method for fixed point problems and variational inequality problems without any assumption on $\left\{x_{n}\right\}$. The proposed iterative scheme was based on the so-called extragradient method and viscosity approximation method. Using this method, they found the common element of the set of fixed points of a nonexpansive mapping and the set of solutions of the variational inequality for monotone mapping.

Theorem 3.1.16: [39] Let $C$ be a closed convex subset of a real Hilbert space $H$. Let $f: C \rightarrow C$ be a contracton with coefficient $k(0<k<1)$. Let $A$ be a monotone, L-Lipschitz continuous mapping of $C$ into $H$ and let $S$ be a nonexpansive mapping of $C$ into itself such that $F(S) \cap V I(C, A) \neq \phi$. Let $\left\{x_{n}\right\},\left\{y_{n}\right\},\left\{z_{n}\right\}$ be the sequences generated by

$\mathrm{x}_{0}=\mathrm{x} \in \mathrm{C}$,

$\mathrm{z}_{\mathrm{n}}=\mathrm{P}_{\mathrm{c}}\left(\mathrm{x}_{\mathrm{n}}-\lambda_{\mathrm{n}} \mathrm{A} \mathrm{x}_{\mathrm{n}}\right)$

$\mathrm{y}_{\mathrm{n}}=\left(1-\gamma_{\mathrm{n}}\right) \mathrm{x}_{\mathrm{n}}+\gamma_{\mathrm{n}} \mathrm{P}_{\mathrm{c}}\left(\mathrm{x}_{\mathrm{n}}-\lambda_{\mathrm{n}} \mathrm{A} \mathrm{z}_{\mathrm{n}}\right)$

$x_{n+1}=\left(1-\alpha_{n}\right) x_{n}+\alpha_{n} S\left[\beta_{n} f\left(x_{n}\right)+\left(1-\beta_{n}\right) y_{n}\right]$,

for every $n=0,1,2, \ldots \ldots \ldots$, where $\left\{\lambda_{n}\right\}$ is a sequence in $(0,1)$ with $\lim _{n \rightarrow \infty} \lambda_{n}=0$ and $\left\{\alpha_{n}\right\},\left\{\beta_{n}\right\}$ and $\left\{\gamma_{n}\right\}$ are three sequences in $[0,1]$ satisfying the conditions:

1) $\lim _{n \rightarrow 0} \beta_{n}=0, \sum_{n=0}^{\infty} \beta_{n}=\infty$,

2) $0<\liminf _{n \rightarrow \infty} \alpha_{n} \leq \lim _{\sup _{n \rightarrow \infty}} \alpha_{n}<1$,

3) $\lim _{n \rightarrow \infty}\left(\gamma_{n+1}-\gamma_{n}\right)=0$.

Then, the sequences $\left\{x_{n}\right\},\left\{y_{n}\right\}$ and $\left\{z_{n}\right\}$ converge strongly to the same point $q=P_{F(S) \cap V I(C, A)} f(q)$.

In 2009, Wangkeeree and Kamraksa [51], introduced an iterative method for finding a common element of the set of fixed points of a family of infinitely nonexpansive mappings and the set of solutions of the variational inequality for an inverse-strongly monotone mapping in a Hilbert space. They showed that the iterative sequence converges strongly to a common element of these two sets.

Theorem 3.1.17: [51] Let $C$ be a closed convex subset of a real Hilbert space $H$, let $f$ be a contraction of $C$ into itself, let $B$ be an $\alpha$-inverse strongly monotone mapping of $C$ into $H$ and let $\left\{T_{i}: C \rightarrow C\right\}$ be a family of infinitely nonexpansive mappings with $F=\bigcap_{\mathrm{i}=1}^{\infty} \mathrm{F}\left(\mathrm{T}_{\mathrm{i}}\right) \bigcap \mathrm{VI}(\mathrm{B}, \mathrm{C}) \neq \phi$. Let $A$ be a strongly positive linear bounded self adjoint operator with the coefficient $\bar{\gamma}>0$ such that// A// $\leq 1$. Assume that $0<\gamma<\bar{\gamma} / \alpha$. Let $\left\{\alpha_{n}\right\},\left\{\beta_{n}\right\},\left\{\gamma_{n}\right\}$ and $\left\{\delta_{n}\right\}$ be sequences in [0, 1] satisfying the following conditions:

(C1). $\lim _{n \rightarrow \infty} \alpha_{n}=0, \sum_{n=0}^{\infty} \alpha_{n}=\infty$,

(C2). $0<\liminf _{\mathrm{n} \rightarrow \infty} \delta_{\mathrm{n}} \leq \lim \sup _{\mathrm{n} \rightarrow \infty} \delta_{\mathrm{n}}<1$,

(C3). $\left(1+\beta_{\mathrm{n}}\right) \gamma_{\mathrm{n}}-2 \beta_{\mathrm{n}}>\mathrm{d}$ for some $\mathrm{d} \in(0,1)$, 
(C4). $\sum_{n=0}^{\infty}\left|\beta_{n+1}-\beta_{n}\right|=\sum_{n=0}^{\infty}\left|\gamma_{n+1}-\gamma_{n}\right|=0$,

(C5). $\sum_{n=0}^{\infty}\left|\lambda_{n+1}-\lambda_{n}\right|<\infty$ and $\left\{\lambda_{n}\right\} \subset[a, b]$ for some a, b $\in(0,2 \alpha)$.

Then the sequence $\left\{x_{n}\right\}$ generated by

$\mathrm{z}_{\mathrm{n}}=\gamma_{\mathrm{n}} \mathrm{x}_{\mathrm{n}}+\left(1-\gamma_{\mathrm{n}}\right) \mathrm{W}_{\mathrm{n}} \mathrm{x}_{\mathrm{n}}$,

$\mathrm{y}_{\mathrm{n}}=\beta_{\mathrm{n}} \mathrm{x}_{\mathrm{n}}+\left(1-\beta_{\mathrm{n}}\right) \mathrm{W}_{\mathrm{n}} \mathrm{z}_{\mathrm{n}}$,

$\mathrm{x}_{\mathrm{n}+1}=\alpha_{\mathrm{n}} \gamma \mathrm{f}\left(\mathrm{x}_{\mathrm{n}}\right)+\delta_{\mathrm{n}} \mathrm{x}_{\mathrm{n}}+\left(\left(1-\delta_{\mathrm{n}}\right) \mathrm{I}-\alpha_{\mathrm{n}} \mathrm{A}\right) \mathrm{P}_{\mathrm{C}}\left(\mathrm{y}_{\mathrm{n}}-\lambda_{\mathrm{n}} \mathrm{B} \mathrm{y}_{\mathrm{n}}\right), \forall \mathrm{n} \geq 1$

converges strongly to $\mathrm{q} \in \mathrm{F}$, where $\mathrm{q}=\mathrm{P}_{\mathrm{F}}(\gamma \mathrm{f}+(\mathrm{I}-\mathrm{A})) \mathrm{q}$ which solves the following variational inequality:

$\langle\gamma \mathrm{f}(\mathrm{q})-\mathrm{Ap}, \mathrm{p}-\mathrm{q}\rangle \leq 0, \forall \mathrm{p} \in \mathrm{F}$.

Here the mapping $\mathrm{W}_{\mathrm{n}}$ is defined by

$\mathrm{U}_{\mathrm{n}, \mathrm{n}+1}=\mathrm{I}$,

$\mathrm{U}_{\mathrm{n}, \mathrm{n}}=\mu_{\mathrm{n}} \mathrm{T}_{\mathrm{n}} \mathrm{U}_{\mathrm{n}, \mathrm{n}+1}+\left(1-\mu_{\mathrm{n}}\right) \mathrm{I}$,

$\mathrm{U}_{\mathrm{n}, \mathrm{n}-1}=\mu_{\mathrm{n}-1} \mathrm{~T}_{\mathrm{n}-1} \mathrm{U}_{\mathrm{n}, \mathrm{n}}+\left(1-\mu_{\mathrm{n}-1}\right) \mathrm{I}$,

$\mathrm{U}_{\mathrm{n}, \mathrm{k}}=\mu_{\mathrm{k}} \mathrm{T}_{\mathrm{k}} \mathrm{U}_{\mathrm{n}, \mathrm{k}+1}+\left(1-\mu_{\mathrm{k}}\right) \mathrm{I}$,

$\mathrm{U}_{\mathrm{n}, \mathrm{k}-1}=\mu_{\mathrm{k}-1} \mathrm{~T}_{\mathrm{k}-1} \mathrm{U}_{\mathrm{n}, \mathrm{k}}+\left(1-\mu_{\mathrm{k}-1}\right) \mathrm{I}$,

$\mathrm{U}_{\mathrm{n}, 2}=\mu_{2} \mathrm{~T}_{2} \mathrm{U}_{\mathrm{n}, 3}+\left(1-\mu_{2}\right) \mathrm{I}$,

$\mathrm{W}_{\mathrm{n}}=\mathrm{U}_{\mathrm{n}, 1}=\mu_{1} \mathrm{~T}_{1} \mathrm{U}_{\mathrm{n}, 2}+\left(1-\mu_{1}\right) \mathrm{I}$,

Such a mapping $\mathrm{W}_{\mathrm{n}}$ is nonexpansive from $\mathrm{C}$ to $\mathrm{C}$ and it is called $\mathrm{W}$-mapping generated by $T_{1}, T_{2}, \ldots \ldots, T_{n}$ and $\mu_{1}$, $\mu_{2}, \ldots \ldots \ldots, \mu_{\mathrm{n}}$.

Remark. A linear bounded operator B is called strongly positive if there is a constant $\gamma>0$ with the property that $\langle\mathrm{Ax}, \mathrm{x}\rangle \geq \gamma\|\mathrm{x}\|^{2}, \forall \mathrm{x} \in \mathrm{H}$.

In 2009, motivated and inspired by above results, Meijuan Shang, Yongfu SU, Xiaolong Qin [41], introduced a general three-step iterative scheme for finding a common element of the set of fixed points of a nonexpansive mapping and the set of solutions of the variational inequality for an inverse-strongly monotone mapping by viscosity approximation methods in a Hilbert space. They showed that the iterative sequence converges strongly to a common element of two sets, which solves some variational inequality.

Theorem 3.1.18: [41] Let $C$ be a closed convex subset of a real Hilbert space H. Let $f: C \rightarrow C$ be a contracton with coefficient $k(0<k<1)$. Let $A$ be an $\alpha$-inverse-strongly-monotone mapping of $C$ into $H$ and let $S$ be a nonexpansive mapping of $C$ into itself such that $F(S) \cap V I(C, A) \neq \phi$. Let $\left\{x_{n}\right\}$ be a sequence generated by

$\mathrm{x}_{0}=\mathrm{x} \in \mathrm{C}$,

$\mathrm{z}_{\mathrm{n}}=\mathrm{P}_{\mathrm{c}}\left(\mathrm{x}_{\mathrm{n}}-\tau_{\mathrm{n}} \mathrm{Ax} \mathrm{x}_{\mathrm{n}}\right)$,

$\mathrm{y}_{\mathrm{n}}=\mathrm{P}_{\mathrm{c}}\left(\mathrm{z}_{\mathrm{n}}-\mu_{\mathrm{n}} \mathrm{A} \mathrm{z}_{\mathrm{n}}\right)$,

$\mathrm{x}_{\mathrm{n}+1}=\alpha_{\mathrm{n}} \mathrm{f}\left(\mathrm{x}_{\mathrm{n}}\right)+\left(1-\alpha_{\mathrm{n}}\right) \mathrm{SP}_{\mathrm{c}}\left(\mathrm{y}_{\mathrm{n}}-\lambda_{\mathrm{n}} A \mathrm{y}_{\mathrm{n}}\right)$,

where $\left\{\alpha_{n}\right\},\left\{\lambda_{n}\right\},\left\{\mu_{n}\right\}$ and $\left\{\tau_{n}\right\}$ satisfy the following conditions:

1) $\left\{\alpha_{n}\right\}$ is a sequence in $(0,1)$;

2) $\quad \lim _{n \rightarrow 0} \alpha_{n}=0, \sum_{n=0}^{\infty} \alpha_{n}=\infty, \sum_{n=0}^{\infty}\left|\alpha_{n}-\alpha_{n-1}\right|<\infty$

3) $\quad \sum_{n=0}^{\infty}\left|\lambda_{n}-\lambda_{n-1}\right|<\infty, \sum_{n=0}^{\infty}\left|\mu_{n}-\mu_{n-1}\right|<\infty, \sum_{n=0}^{\infty}\left|\tau_{n}-\tau_{n-1}\right|<\infty$

4) $\left\{\lambda_{n}\right\},\left\{\mu_{n}\right\}$ and $\left\{\tau_{n}\right\}$ are three sequences in $[a, b]$ for some $a, b \in(0,2 \alpha)$.

Then $\left\{x_{n}\right\}$ converges strongly to $q \in F(S) \cap \operatorname{VI}(C, A)$, which is the unique solution in the $F(S) \cap \operatorname{VI}(C, A)$ to the following variational inequality $<(\mathrm{I}-\mathrm{f}) \mathrm{q}, \mathrm{q}-\mathrm{p}>\leq 0, \forall \mathrm{p} \in \mathrm{F}(\mathrm{S}) \cap \mathrm{VI}(\mathrm{C}, \mathrm{A})$.

In 2009, motivated by the results obtained by Chen et al. [23], Jong Soo Jung [22], introduced a new composite iteration by viscosity approximation methods for finding a common element of the set of fixed points of a nonexpansive mapping and the set of solutions of the variational inequality for an inverse-strongly monotone mapping in a Hilbert space. If we take $\beta_{n}=0$, then iterative scheme (3.24) reduces to iterative scheme (3.18). They showed that the iterative sequence converges strongly to a common element of two sets, which is a solution of some variational inequality.

Theorem 3.1.19: [22] Let $C$ be a closed convex subset of a real Hilbert space $H$. Let $f: C \rightarrow C$ be a contracton with coefficient $k(0<k<1)$. Let $A$ be an $\alpha$-inverse-strongly-monotone mapping of $C$ into $H$ and let $S$ be a nonexpansive mapping of $C$ into itself such that $F(S) \cap V I(C, A) \neq \phi$. Let $\left\{x_{n}\right\}$ be a sequence generated by

$\mathrm{x}_{0}=\mathrm{x} \in \mathrm{C}$,

$y_{n}=\alpha_{n} f\left(x_{n}\right)+\left(1-\alpha_{n}\right) S P_{c}\left(x_{n}-\lambda_{n} A x_{n}\right)$, 
$x_{n+1}=\left(1-\beta_{n}\right) y_{n}+\beta_{n} S P_{c}\left(y_{n}-\lambda_{n} A y_{n}\right)$,

where $\left\{\lambda_{n}\right\} \subset[0,2 \alpha],\left\{\alpha_{n}\right\} \subset[0,1)$ and $\left\{\beta_{n}\right\} \subset[0,1]$. If $\left\{\alpha_{n}\right\},\left\{\lambda_{n}\right\}$ and $\left\{\beta_{n}\right\}$ satisfy the following conditions

1) $\lim _{\mathrm{n} \rightarrow 0} \alpha_{\mathrm{n}}=0, \sum_{\mathrm{n}=0}^{\infty} \alpha_{\mathrm{n}}=\infty$

2) $\beta_{\mathrm{n}} \subset[0, \mathrm{a}) \forall \mathrm{n} \geq 0$ and for some $\mathrm{a} \in(0,1)$.

3) $\lambda_{\mathrm{n}} \in[\mathrm{c}, \mathrm{d}]$ for some $\mathrm{c}, \mathrm{d}$ with $0<\mathrm{c}<\mathrm{d}<2 \alpha$.

4) $\quad \sum_{n=0}^{\infty}\left|\alpha_{n+1}-\alpha_{n}\right|<\infty, \sum_{n=0}^{\infty}\left|\beta_{n+1}-\beta_{n}\right|<\infty, . \sum_{n=0}^{\infty}\left|\lambda_{n+1}-\lambda_{n}\right|<\infty$

Then $\left\{x_{n}\right\}$ converges strongly to $q \in F(S) \cap \operatorname{VI}(C, A)$, which is the unique solution in the set $F(S) \cap V I(C, A)$ to the following variational inequality $<(I-f) q, q-p>\leq 0, p \in F(S) \cap V I(C, A)$.

Definition: Let $\mathrm{H}$ be a real Hilbert space with inner product $\langle.,$.$\rangle and norm \|$.$\| , respectively. Let \mathrm{C}$ be a closed convex subset of $\mathrm{H}$. Let $\mathrm{A}: \mathrm{C} \rightarrow \mathrm{H}$ be a nonlinear mapping.

i) $\quad \mathrm{A}$ is said to be relaxed $\mu$-cocoercive if there exists a constant $\mu>0$ such that $<\mathrm{Ax}-\mathrm{Ay}, \mathrm{x}-\mathrm{y}>\geq(-\mu)\|\mathrm{Ax}-\mathrm{Ay}\|^{2}$, $\forall \mathrm{x}, \mathrm{y} \in \mathrm{C}$.

ii) $\quad \mathrm{A}$ is said to be relaxed $(\mu, v)$-cocoercive if there exists a constants $\mu, v>0$ such that $\langle\mathrm{Ax}-\mathrm{Ay}, \mathrm{x}-\mathrm{y}\rangle$ $\geq(-\mu)\|A x-A y\|^{2}+v\|x-y\|^{2}, \forall x, y \in C$.

Remark. A $\mu$-inverse-strongly monotone mapping is also called $\mu$-cocoercive.

Lemma. [21] Let $C$ is a nonempty closed convex subset of a real Hilbert space $H$ and $T: C \rightarrow C$ be a $k$-strict pseudocontraction with a fixed point. Define $S: C \rightarrow C$ by $S x=k x+(1-k)$ Tx for each $x \in C$. Then $S$ is nonexpansive with $F(S)=F(T)$.

In 2009, using the above lemma Xiaolong Qin, Shin Min Kang, Yongfu Su and Meijuan Shang [58] improved the results given by W. Takahashi and M. Toyoda [57], Korpelevich [15], Iiduka and Takahashi [17], Yonghong Yao, Yeong-Cheng Liou and Jen-Chih Yao [67] and introduced a general iterative scheme to investigate the problem of finding a common element of the fixed point set of a strict pseudocontraction and the solution set of a variational inequality problem for a relaxed cocoercive mapping by viscosity approximation methods. They proved the following strong convergence theorem.

Theorem.3.1.20: [58] Let $H$ be a real Hilbert space, $C$ be a nonempty closed convex subset of $H$ and $A: C \rightarrow H$ be a relaxed $(\mu, v)$-cocoercive and L-Lipschitz continuous mapping. Let $f: C \rightarrow C$ be a contraction with the coefficient $\alpha \epsilon(0$, 1) and $T: C \rightarrow C$ be a strict pseudocontraction with a fixed point. Define a mapping $S: C \rightarrow C$ by $S x=k x+(1-k) T x$ for each $x \in C$. Assume that $\mathcal{F}=F(T) \cap V I(C, A) \neq \varphi$. Let $\left\{x_{n}\right\}$ be a sequence generated by the following algorithm:

$\mathrm{x}_{1} \in \mathrm{C}$ and

$\mathrm{z}_{\mathrm{n}}=\omega_{\mathrm{n}} \mathrm{x}_{\mathrm{n}}+\left(1-\omega_{\mathrm{n}}\right) \mathrm{P}_{\mathrm{C}}\left(\mathrm{x}_{\mathrm{n}}-\mathrm{t}_{\mathrm{n}} \mathrm{A} \mathrm{x}_{\mathrm{n}}\right)$,

$\mathrm{y}_{\mathrm{n}}=\delta_{\mathrm{n}} \mathrm{S} \mathrm{x}_{\mathrm{n}}+\left(1-\delta_{\mathrm{n}}\right) \mathrm{z}_{\mathrm{n}}$,

$\mathrm{x}_{\mathrm{n}+1}=\alpha_{\mathrm{n}} \mathrm{f}\left(\mathrm{x}_{\mathrm{n}}\right)+\beta_{\mathrm{n}} \mathrm{x}_{\mathrm{n}}+\gamma_{\mathrm{n}} \mathrm{y}_{\mathrm{n}}, \forall \mathrm{n} \geq 1$,

where $\left\{\alpha_{n}\right\},\left\{\beta_{n}\right\},\left\{\gamma_{n}\right\},\left\{\delta_{n}\right\},\left\{\omega_{n}\right\}$ are sequences in $(0,1)$ and $\left\{\mathrm{t}_{\mathrm{n}}\right\}$ is a positive sequence. Assume that the above control sequences satisfy the following restrictions:

a) $\quad \alpha_{\mathrm{n}}+\beta_{\mathrm{n}}+\gamma_{\mathrm{n}}=1, \mathrm{n} \geq 1$;

b) $\lim _{n \rightarrow 0} \alpha_{n}=0, \sum_{n=0}^{\infty} \alpha_{n}=\infty$,

c) $\quad 0<\lim \inf _{n \rightarrow \infty} \beta_{n} \leq \lim \sup _{n \rightarrow \infty} \beta_{n}<1$,

d) $0<\mathrm{t} \leq \mathrm{t}_{\mathrm{n}} \leq \frac{2\left(\mathrm{v}-\mathrm{L}^{2} \mu\right)}{\mathrm{L}^{2}}$, where $\mathrm{t}$ is some constant, for each $\mathrm{n} \geq 1$,

e) $\quad \lim _{n \rightarrow \infty}\left|t_{n}-t_{n+1}\right|=1$,

f) $\lim _{n \rightarrow \infty} \delta_{n}=\delta \epsilon(0,1), \lim _{n \rightarrow \infty} \omega_{n}=\omega \epsilon(0,1)$.

Then, the sequence $\left\{x_{n}\right\}$ converges strongly to $u \in \mathcal{F}$, where $u=\mathrm{P}_{\mathcal{F}} \mathrm{f}(\mathrm{u})$, which solves the following variational inequality

$<\mathrm{f}(\mathrm{u})-\mathrm{u}, \mathrm{u}-\mathrm{v}>\leq 0, \forall \mathrm{x} \in \mathcal{F}$.

In 2009, inspired by the research going on in this direction, L. C. Ceng, A. Petrusel, C. Lee and M. Wong [29] obtained two extragradient methods for finding a common element of the set of solutions of a variational inequality for monotone and Lipschitz continuous mapping and fixed points of a family of strict pseudocontractions.

Theorem 3.1.21: [29] Let $C$ be a closed convex subset of a real Hilbert space H. Let $A$ be a monotone and $k$-Lipschitz continuous mapping of $C$ into $H$. Let $N \geq 1$ be an integer. Let for each $1 \leq i \leq N, S_{i}$ : $C \rightarrow C$ be a $\kappa_{i}$-strict pseudocontraction for some $0 \leq \kappa_{i}<1$ such that $\bigcap_{\mathrm{i}=1}^{\mathrm{N}} \mathrm{F}\left(\mathrm{S}_{\mathrm{i}}\right) \bigcap \Omega \neq \varphi$. Let $\kappa=\max \left\{\kappa_{i}: 1 \leq i \leq N\right\}$. Assume that for each $n$, 
$\left\{\lambda_{i}^{(n)}\right\}_{i=1}^{N}$ is a finite sequence of positive numbers such that $\sum_{\mathrm{i}=1}^{\mathrm{N}} \lambda_{\mathrm{i}}^{(\mathrm{n})}=1$ for each $n \geq 0$, where $\lambda_{i}^{(n)}>0$ for all $n \geq 0$ and $1 \leq \mathrm{i} \leq \mathrm{N}$. Given any $\mathrm{x}_{0} \in \mathrm{C}$, let $\left\{\mathrm{x}_{\mathrm{n}}\right\}_{\mathrm{n}=0}^{\infty},\left\{\mathrm{y}_{\mathrm{n}}\right\}_{\mathrm{n}=0}^{\infty}$ be the sequences generated by

$\mathrm{y}_{\mathrm{n}}=\mathrm{P}_{\mathrm{C}}\left(\mathrm{x}_{\mathrm{n}}-\lambda_{\mathrm{n}} \mathrm{A} \mathrm{x}_{\mathrm{n}}\right)$,

$t_{n}=P_{C}\left(x_{n}-\lambda_{n} A y_{n}\right)$,

$\mathrm{x}_{\mathrm{n}+1}=\alpha_{\mathrm{n}} \mathrm{t}_{\mathrm{n}}+\left(1-\alpha_{\mathrm{n}}\right) \sum_{\mathrm{i}=1}^{\mathrm{N}} \lambda_{\mathrm{i}}^{(\mathrm{n})} \mathrm{S}_{\mathrm{i}} \mathrm{t}_{\mathrm{n}}, \forall \mathrm{n} \geq 0$,

where there hold the following conditions

i) $\quad\left\{\lambda_{n}\right\} \subset[a, b]$ for some $a, b \in(0,1 / k)$;

ii) $\left\{\alpha_{n}\right\} \subset[\alpha, \beta]$ for some $\alpha, \beta \in(\kappa, 1)$.

Then, the sequences $\left\{\mathrm{x}_{\mathrm{n}}\right\},\left\{\mathrm{y}_{\mathrm{n}}\right\}$ converge weakly to the same point $\mathrm{z} \in \bigcap_{\mathrm{i}=1}^{\mathrm{N}} \mathrm{F}\left(\mathrm{S}_{\mathrm{i}}\right) \bigcap \Omega$, where $\mathrm{z}=\lim _{\mathrm{n}} \rightarrow \infty$ $\mathrm{P}_{\bigcap_{\mathrm{i}=1}^{\mathrm{N}} \mathrm{F}\left(\mathrm{S}_{\mathrm{i}}\right) \bigcap \Omega} \mathrm{X}_{\mathrm{n}} \cdot$

Algorithm. Let $\left\{\alpha_{n}\right\}^{\infty}{ }_{n=0}$ be a sequence in $(\kappa, 1)$ and $\left\{\lambda_{n}\right\}^{\infty}{ }_{n=0}$ be a sequence in $(0,1 / k)$. Given any $x_{0} \in C$, let $\left\{x_{n}\right\}^{\infty}{ }_{n=0}$, $\left\{\mathrm{y}_{\mathrm{n}}\right\}_{\mathrm{n}=0}^{\infty}$ be the sequences generated by iterative scheme

$\mathrm{y}_{\mathrm{n}}=\mathrm{P}_{\mathrm{C}}\left(\mathrm{x}_{\mathrm{n}}-\lambda_{\mathrm{n}} \mathrm{A} \mathrm{x}_{\mathrm{n}}\right)$

$\mathrm{t}_{\mathrm{n}}=\mathrm{P}_{\mathrm{C}}\left(\mathrm{x}_{\mathrm{n}}-\lambda_{\mathrm{n}} \mathrm{A} \mathrm{y}_{\mathrm{n}}\right)$,

$\mathrm{x}_{\mathrm{n}+1}=\alpha_{\mathrm{n}} \mathrm{t}_{\mathrm{n}}+\left(1-\alpha_{\mathrm{n}}\right) \mathrm{S}_{[\mathrm{n}]} \mathrm{t}_{\mathrm{n}}, \forall \mathrm{n} \geq 0$,

where $S_{[n]}=S_{i}$, with $i=n(\operatorname{modN}), 0 \leq i \leq N-1$, i.e., if $n=j N+i$ for some integers $j \geq 0$ and $0 \leq \mathrm{i} \leq \mathrm{N}-1$, then $S_{[n]}=S_{0}$ if $\mathrm{i}=0$ and $\mathrm{S}_{[\mathrm{n}]}=\mathrm{S}_{\mathrm{i}}$ if $0 \leq \mathrm{i} \leq \mathrm{N}-1$.

Using this algorithm they proved a weak convergence theorem.

Theorem 3.1.22: [29] Let $C$ be a closed convex subset of a real Hilbert space H. Let $A$ be a monotone and $k$-Lipschitz continuous mapping of $C$ into $H$. Let $N \geq 1$ be an integer. Let for each $0 \leq i \leq N-1, S_{i}: C \rightarrow C$ be a $\kappa_{i}$-strict pseudocontraction for some $0 \leq \kappa_{i}<1$ such that $\bigcap_{\mathrm{i}=1}^{\mathrm{N}} \mathrm{F}\left(\mathrm{S}_{\mathrm{i}}\right) \bigcap \Omega \neq \varphi$. Let $\kappa=\max \left\{\kappa_{i}: 0 \leq i \leq N-1\right\}$. Given any $x_{0} \epsilon C$, let $\left\{x_{n}\right\}^{\infty}{ }_{n=0},\left\{y_{n}\right\}_{n=0}^{\infty}$ be the sequences generated by

$\mathrm{y}_{\mathrm{n}}=\mathrm{P}_{\mathrm{C}}\left(\mathrm{x}_{\mathrm{n}}-\lambda_{\mathrm{n}} \mathrm{A} \mathrm{x}_{\mathrm{n}}\right)$,

$\mathrm{t}_{\mathrm{n}}=\mathrm{P}_{\mathrm{C}}\left(\mathrm{x}_{\mathrm{n}}-\lambda_{\mathrm{n}} \mathrm{A} \mathrm{y}_{\mathrm{n}}\right)$,

$\mathrm{x}_{\mathrm{n}+1}=\alpha_{\mathrm{n}} \mathrm{t}_{\mathrm{n}}+\left(1-\alpha_{\mathrm{n}}\right) \mathrm{S}_{[\mathrm{n}]} \mathrm{t}_{\mathrm{n}}, \forall \mathrm{n} \geq 0$,

Assume that the sequences $\left\{\alpha_{n}\right\} \subset(\kappa, 1)$ and $\left\{\lambda_{n}\right\} \subset(0,1 / k)$ satisfy the following conditions

i) $\quad\left\{\lambda_{\mathrm{n}}\right\} \subset[\mathrm{a}, \mathrm{b}]$ for some $\mathrm{a}, \mathrm{b} \in(0,1 / \mathrm{k})$;

ii) $\left\{\alpha_{n}\right\} \subset[\alpha, \beta]$ for some $\alpha, \beta \in(\kappa, 1)$.

Then, the sequences $\left\{x_{n}\right\},\left\{y_{n}\right\}$ converge weakly to the same point $z \in \bigcap_{i=1}^{N} F\left(S_{i}\right) \bigcap \Omega$, where $z=\lim _{n} \rightarrow \infty$ $\mathrm{P}_{\bigcap_{\mathrm{i}=1}^{\mathrm{N}} \mathrm{F}\left(\mathrm{S}_{\mathrm{i}}\right) \bigcap \Omega} \mathrm{X}_{\mathrm{n}} \cdot$

In 2011, motivated by the results obtained by Iiduka and Takahashi [17] and Y. Yao and J. C. Yao [67], Yuan Qing, Sun Young Cho and Xiaolong Qin [62], considered the class of strict pseudocontractions and class of inverse strongly monotone mappings and introduced a new iterative method for finding a common element of the fixed point set of a strict pseudocontraction and the solution set of variational inequality in a real Hilbert space.

Theorem 3.1.23: [62] Let $C$ be a closed convex subset of a real Hilbert space $H$. Let $A$ be an $\alpha$-inverse-stronglymonotone mapping of $C$ into $H$ and $B$ be an $\beta$-inverse-strongly-monotone mapping of $C$ into $H$ and $T: C \rightarrow C$ be a $k$ strict pseudocontraction. . Assume that $\mathcal{F}=F(T) \cap \operatorname{VI}(C, A) \cap \operatorname{VI}(C, B) \neq \varphi$. Let $\left\{x_{n}\right\}$ be a sequence generated by the following algorithm:

$\mathrm{x}_{0} \in \mathrm{C}$ and

$z_{\mathrm{n}}=\eta_{\mathrm{n}} \mathrm{x}_{\mathrm{n}}+\left(1-\eta_{\mathrm{n}}\right) \mathrm{P}_{\mathrm{C}}\left(\mathrm{x}_{\mathrm{n}}-\rho_{\mathrm{n}} \mathrm{A} \mathrm{x}_{\mathrm{n}}\right)$

$\mathrm{y}_{\mathrm{n}}=\delta_{\mathrm{n}} \mathrm{P}_{\mathrm{C}}\left(\mathrm{z}_{\mathrm{n}}-\lambda_{\mathrm{n}} \mathrm{B} \mathrm{z}_{\mathrm{n}}\right)+\left(1-\delta_{\mathrm{n}}\right) \mathrm{T} \mathrm{P}_{\mathrm{C}}\left(\mathrm{z}_{\mathrm{n}}-\lambda_{\mathrm{n}} \mathrm{B} \mathrm{z}_{\mathrm{n}}\right)$,

$\mathrm{x}_{\mathrm{n}+1}=\alpha_{\mathrm{n}} \mathrm{u}+\beta_{\mathrm{n}} \mathrm{x}_{\mathrm{n}}+\gamma_{\mathrm{n}} \mathrm{y}_{\mathrm{n}}, \forall \mathrm{n} \geq 0$,

where $u$ is a fixed element in $C,\left\{\alpha_{n}\right\},\left\{\beta_{n}\right\},\left\{\gamma_{n}\right\},\left\{\delta_{n}\right\},\left\{\eta_{n}\right\}$ are sequences in $(0,1)$ and $\left\{\rho_{n}\right\}$ is a positive sequence.

Assume that the above control sequences satisfy the following restrictions:

a) $\quad \alpha_{\mathrm{n}}+\beta_{\mathrm{n}}+\gamma_{\mathrm{n}}=1, \mathrm{n} \geq 0$

b) $\quad \lim _{n \rightarrow 0} \alpha_{n}=0, \sum_{n=0}^{\infty} \alpha_{n}=\infty$,

c) $0<\liminf _{n \rightarrow \infty} \beta_{n} \leq \lim \sup _{n \rightarrow \infty} \beta_{n}<1$, 
d) $\quad \lim _{n \rightarrow \infty} \sum_{n=0}^{\infty}\left|\lambda_{n+1}-\lambda_{n}\right|=\lim _{n \rightarrow \infty} \sum_{n=0}^{\infty}\left|\delta_{n+1}-\delta_{n}\right|=\lim _{n \rightarrow \infty} \sum_{n=0}^{\infty}\left|\rho_{n+1}-\rho_{n}\right|=0$.

e) $\left\{\lambda_{\mathrm{n}}\right\},\left\{\rho_{\mathrm{n}}\right\} \in[\mathrm{a}, \mathrm{b}]$ for some a, b with $0<\mathrm{a}<\mathrm{b}<\min \{2 \alpha, 2 \beta\}$

f) $\quad \lim _{\mathrm{n} \rightarrow \infty} \eta_{\mathrm{n}}=0$ and $\mathrm{k} \leq \delta_{\mathrm{n}} \leq \mathrm{e}<1$, where e $\epsilon[\mathrm{k}, 1)$ is some constant.

Then, the sequence $\left\{\mathrm{x}_{\mathrm{n}}\right\}$ converges strongly to $\mathrm{u} \in \mathcal{F}$, where $\mathrm{u}=\mathrm{P}_{\mathcal{F}} \mathrm{u}$.

In 2011, Bunyawat A. and Suantal S. [1], further generalized the above results and introduced an iterative method for finding a common element of the set of fixed points of a countable family of nonexpansive mappings and the set of solutions of some variational inequality problem for an inverse strongly monotone mapping in a Hilbert space and obtained a strong convergence result.

Theorem 3.1.24: [1] Let $C$ be a nonempty closed convex subset of a Hilbert space $H$. Assume that B: $C \rightarrow H$ is a $\beta$ inverse strongly monotone mapping. . Let A be a strongly positive linear bounded operator with the coefficient $\bar{\gamma}>0$ such that $\|A\| \leq 1$ and let $f$ be a contraction of $C$ into itself. Assume that $0<\gamma<\bar{\gamma} / \alpha$. Let $\left\{T_{n}: C \rightarrow C\right\}$ be a countable family of nonexpansive mappings with $F=\bigcap_{\mathrm{n}=1}^{\infty} \mathrm{F}\left(\mathrm{T}_{\mathrm{n}}\right) \bigcap \mathrm{VI}(\mathrm{C}, \mathrm{B}) \neq \phi$. Let $\left\{x_{n}\right\}$ be sequence generated by the following algorithm:

$\mathrm{x}_{0} \in \mathrm{C}$,

$\mathrm{x}_{\mathrm{n}+1}=\mathrm{P}_{\mathrm{C}}\left(\alpha_{\mathrm{n}} \gamma \mathrm{f}\left(\mathrm{x}_{\mathrm{n}}\right)+\left(1-\alpha_{\mathrm{n}} \mathrm{A}\right) \mathrm{T}_{\mathrm{n}} \mathrm{P}_{\mathrm{C}}\left(\mathrm{x}_{\mathrm{n}}-\lambda_{\mathrm{n}} \mathrm{B} \mathrm{x}_{\mathrm{n}}\right)\right)$

for all $\mathrm{n}=0,1,2, \ldots \ldots \ldots \ldots \ldots$, where $\left\{\alpha_{\mathrm{n}}\right\} \subset(0,1)$ and $\left\{\lambda_{\mathrm{n}}\right\} \subset(0,2 \beta)$. If $\left\{\alpha_{\mathrm{n}}\right\}$ and $\left\{\lambda_{\mathrm{n}}\right\}$ are chosen so that $\lambda_{\mathrm{n}} \in[\mathrm{a}, \mathrm{b}]$ for some $\mathrm{a}, \mathrm{b}$ with $0<\mathrm{a}<\mathrm{b}<2 \beta$,

(C1). $\lim _{\mathrm{n} \rightarrow \infty} \alpha_{\mathrm{n}}=0$,

(C2). $\sum_{n=0}^{\infty} \alpha_{n}=\infty$,

(C3). $\sum_{n=0}^{\infty}\left|\alpha_{n+1}-\alpha_{n}\right|<\infty$,

(C4). $\sum_{n=0}^{\infty}\left|\lambda_{n+1}-\lambda_{n}\right|<\infty$.

Suppose that $\left(\left\{T_{n}\right\}, T\right)$ satisfies the AKTT- condition. Then the sequence $\left\{x_{n}\right\}$ converges strongly to $q \in F$, where $q=$ $\mathrm{P}_{\mathrm{F}}(\gamma \mathrm{f}+(\mathrm{I}-\mathrm{A})) \mathrm{q}$ which solves the following variational inequality:

$\langle\gamma \mathrm{f}(\mathrm{q})-\mathrm{Ap}, \mathrm{p}-\mathrm{q}\rangle \leq 0, \forall \mathrm{p} \in \mathrm{F}$.

Remark. To deal with a family of mappings, the following condition was introduced:

Let $C$ be a subset of a real Banach space $E$ and let $\left\{T_{n}\right\}_{n=1}^{\infty}$ be a family of mappings of $C$ such that $\bigcap_{n=1}^{\infty} F\left(T_{n}\right) \neq \phi$ Then $\left\{T_{n}\right\}$ is said to satisfy the AKTT-condition [27] if for each bounded subset B of C,

$\sum_{n=1}^{\infty} \sup \left\{\left\|T_{n+1} z-T_{n} z\right\|: z \varepsilon B\right\}<\infty$.

In 2011, Ceng et al [8], investigated the problem of finding a common element of the set of fixed points of an asymptotically $\kappa$ - strict pseudocontractive mapping in the intermediate sense and the set of solutions of a variational inequality problem for a monotone and Lipschitz continuous mapping. They obtained an extragradient-like iterative algorithm that is based on an extragradient-like approximation method and the modified Mann iteration method. They established a strong convergence theorem for two sequences generated by this extragradient-like iterative algorithm.

Theorem 3.1.25: [8] Let A: $C \rightarrow H$ be a monotone and L-Lipschitz continuous mapping, $f: C \rightarrow C$ be a contraction with contractive constant $\alpha \epsilon(0,1)$ and $S: C \rightarrow C$ be a uniformly continuous asymptotically $\kappa$ - strict pseudocontractive mapping in the intermediate sense with sequence $\left\{\gamma_{n}\right\}$ such that $F(S) \cap \Omega \neq \varphi$ and $\sum_{\mathrm{n}=1}^{\infty} \gamma_{\mathrm{n}}<\infty$. Let $\left\{x_{n}\right\}$, \{ $\left\{y_{n}\right\}$ be sequences generated by

$\mathrm{x}_{1} \in \mathrm{C}$

$\gamma_{\mathrm{n}}=\left(1-\mu_{\mathrm{n}}\right) \mathrm{x}_{\mathrm{n}}+\mu_{\mathrm{n}} \mathrm{P}_{\mathrm{C}}\left(\mathrm{x}_{\mathrm{n}}-\lambda_{\mathrm{n}} \mathrm{A} \mathrm{x}_{\mathrm{n}}\right)$

$\mathrm{t}_{\mathrm{n}}=\mathrm{P}_{\mathrm{C}}\left(\mathrm{x}_{\mathrm{n}}-\lambda_{\mathrm{n}} \mathrm{A} \gamma_{\mathrm{n}}\right)$,

$\mathrm{x}_{\mathrm{n}+1}=\left(1-\alpha_{\mathrm{n}}-\beta_{\mathrm{n}}-v_{\mathrm{n}}\right) \mathrm{x}_{\mathrm{n}}+\alpha_{\mathrm{n}} \mathrm{f}\left(\gamma_{\mathrm{n}}\right)+\beta_{\mathrm{n}} \mathrm{t}_{\mathrm{n}}+v_{\mathrm{n}} \mathrm{S}^{\mathrm{n}} \mathrm{t}_{\mathrm{n}}, \quad \forall \mathrm{n} \geq 1$,

where $\left\{\lambda_{n}\right\}$ is a sequence in $(0,1)$ with $\sum_{n=1}^{\infty} \lambda_{n}<\infty$ and $\left\{\alpha_{n}\right\},\left\{\beta_{n}\right\},\left\{\gamma_{n}\right\},\left\{\mu_{n}\right\}$ are sequences in [0, 1] satisfying the following restrictions: 
a) $\quad \alpha_{\mathrm{n}}+\beta_{\mathrm{n}}+v_{\mathrm{n}} \leq 1, \mathrm{n} \geq 1$;

b) $\quad \lim _{n \rightarrow 0} \alpha_{n}=0, \sum_{n=0}^{\infty} \alpha_{n}=\infty$,

c) $\quad \kappa<\lim \inf _{n \rightarrow \infty} \beta_{n} \leq \lim \sup _{n \rightarrow \infty} \beta_{n}<1$,

d) $\quad \sum_{n=1}^{\infty} v_{n}=\infty$.

Then, the sequences $\left\{x_{n}\right\},\left\{y_{n}\right\}$ converge strongly to the same point $q=P_{F(S) \cap \Omega} f(q)$ if and only if $\left\{A x_{n}\right\}$ is bonded, $\|(I-$ $\left.\mathrm{S}^{\mathrm{n}}\right) \mathrm{X}_{\mathrm{n}} \| \rightarrow 0$ and $\lim _{\mathrm{inf}} \mathrm{n}_{\mathrm{n}}<\mathrm{Ax}_{\mathrm{n}}, \mathrm{y}-\mathrm{x}_{\mathrm{n}}>\geq 0$ for all $\mathrm{y} \in \mathrm{C}$.

In 2012, inspired by Wangkeeree and Kamraksa [51], Yonghong Yao and Mihai Postolache [66] introduced an iterative scheme for finding a common element of the set of solutions of a pseudomonotone, Lipschitz-continuous variational inequality problem and the set of fixed points of an infinite family of nonexpansive mappings. The proposed iterative method combined two well-known schemes: extragradient and approximate proximal methods. They derived some necessary and sufficient conditions for strong convergence of the sequences generated by the proposed scheme.

Theorem 3.1.26: [66] Let $C$ be a closed convex subset of a real Hilbert space H. Let A: $C \rightarrow$ H be a pseudomonotone and L-Lipschitz continuous and (w, s)-sequentially-continuous mapping mapping and let $\left\{\mathrm{S}_{\mathrm{n}}\right\}_{\mathrm{n}=1}^{\infty}$ be an infinite family of nonexpansive mappings of $C$ into itself such that $\bigcap_{n=1}^{\infty}$ Fix $\left(S_{n}\right) \cap \Omega \neq \Phi$.

Let $\left\{\mathrm{x}_{\mathrm{n}}\right\},\left\{\mathrm{y}_{\mathrm{n}}\right\},\left\{\mathrm{z}_{\mathrm{n}}\right\}$ be sequences generated by

$\mathrm{x}_{1} \in \mathrm{C}$

$\gamma_{\mathrm{n}}=\mathrm{P}_{\mathrm{C}}\left(\mathrm{x}_{\mathrm{n}}-\lambda_{\mathrm{n}} \mathrm{A} \mathrm{x}_{\mathrm{n}}\right)$,

$\mathrm{z}_{\mathrm{n}}=\alpha_{\mathrm{n}} \mathrm{x}_{\mathrm{n}}+\left(1-\alpha_{\mathrm{n}}\right) \mathrm{W}_{\mathrm{n}} \mathrm{P}_{\mathrm{C}}\left(\mathrm{x}_{\mathrm{n}}-\lambda_{\mathrm{n}} \mathrm{A} \mathrm{y}_{\mathrm{n}}\right)$,

$\mathrm{C}_{\mathrm{n}}=\left\{\mathrm{z} \in \mathrm{C}:\left\|\mathrm{z}_{\mathrm{n}}-\mathrm{z}\right\| \leq\left\|\mathrm{x}_{\mathrm{n}}-\mathrm{z}\right\|\right\}$,

Find $x_{n+1} \in C_{n}$ such that

$<\left(1-\beta_{n}\right) x_{n}-x_{n+1}+e_{n}-\sigma_{n} A x_{n+1}, x_{n+1}-x>\geq 0, \forall x \in C_{n}, n \geq 1$, where $W_{n}$ is a W-mapping defined by

$\mathrm{U}_{\mathrm{n}, \mathrm{n}+1}=\mathrm{I}$,

$\mathrm{U}_{\mathrm{n}, \mathrm{n}}=\xi_{\mathrm{n}} \mathrm{S}_{\mathrm{n}} \mathrm{U}_{\mathrm{n}, \mathrm{n}+1}+\left(1-\xi_{\mathrm{n}}\right) \mathrm{I}$,

$\mathrm{U}_{\mathrm{n}, \mathrm{n}-1}=\xi_{\mathrm{n}-1} \mathrm{~S}_{\mathrm{n}-1} \mathrm{U}_{\mathrm{n}, \mathrm{n}}+\left(1-\xi_{\mathrm{n}-1}\right) \mathrm{I}$,

:

$\mathrm{U}_{\mathrm{n}, \mathrm{k}}=\xi_{\mathrm{k}} \mathrm{S}_{\mathrm{k}} \mathrm{U}_{\mathrm{n}, \mathrm{k}+1}+\left(1-\xi_{\mathrm{k}}\right) \mathrm{I}$,

$\mathrm{U}_{\mathrm{n}, \mathrm{k}-1}=\xi_{\mathrm{k}-1} \mathrm{~S}_{\mathrm{k}-1} \mathrm{U}_{\mathrm{n}, \mathrm{k}}+\left(1-\xi_{\mathrm{k}-1}\right) \mathrm{I}$,

:

$\mathrm{U}_{\mathrm{n}, 2}=\xi_{2} \mathrm{~S}_{2} \mathrm{U}_{\mathrm{n}, 3}+\left(1-\xi_{2}\right) \mathrm{I}$,

$\mathrm{W}_{\mathrm{n}}=\mathrm{U}_{\mathrm{n}, 1}=\xi_{1} \mathrm{~S}_{1} \mathrm{U}_{\mathrm{n}, 2}+\left(1-\xi_{1}\right) \mathrm{I}$, and $\left\{\mathrm{e}_{\mathrm{n}}\right\}$ is error sequence in $\mathrm{H}$ which satisfies $\sum_{\mathrm{n}}\left\|\mathrm{e}_{\mathrm{n}}\right\|<\infty$.

Suppose the following conditions hold:

i) $\quad\left\{\lambda_{\mathrm{n}}\right\} \subset[\mathrm{a}, \mathrm{b}]$ for some $\mathrm{a}, \mathrm{b} \in(0,1 / \mathrm{k})$;

ii) $\left\{\alpha_{n}\right\} \subset[0, c]$ for some $c \in(0,1)$.

iii) $\left\{\sigma_{\mathrm{n}}\right\} \subset(0,1 / \mathrm{k})$ and $\left\{\beta_{\mathrm{n}}\right\} \subset[0,1]$ satisfies $\lim _{\mathrm{n} \rightarrow 0} \beta_{\mathrm{n}}=0, \sum_{\mathrm{n}=0}^{\infty} \beta_{\mathrm{n}}=\infty$.

Then the sequences $\left\{x_{n}\right\},\left\{y_{n}\right\}$ and $\left\{z_{n}\right\}$ converge strongly to the same element of $\bigcap_{n=1}^{\infty}$ Fix $\left(S_{n}\right) \cap \Omega$ if and only if $\left\|\mathrm{x}_{\mathrm{n}+1}-\mathrm{x}_{\mathrm{n}}\right\| \rightarrow 0$ and $\lim \inf _{\mathrm{n} \rightarrow \infty}<\mathrm{Ax}_{\mathrm{n}}, \mathrm{x}-\mathrm{x}_{\mathrm{n}}>\geq 0$ for all $\mathrm{x} \in \mathrm{C}$.

In 2012, Liou et al. [61], considered a general variational inequality and fixed point problem, which is to find a point $\mathrm{x}$ with the property that $x \in \operatorname{GVI}(C, A)$ and $g(x) \in \operatorname{Fix}(S)$, where $\operatorname{GVI}(C, A)$ is the solution set of variational inequality, Fix $(S)$ is fixed points set of nonexpansive mapping $S$ and $g$ is nonlinear operator. For solving $G$ VI $(C, A)$, they suggested an iterative method and showed that the sequence generated by this method converges strongly to a unique solution of variational inequality problem.

Theorem 3.1.27: [61] Let $C$ be a nonempty closed convex subset of a Hilbert space H. Let F: $C \rightarrow H$ be L-Lipschitz continuous mapping, $g: C \rightarrow C$ be a weakly continuous and $\gamma$-strongly monotone mapping such that $R(g)=C$. Let $A: C$ $\rightarrow H$ be an $\alpha$-inverse strongly $g$-monotone mapping and let $S: C \rightarrow C$ be a nonexpansive mapping. Suppose that $\Omega \neq \phi$. Let $\beta \in(0,1)$ and $\gamma \in(L, 2 \alpha)$. For given $x_{0} \in C$, let $\left\{x_{n}\right\} \subset C$ be a sequence generated by

$\mathrm{g}\left(\mathrm{x}_{\mathrm{n}+1}\right)=\beta \mathrm{g}\left(\mathrm{x}_{\mathrm{n}}\right)+(1-\beta) \mathrm{SP}_{\mathrm{C}}\left[\alpha_{\mathrm{n}} \mathrm{F}\left(\mathrm{x}_{\mathrm{n}}\right)+\left(1-\alpha_{\mathrm{n}}\right)\left(\mathrm{g}\left(\mathrm{x}_{\mathrm{n}}\right)-\lambda \mathrm{Ax}\right)\right], \mathrm{n} \geq 0$,

where $\left\{\alpha_{n}\right\} \subset(0,1)$ satisfies:

(C1). $\lim _{n \rightarrow \infty} \alpha_{n}=0$,

(C2). $\sum_{n=0}^{\infty} \alpha_{n}=\infty$. 
Then the sequence $\left\{x_{n}\right\}$ converges strongly to $x^{*} \in \Omega$ which is the unique solution of the following variational inequality:

$\left\langle\mathrm{F}\left(\mathrm{x}^{*}\right)-\mathrm{g}\left(\mathrm{x}^{*}\right), \mathrm{g}(\mathrm{x})-\mathrm{g}\left(\mathrm{x}^{*}\right)\right\rangle \leq 0, \forall \mathrm{x} \in \Omega$.

Further, in 2008, Ceng et al. [9] introduced a new a problem of finding $\left(\mathrm{x}^{*}, \mathrm{z}^{*}\right) \in \mathrm{C} \times \mathrm{C}$ such that $\left\langle\lambda_{1} \mathrm{D}_{1} \mathrm{z}^{*}+\mathrm{x}^{*}-\mathrm{z}^{*}, \mathrm{x}-\mathrm{x}^{*}\right\rangle \geq 0, \forall \mathrm{x} \in \mathrm{C}$,

$\left\langle\lambda_{2} \mathrm{D}_{2} \mathrm{x}^{*}+\mathrm{z}^{*}-\mathrm{x}^{*}, \mathrm{x}-\mathrm{z}^{*}\right\rangle \geq 0, \forall \mathrm{x} \in \mathrm{C}$,

where $\mathrm{D}_{1}, \mathrm{D}_{2}$ : $\mathrm{C} \rightarrow \mathrm{H}$ are any two mappings and $\lambda_{1}, \lambda_{2}>0$. This system is called a system of variational inequalities.

They studied a relaxed extragradient method for finding solutions of a general system of variational inequalities with inverse strongly monotone mappings in a real Hilbert as follows:

Theorem 3.1.28: [30] Let $C$ be a nonempty closed convex subset of a real Hilbert space $H$ and let $A, B: C \rightarrow H$ be $\alpha$ inverse strongly monotone and $\beta$-inverse strongly monotone, respectively. Define the mapping Let $S: C \rightarrow C$ be a nonexpansive mapping with $F(S) \cap \Omega \neq \phi$, where $\Omega$ is the set of fixed points of the mapping $G: C \rightarrow C$ defined by $\mathrm{G}(\mathrm{x})$ $=\mathrm{P}_{\mathrm{C}}\left(\mathrm{P}_{\mathrm{C}}(\mathrm{x}-\mu \mathrm{Bx})-\lambda \mathrm{AP}_{\mathrm{C}}(\mathrm{x}-\mu \mathrm{Bx})\right.$ for all $\mathrm{x} \in \mathrm{C}$. Let $\mathrm{x}_{1}=\mathrm{u} \in \mathrm{C}$ and let $\left\{\mathrm{x}_{\mathrm{n}}\right\}$ be the sequence generated by

$\mathrm{y}_{\mathrm{n}}=\mathrm{P}_{\mathrm{C}}\left(\mathrm{x}_{\mathrm{n}}-\mu \mathrm{Bx} \mathrm{x}_{\mathrm{n}}\right)$,

$\mathrm{x}_{\mathrm{n}+1}=\alpha_{\mathrm{n}} \mathrm{u}+\beta_{\mathrm{n}} \mathrm{x}_{\mathrm{n}}+\gamma_{\mathrm{n}} \mathrm{P}_{\mathrm{C}}\left(\mathrm{x}_{\mathrm{n}}-\lambda \mathrm{Ax}_{\mathrm{n}}\right.$,

where $\lambda \in(0,2 \alpha), \mu \in(0,2 \beta)$ and $\left\{\alpha_{n}\right\},\left\{\beta_{n}\right\},\left\{\gamma_{n}\right\} \in[0,1]$. Assume that the following conditions hold:

i) $\left.\quad \alpha_{\mathrm{n}}+\beta_{\mathrm{n}}+\gamma_{\mathrm{n}}=1,\right), \mathrm{n} \geq 1$,

ii) $\lim _{\mathrm{n} \rightarrow \infty} \alpha_{\mathrm{n}}=0, \sum_{\mathrm{n}=0}^{\infty} \alpha_{\mathrm{n}}=\infty$,

iii) $\quad 0<\lim \inf _{n \rightarrow \infty} \beta_{n} \leq \lim \sup _{n \rightarrow \infty} \beta_{n}<1$,

Then $\left\{\mathrm{x}_{\mathrm{n}}\right\}$ converges strongly to $\mathrm{x}_{0}=\mathrm{P}_{\mathrm{F}(\mathrm{S})} \cap_{\Omega} \mathrm{u}$ and $\left(\mathrm{x}_{0}, \mathrm{y}_{0}\right)$ is a solution of (3.32), where $\mathrm{y}_{0}=\mathrm{P}_{\mathrm{C}}\left(\mathrm{x}_{0}-\mu \mathrm{Bx}_{0}\right)$.

In 2013, motivated by the work of Ceng et al. [30], Kangtunyakarn [4] considered a new problem of finding ( $\left.x^{*}, z^{*}\right) \in C$ $\times \mathrm{C}$ such that

$\left\langle\mathrm{x}^{*}-\left(\mathrm{I}-\lambda_{1} \mathrm{D}_{1}\right)\left(\mathrm{ax}{ }^{*}+(1-\mathrm{a}) \mathrm{z}^{*}\right), \mathrm{x}-\mathrm{x}^{*}\right\rangle \geq 0, \forall \mathrm{x} \in \mathrm{C}$,

$\left\langle\mathrm{z}^{*}-\left(\mathrm{I}-\lambda_{2} \mathrm{D}_{2}\right) \mathrm{x}^{*}, \mathrm{x}-\mathrm{z}^{*}\right\rangle \geq 0, \forall \mathrm{x} \in \mathrm{C}$,

where $D_{1}, D_{2}: C \rightarrow H$ are any two mappings. This system is called a modification of system of variational inequalities, for every $\lambda_{1}, \lambda_{2}>0$ and $\mathrm{a} \in[0,1]$. If $\mathrm{a}=0$, then (3.35) reduces to (3.33).

He proved a strong convergence theorem for finding a common element of the set of fixed points of a finite family of $\mathrm{k}_{\mathrm{i}}$-strictly pseudocontractive mappings and the set of solutions of a modified general system of variational inequalities problems.

Now we give a definition:

Definition: Let $\mathrm{C}$ be a nonempty closed convex subset of a Hilbert space H. Let $\left\{\mathrm{T}_{\mathrm{i}}\right\}_{\mathrm{i}=1}^{\mathrm{N}}$ be a finite family of $\mathrm{k}_{\mathrm{i}}$-strict pseudo-contractions of $\mathrm{C}$ into itself. For each $\mathrm{j}=1,2, \ldots \ldots, \mathrm{N}$, let $\alpha_{\mathrm{j}}=\left(\alpha_{1}{ }^{\mathrm{j}}, \alpha_{2}{ }^{\mathrm{j}}, \alpha_{3}{ }^{\mathrm{j}}\right) \in \mathrm{I} \times \mathrm{I} \times \mathrm{I}$, where $\mathrm{I} \in[0,1]$ and $\alpha_{1}{ }^{\mathrm{j}}$ $+\alpha_{2}{ }^{\mathrm{j}}+\alpha_{3}{ }^{\mathrm{j}}=1$. Define the mapping $\mathrm{S}: \mathrm{C} \rightarrow \mathrm{C}$ as follows:

$\mathcal{U}_{0}=\mathrm{I}$,

$U_{1}=\alpha_{1} \mathrm{~T}_{1} U_{0}+\alpha_{2}{ }^{1} U_{0}+\alpha_{3}{ }^{1} \mathrm{I}$

$\mathcal{U}_{2}=\alpha_{1}^{2} \mathrm{~T}_{2} \mathcal{U}_{1}+\alpha_{2}^{2} \mathcal{U}_{1}+\alpha_{3}^{2} \mathrm{I}$

$\mathcal{U}_{3}=\alpha_{1}^{3} \mathrm{~T}_{3} \mathcal{U}_{2}+\alpha_{2}^{3} \mathcal{U}_{2}+\alpha_{3}{ }^{3} \mathrm{I}$,

$\mathcal{U}_{\mathrm{N}-1}=\alpha_{1}^{\mathrm{N}-1} \mathrm{~T}_{\mathrm{N}-1} \mathcal{U}_{\mathrm{N}-2}+\alpha_{2}^{\mathrm{N}-1} \mathcal{U}_{\mathrm{N}-2}+\alpha_{3}^{\mathrm{N}-1} \mathrm{I}$

$\mathrm{S}=\mathcal{U}_{\mathrm{N}}=\alpha_{1}{ }^{\mathrm{N}} \mathrm{S}_{\mathrm{N}} \mathcal{U}_{\mathrm{N}-1}+\alpha_{2}{ }^{\mathrm{N}} \mathcal{U}_{\mathrm{N}-1}+\alpha_{3}^{\mathrm{N}} \mathrm{I}$

This mapping is called the $\mathrm{S}$-mapping generated by $\mathrm{T}_{1}, \mathrm{~T}_{2}, \ldots \ldots \mathrm{T}_{\mathrm{N}}$ and $\alpha_{1}, \alpha_{2}, \ldots \ldots, \alpha_{\mathrm{N}}$.

Theorem 3.1.29: [4] Let $C$ is a nonempty closed convex subset of a real Hilbert space $H$ and let $D_{1}, D_{2:} C \rightarrow H$ be $d_{1}, d_{2}$ -inverse strongly monotone mappings, respectively. Define the mapping G: $\mathrm{C} \rightarrow \mathrm{C}$ by $\mathrm{G}(\mathrm{x})=\mathrm{P}_{\mathrm{C}}\left(\mathrm{I}-\lambda_{1} \mathrm{D}_{1}\right)(\mathrm{ax}+(1-$ a) $\left.\mathrm{P}_{\mathrm{C}}\left(\mathrm{I}-\lambda_{2} \mathrm{D}_{2}\right) \mathrm{x}\right)$ for all $\mathrm{x} \in \mathrm{C}, \lambda_{1}, \lambda_{2}>0$ and $\mathrm{a} \in[0,1)$. Let $\left\{\mathrm{T}_{\mathrm{i}}\right\}_{\mathrm{i}=1}^{\mathrm{N}}$ be a finite family of k-strict pseudocontractive mappings of $C$ into itself with $F=\bigcap_{i=1}^{N} F\left(T_{i}\right) \cap F(G) \neq \phi$ and $k=\min \left\{k_{i}: i=1,2, \ldots \ldots, N\right\}$ and let $\alpha_{j}=\left(\alpha_{1}{ }^{j}, \alpha_{2}{ }^{j}, \alpha_{3}{ }^{j}\right) \in I$ $\times I \times I$, where $I \in[0,1], \alpha_{1}{ }^{j}+\alpha_{2}{ }^{j}+\alpha_{3}{ }^{j}=1, \alpha_{1}{ }^{j}, \alpha_{3}{ }^{j} \in(k, 1)$ and $\alpha_{1}{ }^{N} \in(k, 1], \alpha_{3}{ }^{N} \in[k, 1), \alpha_{2}{ }^{j} \in[k, 1)$ for all $j=1,2, \ldots . .$, $\mathrm{N}$. Let $\mathrm{S}$ be the $\mathrm{S}-$ mapping generated by $\mathrm{T}_{1}, \mathrm{~T}_{2}, \ldots \ldots \mathrm{T}_{\mathrm{N}}$ and $\alpha_{1}, \alpha_{2}, \ldots \ldots, \alpha_{\mathrm{N}}$. Let $\mathrm{x}_{1}, \mathrm{u} \in \mathrm{C}$ and let $\left\{\mathrm{x}_{\mathrm{n}}\right\}$ be the sequence generated by

$\mathrm{y}_{\mathrm{n}}=\mathrm{P}_{\mathrm{C}}\left(\mathrm{I}-\lambda_{2} \mathrm{D}_{2}\right) \mathrm{x}_{\mathrm{n}}$

$\mathrm{x}_{\mathrm{n}+1}=\alpha_{\mathrm{n}} \mathrm{u}+\beta_{\mathrm{n}} \mathrm{x}_{\mathrm{n}}+\gamma_{\mathrm{n}} \mathrm{SP}_{\mathrm{C}}\left(\mathrm{ax}_{\mathrm{n}}+(1-\mathrm{a}) \mathrm{y}_{\mathrm{n}}-\lambda_{1} \mathrm{D}_{1}\left(\mathrm{ax}_{\mathrm{n}}+(1-\mathrm{a}) \mathrm{y}_{\mathrm{n}}\right)\right), \mathrm{n} \geq 1$,

where $\lambda_{1} \in\left(0,2 \mathrm{~d}_{1}\right), \lambda_{2} \in\left(0,2 \mathrm{~d}_{2}\right)$ and $\left\{\alpha_{\mathrm{n}}\right\},\left\{\beta_{\mathrm{n}}\right\},\left\{\gamma_{\mathrm{n}}\right\} \in[0,1]$. Assume that the following conditions hold:

i) $\alpha_{\mathrm{n}}+\beta_{\mathrm{n}}+\gamma_{\mathrm{n}}=1$, 
ii) $\lim _{\mathrm{n} \rightarrow \infty} \alpha_{\mathrm{n}}=0, \sum_{\mathrm{n}=0}^{\infty} \alpha_{\mathrm{n}}=\infty$,

iii) $0<\lim$ infn $\rightarrow \infty \beta_{\mathrm{n}} \leq \lim \operatorname{supn} \rightarrow \infty \beta_{\mathrm{n}}<1$,

Then $\left\{\mathrm{x}_{\mathrm{n}}\right\}$ converges strongly to $\mathrm{x}_{0}=\mathrm{P}_{\mathrm{F}} \mathrm{u}$ and $\left(\mathrm{x}_{0}, \mathrm{y}_{0}\right)$ is a solution of $(3.35)$, where $\mathrm{y}_{0}=\mathrm{P}_{\mathrm{C}}\left(\mathrm{I}-\lambda_{2} \mathrm{D}_{2}\right) \mathrm{x}_{0}$

\subsection{Results regarding solution of variational inequalities and fixed point problems in Banach spaces}

Generalized variational inequality problem in Banach spaces is defined as follows:

Find $x^{*} \in C$ such that

$<A x^{*}, j\left(x-x^{*}\right)>\geq 0, \forall x \in C$ and $j\left(x-x^{*}\right) \in J(x-y)$.

The set of solutions of variational inequality (3.38) is denoted by $\mathrm{S}(\mathrm{C}, \mathrm{A})$.

Let $\mathrm{E}$ be a real normed linear space with dual $\mathrm{E}^{*}$. We denote by $\mathrm{J}$, the normalized duality mapping from $\mathrm{E}$ to $\mathrm{E}^{*}$ defined by

$\mathrm{J}(\mathrm{x})=\left\{\mathrm{f} \in \mathrm{E}^{*},\langle\mathrm{x}, \mathrm{f}\rangle=\|\mathrm{x}\|\|\mathrm{f}\|,\|\mathrm{x}\|=\|\mathrm{f}\|\right\}, \forall \mathrm{x} \in \mathrm{E}$,

where $\langle.,$.$\rangle denotes the generalized duality pair. It is well known that if \mathrm{E}^{*}$ is strictly convex, then $\mathbf{J}$ is single-valued. We shall denote the single-valued duality mapping by $\mathrm{j}$.

Let $\mathrm{C}$ be a nonempty closed convex subset of a Banach space $\mathrm{E}$. An operator $\mathrm{A}$ of $\mathrm{C}$ into $\mathrm{E}$ is said to be $\alpha$-inverse strongly accretive if there exists a constant $\alpha>0$ such that

$<\mathrm{Ax}-\mathrm{Ay}, \mathrm{J}(\mathrm{x}-\mathrm{y})>\geq \alpha\|\mathrm{Ax}-\mathrm{Ay}\|^{2}, \forall \mathrm{x}, \mathrm{y} \in \mathrm{C}$.

Definition: A Banach space $\mathrm{E}$ is said to be uniformly convex iff for any $\in, 0<\epsilon \leq 2$, the inequalities $\|x\| \leq 1$, $\|y\| \leq 1$ and $\|\mathrm{x}-\mathrm{y}\| \geq \in$ imply there exists a $\delta>0$ such that $\left\|\frac{\mathrm{x}+\mathrm{y}}{2}\right\| \leq 1-\delta$.

Definition: Let $\mathrm{E}$ be a Banach space. Then a function $\rho_{\mathrm{E}}: \mathrm{R}^{+} \rightarrow \mathrm{R}^{+}$is said to be the modulus of smoothness of $\mathrm{E}$ if $\rho_{\mathrm{E}}(\mathrm{t})=\sup \left\{\frac{\|\mathrm{x}+\mathrm{y}\|+\|\mathrm{x}-\mathrm{y}\|}{2}-1:\|\mathrm{x}\|=1,\|\mathrm{y}\|=\mathrm{t}\right\}$.

A Banach space $\mathrm{E}$ is said to be uniformly smooth if

$\lim _{t \rightarrow 0} \frac{\rho_{E}(t)}{t}=0$.

Let $\mathrm{q}>1$. A Banach space $\mathrm{E}$ is said to be q-uniformly smooth if there exists a fixed constant $\mathrm{c}>0$ such that $\rho_{\mathrm{E}}(\mathrm{t}) \leq \mathrm{ct}^{\mathrm{q}}$. It is easy to see that if $\mathrm{E}$ is q-uniformly smooth, then $\mathrm{q} \leq 2$ and $\mathrm{E}$ is uniformly smooth.

In 2000, Moudafi [5] gave viscosity approximation methods. Later H. K. Xu [19] generalized the results of [5] for nonexpansive mappings in uniformly smooth Banach space. He proved the following theorems:

Theorem 3.2.1: [19] Let $E$ be a uniformly smooth Banach space, $K$ be a nonempty closed convex subset of $E$ and $T: K$ $\rightarrow K$ be a nonexpansive mapping with $F(T) \neq \varnothing$ and $f$ is a contraction on $K$. Then the path $\left\{x_{t}\right\}$ defined by

$\mathrm{x}_{\mathrm{t}}=\mathrm{tf}\left(\mathrm{x}_{\mathrm{t}}\right)+(1-\mathrm{t}) \mathrm{T} \mathrm{x}_{\mathrm{t}}, \mathrm{t} \in(0,1)$.

converges strongly to a point in $F(T)$. If we define $Q: \Pi_{K} \rightarrow F(T)$ by $Q(f)=\lim _{t \rightarrow \infty} x_{t}$, where $\Pi_{K}=\{f: f: K \rightarrow K$ a contraction \}, then $\mathrm{Q}(\mathrm{f})$ solves the variational inequality:

$\langle(\mathrm{I}-\mathrm{f}) \mathrm{Q}(\mathrm{f}), \mathrm{j}(\mathrm{Q}(\mathrm{f})-\mathrm{x})\rangle \leq 0, \forall \mathrm{x} \in \mathrm{F}(\mathrm{T})$.

Theorem 3.2.2: [19] Let $E$ be a uniformly smooth Banach space, $K$ be a nonempty closed convex subset of $E$ and $T: K$ $\rightarrow K$ be a nonexpansive mapping with $F(T) \neq \phi$ and $f$ is a contraction on $K$. Assume that $\left\{\alpha_{n}\right\} \subset(0,1)$ satisfies the following conditions:

i) $\quad \lim _{n \rightarrow \infty} \alpha_{n}=0$,

ii) $\sum_{n=0}^{\infty} \alpha_{n}=\infty$.

iii) Either $\sum_{n=0}^{\infty}\left|\alpha_{n+1}-\alpha_{n}\right|<\infty$ or $\lim _{n \rightarrow \infty}\left(\alpha_{n+1} / \alpha_{n}\right)=1$.

Then the sequence $\left\{x_{n}\right\}$ generated by

$\mathrm{x}_{\mathrm{n}+1}=\alpha_{\mathrm{n}} \mathrm{f}\left(\mathrm{x}_{\mathrm{n}}\right)+\left(1-\alpha_{\mathrm{n}}\right) \mathrm{Tx}_{\mathrm{n}}, \mathrm{n}=0,1,2, \ldots$

converges strongly to a fixed point of $\mathrm{T}$.

Let $E$ be a real normed linear space with $\operatorname{dim} E \geq 2$. The norm of $E$ is said to be uniformly Gateaux differentiable if for each $y \in S=\{x \in E:\|x\|=1\}$, the $\operatorname{limitlim}_{n \rightarrow \infty} \frac{\| x+\text { ty }\|-\| x \|}{t}$ is attained uniformly for $x \in S$. 
Let $\mathrm{K}$ be a nonempty bounded closed convex subset of $\mathrm{E}$ and let $\mathrm{d}(\mathrm{K})=\sup \{\|\mathrm{x}-\mathrm{y}\|: \mathrm{x}, \mathrm{y} \in \mathrm{K}\}$ be the diameter of $\mathrm{K}$. For each $x \in K$, let $r(x, K)=\sup \{\|x-y\|: y \in K\}$ and let $r(K)=\inf \{r(x, K): x \in K\}$. The normal structure coefficient of $\mathrm{E}$ is defined as the number

$N(E)=\inf \{d(K) / r(K): K$ is a bounded closed convex subset of $E$ with $d(K)>0\}$.

A space $\mathrm{E}$ such that $\mathrm{N}(\mathrm{E})>1$ is said to have uniformly normal structure. A space with a uniformly normal structure is reflexive and all uniformly convex Banach spaces have uniformly normal structure.

In 2006, Naseer Shahzad and Aniefiok Udomene [43] extended the results of H. K. Xu [19] from nonexpansive to asymptotically nonexpansive and obtained the following theorems:

Theorem 3.2.3: [43] Let E be a real Banach space with a uniformly Gateaux differentiable norm possessing uniform normal structure, $K$ be a nonempty closed convex and bounded subset of $E, T: K \rightarrow K$ be an asymptotically nonexpansive mapping with sequence $\left\{k_{n}\right\} \subset[1, \infty)$ and $f: K \rightarrow K$ be a fixed contraction with constant $\alpha \in[0,1)$. Let $\left\{t_{n}\right\} \subset\left(0, \frac{(1-\alpha) k_{n}}{k_{n}-\alpha}\right)$ be such that $\lim _{n \rightarrow \infty} t_{n}=1$ and $\lim _{n \rightarrow \infty} \frac{k_{n}-1}{k_{n}-t_{n}}=0$. Then,

i) for each integer $n \geq 0$, there is a unique $x_{n} \in K$ such that

$\mathrm{x}_{\mathrm{n}}=\left(1-\frac{\mathrm{t}_{\mathrm{n}}}{\mathrm{k}_{\mathrm{n}}}\right) f\left(\mathrm{x}_{\mathrm{n}}\right)+\frac{\mathrm{t}_{\mathrm{n}}}{\mathrm{k}_{\mathrm{n}}} \mathrm{T}^{\mathrm{n}} \mathrm{x}_{\mathrm{n}}$

And if in addition, $\lim _{\mathrm{n} \rightarrow \infty}\left\|\mathrm{x}_{\mathrm{n}}-\mathrm{Tx}_{\mathrm{n}}\right\|=0$, then,

ii) The sequence $\{\mathrm{xn}\}$ converges strongly to some fixed point $\mathrm{p}$ of $\mathrm{T}$, which is the unique solution of variational inequality:

$\left\langle(\mathrm{I}-\mathrm{f}) \mathrm{p}, \mathrm{j}\left(\mathrm{p}-\mathrm{x}^{*}\right)\right\rangle \leq 0, \forall \mathrm{x}^{*} \in \mathrm{F}(\mathrm{T})$.

Theorem 3.2.4: [43] Let E be a real Banach space with a uniformly Gateaux differentiable norm possessing uniform normal structure, $K$ be a nonempty closed convex and bounded subset of $E, T: K \rightarrow K$ be an asymptotically nonexpansive mapping with sequence $\left\{k_{n}\right\} \subset[1, \infty)$ and $f: K \rightarrow K$ be a fixed contraction with constant $\alpha \in[0,1)$. Let $\left\{\mathrm{t}_{\mathrm{n}}\right\} \subset\left(0, \xi_{\mathrm{n}}\right)$ be such that $\lim _{\mathrm{n} \rightarrow \infty} \mathrm{t}_{\mathrm{n}}=1, \sum_{\mathrm{n}=0}^{\infty} \mathrm{t}_{\mathrm{n}}\left(1-\mathrm{t}_{\mathrm{n}}\right)=\infty$ and $\lim _{\mathrm{n} \rightarrow \infty} \frac{\mathrm{k}_{\mathrm{n}}-1}{\mathrm{k}_{\mathrm{n}}-\mathrm{t}_{\mathrm{n}}}=0$, where $\xi_{\mathrm{n}}=\min \left\{\frac{(1-\alpha) \mathrm{k}_{\mathrm{n}}}{\mathrm{k}_{\mathrm{n}}-\alpha}, \frac{1}{\mathrm{k}_{\mathrm{n}}}\right\}$.

For an arbitrary $\mathrm{y}_{0} \in \mathrm{K}$, let the sequence $\left\{\mathrm{y}_{\mathrm{n}}\right\}$ be iteratively defined by

$\mathrm{y}_{\mathrm{n}+1}=\left(1-\frac{\mathrm{t}_{\mathrm{n}}}{\mathrm{k}_{\mathrm{n}}}\right) \mathrm{f}\left(\mathrm{y}_{\mathrm{n}}\right)+\frac{\mathrm{t}_{\mathrm{n}}}{\mathrm{k}_{\mathrm{n}}} \mathrm{T}^{\mathrm{n}} \mathrm{y}_{\mathrm{n}}$

Then,

i) For each integer $n \geq 0$, there is a unique $x_{n} \in K$ such that the equality (3.35) holds.

And if in addition, $\lim _{n \rightarrow \infty}\left\|x_{n}-T x_{n}\right\|=0, \lim _{n \rightarrow \infty}\left\|y_{n}-T y_{n}\right\|=0$, then,

ii) The sequence $\left\{y_{n}\right\}$ converges strongly to some fixed point $\mathrm{p}$ of $\mathrm{T}$, which is the unique solution of variational inequality :

$\left\langle(\mathrm{I}-\mathrm{f}) \mathrm{p}, \mathrm{j}\left(\mathrm{p}-\mathrm{x}^{*}\right)\right\rangle \leq 0, \forall \mathrm{x}^{*} \in \mathrm{F}(\mathrm{T})$.

In 2007, Ying Chen, Huimin He and Rudong Chen [60], extended the results of Naseer Shahzad and Aniefiok Udomene [43] to more general class of asymptotically pseudocontractive mappings and more general class of Banach spaces. They obtained fixed point solutions of variational inequalities for asymptotically pseudocontractive mapping defined on a real reflexive Banach space with uniformly Gateaux differentiable norm possessing uniform normal structure. They proved under some conditions on $\mathrm{K}, \mathrm{T}$ and $\left\{\mathrm{t}_{\mathrm{n}}\right\} \subset(0,1)$ that the generated by (3.41) and (3.42) converges strongly to some fixed point $\mathrm{p}$ of $\mathrm{T}$, which is the unique solution of the variational inequality:

$\left\langle(\mathrm{I}-\mathrm{f}) \mathrm{p}, \mathrm{j}\left(\mathrm{p}-\mathrm{x}^{*}\right)\right\rangle \leq 0, \forall \mathrm{x}^{*} \in \mathrm{F}(\mathrm{T})$.

Theorem 3.2.5: [60] Let $E$ be a real Banach space with a uniformly Gateaux differentiable norm possessing uniform normal structure, $K$ be a nonempty closed convex and bounded subset of $E, T: K \rightarrow K$ be an asymptotically pseudocontractive mapping with sequence $\left\{k_{n}\right\} \subset[1, \infty)$, uniformly asymptotically regular and uniformly LLipschitzian. Let $\mathrm{f}: \mathrm{K} \rightarrow \mathrm{K}$ be a fixed contraction with constant $\alpha \in[0,1)$. Let $\left\{\mathrm{t}_{\mathrm{n}}\right\} \subset\left(0, \frac{(1-\alpha) \mathrm{k}_{\mathrm{n}}}{\mathrm{k}_{\mathrm{n}}-\alpha}\right)$ be such that $\lim _{n \rightarrow \infty} t_{n}=1$ and $\lim _{n \rightarrow \infty} \frac{k_{n}-1}{k_{n}-t_{n}}=0$ and $L<N(E)^{1 / 2}$. Then,

i) for each integer $n \geq 0$, there is a unique $x_{n} \in K$ such that

$\mathrm{x}_{\mathrm{n}}=\left(1-\frac{\mathrm{t}_{\mathrm{n}}}{\mathrm{k}_{\mathrm{n}}}\right) \mathrm{f}\left(\mathrm{x}_{\mathrm{n}}\right)+\frac{\mathrm{t}_{\mathrm{n}}}{\mathrm{k}_{\mathrm{n}}} \mathrm{T}^{\mathrm{n}} \mathrm{x}_{\mathrm{n}}$ and $\lim _{\mathrm{n} \rightarrow \infty}\left\|\mathrm{x}_{\mathrm{n}}-\mathrm{Tx}_{\mathrm{n}}\right\|=0$

ii) If in addition,

$\left\|\mathrm{x}_{\mathrm{n}}-\mathrm{T}^{\mathrm{m}} \mathrm{x}\right\|^{2} \leq\left\langle\mathrm{x}_{\mathrm{n}}-\mathrm{T}^{\mathrm{m}} \mathrm{x}, \mathrm{j}\left(\mathrm{x}_{\mathrm{n}}-\mathrm{x}\right)\right\rangle \forall \mathrm{m}, \mathrm{n} \geq 1, \forall \mathrm{x} \in \mathrm{K}$

Then the sequence $\left\{x_{n}\right\}$ converges strongly to some fixed point $\mathrm{p}$ of $\mathrm{T}$, which is the unique solution of variational inequality: 
$\left\langle(\mathrm{I}-\mathrm{f}) \mathrm{p}, \mathrm{j}\left(\mathrm{p}-\mathrm{x}^{*}\right)\right\rangle \leq 0, \forall \mathrm{x}^{*} \in \mathrm{F}(\mathrm{T})$.

Theorem 3.2.6: [60] Let E be a real Banach space with a uniformly Gateaux differentiable norm possessing uniform normal structure, $K$ be a nonempty closed convex and bounded subset of $E, T: K \rightarrow K$ be an asymptotically pseudocontractive mapping with sequence $\left\{k_{n}\right\} \subset[1, \infty)$, uniformly asymptotically regular and uniformly LLipschitzian. Let $\mathrm{f}: \mathrm{K} \rightarrow \mathrm{K}$ be a fixed contraction with constant $\alpha \in[0,1)$. Let $\left\{\mathrm{t}_{\mathrm{n}}\right\} \subset\left(0, \xi_{\mathrm{n}}\right),(2 \alpha)^{1 / 2}<\mathrm{L} \neq 1, \alpha \in\left(0, \frac{1}{2}\right)$ be such that $\lim _{n \rightarrow \infty} t_{n}=1, \lim _{n \rightarrow \infty} \frac{k_{n}-1}{k_{n}-t_{n}}=0$, and $L<N(E)^{1 / 2}$, where $\xi_{n}=\min \left\{\frac{(1-\alpha) k_{n}}{k_{n}-\alpha}, \frac{k_{n}(1-2 \alpha)}{L^{2}-2 \alpha}\right\}$. Suppose that $\left\|x_{n}-T^{m} x\right\|^{2} \leq\left\langle x_{n}-T^{m} x, j\left(x_{n}-x\right)\right\rangle, \lim _{n \rightarrow \infty}\left\|y_{n}-T y_{n}\right\|=0$

For an arbitrary $\mathrm{y}_{0} \in \mathrm{K}$, let the sequence $\left\{\mathrm{y}_{\mathrm{n}}\right\}$ be iteratively defined by

$\mathrm{y}_{\mathrm{n}+1}=\left(1-\frac{\mathrm{t}_{\mathrm{n}}}{\mathrm{k}_{\mathrm{n}}}\right) \mathrm{f}\left(\mathrm{y}_{\mathrm{n}}\right)+\frac{\mathrm{t}_{\mathrm{n}}}{\mathrm{k}_{\mathrm{n}}} \mathrm{T}^{\mathrm{n}} \mathrm{y}_{\mathrm{n}}$

converges strongly to some fixed point $\mathrm{p}$ of $\mathrm{T}$, which is the unique solution of variational inequality:

$\left\langle(\mathrm{I}-\mathrm{f}) \mathrm{p}, \mathrm{j}\left(\mathrm{p}-\mathrm{x}^{*}\right)\right\rangle \leq 0, \forall \mathrm{x}^{*} \in \mathrm{F}(\mathrm{T})$.

Definition: Let $\mathrm{D}$ be a subset of $\mathrm{C}$ and $\mathrm{Q}$ be a mapping of $\mathrm{C}$ into $\mathrm{D}$. Then $\mathrm{Q}$ is said to be sunny if

$\mathrm{Q}(\mathrm{Qx}+\mathrm{t}(\mathrm{x}-\mathrm{Qx}))=\mathrm{Qx}$, whenever $\mathrm{Qx}+\mathrm{t}(\mathrm{x}-\mathrm{Qx}) \in \mathrm{C}$ for $\mathrm{x} \in \mathrm{C}$ and $\mathrm{t} \geq 0$. A mapping $\mathrm{Q}$ of $\mathrm{C}$ into itself is called $\mathrm{a}$ retraction if $Q^{2}=Q$. A subset $D$ of $C$ is called a sunny nonexpansive retract of $C$ if there exists a sunny nonexpansive retraction from $\mathrm{C}$ onto $\mathrm{D}$.

In 2005, in order to find a solution of the variational inequality (3.33), Aoyama et al. [26] obtained a weak convergence theorem as follows:

Theorem 3.2.7: [26] Let $\mathrm{C}$ be a nonempty closed convex subset of a uniformly convex and 2-uniformly smooth Banach space $\mathrm{E}$. Let $\mathrm{Q}_{\mathrm{C}}$ be a sunny nonexpansive retraction from $\mathrm{E}$ onto $\mathrm{C}$, let $\alpha>0$ and let $\mathrm{A}$ be inverse strongly accretive operator of $\mathrm{C}$ into $\mathrm{E}$ with $\mathrm{S}(\mathrm{C}, \mathrm{A}) \neq \phi$. Suppose that $\mathrm{x}_{1}=\mathrm{x} \in \mathrm{C}$ and $\left\{\mathrm{x}_{\mathrm{n}}\right\}$ is given by

$x_{n+1}=\alpha_{n} x_{n}+\left(1-\alpha_{n}\right) Q_{C}\left(x_{n}-\lambda_{n} A x_{n}\right), n \geq 0$,

where $\left\{\lambda_{n}\right\}$ is a sequence of positive real numbers and $\left\{\alpha_{n}\right\}$ is a sequence in $[0,1]$. If $\left\{\lambda_{n}\right\}$ and $\left\{\alpha_{n}\right\}$ are chosen so that $\lambda_{n}$ $\in\left[\mathrm{a}, \frac{\alpha}{\mathrm{K}^{2}}\right]$ for some $\mathrm{a}>0$ and $\alpha_{\mathrm{n}} \in[\mathrm{b}, \mathrm{c}]$ for some $\mathrm{b}, \mathrm{c}$ with $0<\mathrm{b}<\mathrm{c}<1$, then $\left\{\mathrm{x}_{\mathrm{n}}\right\}$ converges weakly to some element $\mathrm{Z}$ of $\mathrm{S}(\mathrm{C}, \mathrm{A})$, where $\mathrm{K}$ is the 2-uniformly smoothness constant of $\mathrm{E}$.

However they only obtained the weak convergence of the proposed scheme (3.45). Hence, it is an interesting topic to construct an iterative scheme which converges strongly to the solution of variational inequality (3.38). In this regard, Aoyama, Iiduka and Takahashi [25] further introduced another iterative scheme which has strong convergence.

Let $\mathrm{G}$ be an unbounded subset of $\mathrm{R}^{+}$such that $\mathrm{s}+\mathrm{t} \in \mathrm{G}$ whenever $\mathrm{s}, \mathrm{t} \in \mathrm{G}$. Let $\mathrm{X}$ be a smooth Banach space, $\mathrm{C}$ be a nonempty closed convex subset of $X$ and $J=\left\{T_{s}: s \in G\right\}$ be a commutative family of nonexpansive self-mappings of C. Denote by $F$, the set of common fixed points of $J$ i. e. $F=\left\{x \in C: T_{s} x=x, s \in G\right\}$.

In 2007, Yao and Noor [65] suggested a new viscosity iterative method for a commutative family of nonexpansive mappings and a contraction in Banach space.

Theorem 3.2.8: [65] Let $C$ be a nonempty closed convex subset of a reflexive Banach space $X$ with a weakly sequentially continuous duality mapping. Let $\left\{\alpha_{n}\right\},\left\{\beta_{n}\right\},\left\{\gamma_{n}\right\}$ be three sequences in $(0,1)$ and $\left\{r_{n}\right\}$ be a sequence in $G$. Let $\left\{\alpha_{\mathrm{n}}\right\},\left\{\beta_{\mathrm{n}}\right\},\left\{\gamma_{\mathrm{n}}\right\}$ satisfy the control conditions:

i) $\quad \alpha_{\mathrm{n}}+\beta_{\mathrm{n}}+\gamma_{\mathrm{n}}=1$.

ii) $\quad 0<\liminf _{\mathrm{n} \rightarrow \infty} \beta_{\mathrm{n}} \leq \lim \sup _{\mathrm{n} \rightarrow \infty} \beta_{\mathrm{n}}<1$,

iii) $\quad r_{n} \rightarrow \infty$

iv) $\quad \tilde{J}$ is a semigroup (i. e. $T_{r} T_{s}=T_{r+s}$ for $r, s \in G$ ) and satisfies the uniformly asymptotically regularity condition $\lim _{\mathrm{r} \varepsilon \mathrm{G}, \mathrm{r} \rightarrow \infty} \sup _{\mathrm{x} \varepsilon \mathrm{C}}\left\|\mathrm{T}_{\mathrm{s}} \mathrm{T}_{\mathrm{r}} \mathrm{x}-\mathrm{T}_{\mathrm{r}} \mathrm{x}\right\|=0$, uniformly in $\mathrm{s} \in \mathrm{G}$,

where $\tilde{\mathrm{C}}$ is any bounded of $\mathrm{C}$. If there exists $\mathrm{Q}(\mathrm{f}) \in \mathrm{F}$ which solves the variational inequality

$<(\mathrm{I}-\mathrm{f}) \mathrm{Q}(\mathrm{f}), \mathrm{J}(\mathrm{Q}(\mathrm{f})-\mathrm{p})>\leq 0$,

Then the sequence $\left\{x_{n}\right\}$ generated by

$\mathrm{x}_{\mathrm{n}+1}=\alpha_{\mathrm{n}} \mathrm{f}\left(\mathrm{x}_{\mathrm{n}}\right)+\beta_{\mathrm{n}} \mathrm{x}_{\mathrm{n}}+\gamma_{\mathrm{n}} \mathrm{Tr}_{\mathrm{n}} \mathrm{x}_{\mathrm{n}}, \mathrm{n} \geq 0$

converges strongly to $\mathrm{Q}$ (f) $\in \mathrm{F}$.

Then they gave another interesting theorem: 
Theorem 3.2.9 [65] Let $X$ be a reflexive Banach space with a uniformly Gateaux differentiable norm. Suppose that every weakly compact convex subset of $\mathrm{X}$ has the fixed point property for nonexpansive mappings. Let $\mathrm{C}$ be a nonempty closed convex sebset of $\mathrm{X}$. Assume $\tilde{\mathrm{J}}$ is uniformly asymptotically regular on bounded subsets of $\mathrm{C}$; that is, for each bounded subset $\tilde{\mathrm{C}}$ of $\mathrm{C}$ and each $\mathrm{r} \in \mathrm{G}$, there holds

$\lim _{\mathrm{s} \rightarrow \infty} \sup _{\mathrm{x} s=\tilde{\mathrm{C}}}\left\|\mathrm{T}_{\mathrm{r}} \mathrm{T}_{\mathrm{s}} \mathrm{x}-\mathrm{T}_{\mathrm{s}} \mathrm{x}\right\|=0$, uniformly in $\mathrm{s} \in \mathrm{G}$.

Then the net $\left\{z_{s}\right\}$ defined by

$z_{\mathrm{s}}=\alpha_{\mathrm{s}} \mathrm{f}\left(\mathrm{z}_{\mathrm{s}}\right)+\left(1-\alpha_{\mathrm{s}}\right) \mathrm{T}_{\mathrm{s}} \mathrm{z}_{\mathrm{s}}$,

converges strongly to a point in $\mathrm{F}$. If we define $\mathrm{Q}: \Pi_{\mathrm{C}} \rightarrow \mathrm{F}$ by

$Q(f)=\lim _{s \rightarrow \infty} z_{s}, f \in \Pi_{C}$,

Then, $\mathrm{Q}(\mathrm{f})$ solves the variational inequality

$<(\mathrm{I}-\mathrm{f}) \mathrm{Q}(\mathrm{f}), \mathrm{J}(\mathrm{Q}(\mathrm{f})-\mathrm{p})>\leq 0, \mathrm{f} \in \Pi_{\mathrm{C}}, \mathrm{p} \in \mathrm{F}$.

In particular, if $\mathrm{f}=\mathrm{u} \in \mathrm{C}$ is a constant, then the above limit defines the sunny nonexpansive retraction $\mathrm{Q}$ from $\mathrm{C}$ to $\mathrm{F}$, $<\mathrm{Q}(\mathrm{u})-\mathrm{u}, \mathrm{J}(\mathrm{Q}(\mathrm{u})-\mathrm{p})>\leq 0, \mathrm{u} \in \mathrm{C}, \mathrm{p} \in \mathrm{F}$.

Combining above two results, they obtained another result as follows:

Theorem 3.2.10: [65] Let $X$ be a reflexive Banach space with a uniformly Gateaux differentiable norm. Suppose that every weakly compact convex subset of $X$ has the fixed point property for nonexpansive mappings and $X$ has a weakly sequentially continuous duality mapping. Let $C$ be a nonempty closed convex subset of $X$. Let $\left\{\alpha_{n}\right\},\left\{\beta_{n}\right\},\left\{\gamma_{n}\right\}$ satisfies the control conditions:

i) $\alpha_{\mathrm{n}}+\beta_{\mathrm{n}}+\gamma_{\mathrm{n}}=1$.

ii) $0<\liminf _{n \rightarrow \infty} \beta_{\mathrm{n}} \leq \lim \sup _{\mathrm{n} \rightarrow \infty} \beta_{\mathrm{n}}<1$,

iii) $\quad r_{n} \rightarrow \infty$

iv) $\quad \tilde{J}$ is a semigroup (i. e. $T_{r} T_{s}=T_{r+s}$ for $r, s \in G$ ) and satisfies the uniformly asymptotically regularity condition $\lim _{\mathrm{r} \varepsilon \mathrm{G}, \mathrm{r} \rightarrow \infty} \sup _{\mathrm{x} \varepsilon \mathrm{C}}\left\|\mathrm{T}_{\mathrm{s}} \mathrm{T}_{\mathrm{r}} \mathrm{x}-\mathrm{T}_{\mathrm{r}} \mathrm{x}\right\|=0$, uniformly in $\mathrm{s} \in \mathrm{G}$,

Assume $\tilde{\mathbf{J}}$ is uniformly asymptotically regular on bounded subsets of $\mathrm{C}$; that is, for each bounded subset $\tilde{\mathbf{C}}$ of $\mathrm{C}$ and each $r \in G$, there holds

$\lim _{\mathrm{s} \rightarrow \infty} \sup _{\tilde{\mathrm{C}}}\left\|\mathrm{T}_{\mathrm{r}} \mathrm{T}_{\mathrm{s}} \mathrm{x}-\mathrm{T}_{\mathrm{s}} \mathrm{x}\right\|=0$, uniformly in $\mathrm{s} \in \mathrm{G}$, where $\tilde{\mathrm{C}}$ is any bounded of $\mathrm{C}$. Then the sequence $\left\{\mathrm{x}_{\mathrm{n}}\right\}$ generated by

$\mathrm{x}_{\mathrm{n}+1}=\alpha_{\mathrm{n}} \mathrm{f}\left(\mathrm{x}_{\mathrm{n}}\right)+\beta_{\mathrm{n}} \mathrm{x}_{\mathrm{n}}+\gamma_{\mathrm{n}} \mathrm{Tr}_{\mathrm{n}} \mathrm{x}_{\mathrm{n}}, \mathrm{n} \geq 0$

converges strongly to $Q(f) \in F$, where $Q(f)$ is a solution of the variational inequality

$<(\mathrm{I}-\mathrm{f}) \mathrm{Q}(\mathrm{f}), \mathrm{J}(\mathrm{Q}(\mathrm{f})-\mathrm{p})>\leq 0, \mathrm{f} \in \Pi_{\mathrm{C}}, \mathrm{p} \in \mathrm{F}$.

In 2011, motivated by the research going on in this direction, Yao Y., Noor M. A., Noor K. I. and Loiu Y. C. [64], suggested a new iterative method for solving some variational inequality involving an accretive operator in Banach spaces. They proved the strong convergence of the proposed iterative method under certain conditions.

Theorem 3.2.11: [64] Let $C$ be a nonempty closed convex subset of a uniformly convex and 2-uniformly smooth Banach space $E$ which admits a weakly sequentially continuous duality mapping. Let $A: C \rightarrow E$ be an $\alpha$-inverse strongly accretive operator such that $S(C, A) \neq \phi$. Let $\left\{\alpha_{n}\right\},\left\{\beta_{n}\right\}$ be two sequences in $(0,1)$ and $\left\{\lambda_{n}\right\}$ be a real number sequence in [a, $\frac{\alpha}{\mathrm{K}^{2}}$ ]. Suppose the following conditions are satisfied:

i) $\quad 0<\lim \inf _{n \rightarrow \infty} \alpha_{n} \leq \lim \sup _{n \rightarrow \infty} \alpha_{n}<1$,

ii) $\lim _{\mathrm{n} \rightarrow \infty} \beta_{\mathrm{n}}=0, \sum_{\mathrm{n}=0}^{\infty} \beta_{\mathrm{n}}=\infty$,

iii) $\lim _{\mathrm{n} \rightarrow 0}\left(\lambda_{\mathrm{n}+1}-\lambda_{\mathrm{n}}\right)=0$,

Then the sequence $\left\{x_{n}\right\}$ generated by

$\mathrm{x}_{\mathrm{n}+1}=\alpha_{\mathrm{n}} \mathrm{x}_{\mathrm{n}}+\left(1-\alpha_{\mathrm{n}}\right) \mathrm{Q}\left[\beta_{\mathrm{n}} \mathrm{u}+\left(1-\beta_{\mathrm{n}}\right) \mathrm{Q}\left(\mathrm{x}_{\mathrm{n}}-\lambda_{\mathrm{n}} \mathrm{A} \mathrm{x}_{\mathrm{n}}\right)\right], \mathrm{n} \geq 0$,

converges strongly to $Q^{\prime} u$, where $Q^{\prime}$ is a sunny nonexpansive retraction of $E$ onto $S(C, A)$.

In particular, if we take $u=0$, then the sequence $\left\{x_{n}\right\}$ converges strongly to the minimum norm element in $S(C, A)$.

Using the above result, they obtained the following corollary also.

Corollary (i) [64] Let C is a nonempty closed convex subset of a uniformly convex and 2-uniformly smooth Banach space $\mathrm{E}$ which admits a weakly sequentially continuous duality mapping. Let $\mathrm{A}: \mathrm{C} \rightarrow \mathrm{E}$ be an $\alpha$-inverse strongly accretive operator such that $\mathrm{S}(\mathrm{C}, \mathrm{A}) \neq \phi$. Let $\left\{\alpha_{\mathrm{n}}\right\},\left\{\beta_{\mathrm{n}}\right\}$ be two sequences in $(0,1)$ and $\left\{\lambda_{\mathrm{n}}\right\}$ be a real number sequence in $\left[\mathrm{a}, \frac{\alpha}{\mathrm{K}^{2}}\right]$. Suppose the following conditions are satisfied: 
i) $\quad 0<\lim \inf _{n \rightarrow \infty} \alpha_{n} \leq \lim \sup _{n \rightarrow \infty} \alpha_{n}<1$,

ii) $\lim _{n \rightarrow \infty} \beta_{n}=0, \sum_{n=0}^{\infty} \beta_{n}=\infty$

iii) $\lim _{\mathrm{n} \rightarrow 0}\left(\lambda_{\mathrm{n}+1}-\lambda_{\mathrm{n}}\right)=0$,

For fixed $\mathrm{u} \in \mathrm{C}$ and given $\mathrm{x}_{0} \in \mathrm{C}$ arbitrary, let the the sequence $\left\{\mathrm{x}_{\mathrm{n}}\right\}$ be generated by

$\mathrm{x}_{\mathrm{n}+1}=\alpha_{\mathrm{n}} \mathrm{x}_{\mathrm{n}}+\left(1-\alpha_{\mathrm{n}}\right)\left[\beta_{\mathrm{n}} \mathrm{u}+\left(1-\beta_{\mathrm{n}}\right) \mathrm{Q}\left(\mathrm{x}_{\mathrm{n}}-\lambda_{\mathrm{n}} \mathrm{A} \mathrm{x}_{\mathrm{n}}\right)\right], \mathrm{n} \geq 0$,

Then the sequence $\left\{x_{n}\right\}$ defined by (3.50) converges strongly to Q'u, where $Q^{\prime}$ is a sunny nonexpansive retraction of $C$ onto $\mathrm{S}(\mathrm{C}, \mathrm{A})$.

In particular, if we take $u=0$, then the sequence $\left\{x_{n}\right\}$ generated by

$\mathrm{x}_{\mathrm{n}+1}=\alpha_{\mathrm{n}} \mathrm{x}_{\mathrm{n}}+\left(1-\alpha_{\mathrm{n}}\right)\left[\beta_{\mathrm{n}} \mathrm{u}+\left(1-\beta_{\mathrm{n}}\right) \mathrm{Q}\left(\mathrm{x}_{\mathrm{n}}-\lambda_{\mathrm{n}} \mathrm{A} \mathrm{x}_{\mathrm{n}}\right)\right], \mathrm{n} \geq 0$,

converges strongly to the minimum norm element in $\mathrm{S}(\mathrm{C}, \mathrm{A})$.

In 2013, Ceng et al. [33] gave an implicit iterative scheme by two step relaxed extragradient method in the setting of uniformly convex and 2-uniformly smooth Banach spaces as follows:

Theorem 3.2.12: [33] Let $C$ be a nonempty closed convex subset of a uniformly convex and 2-uniformly smooth Banach space $X$. Let $\Pi_{C}$ be a sunny nonexpansive retraction from $X$ onto $C$. Let $B_{i}: C \rightarrow X$ be a $\alpha_{i}$-inverse strongly accretive for $i=1$, 2. Let $f: C \rightarrow C$ be a contraction with coefficient $\rho \in(0,1)$. Let $\left\{\mathrm{S}_{\mathrm{n}}\right\}_{\mathrm{n}=0}^{\infty}$ be an infinite family of nonexpansive mappings of $C$ into itself such that $F=\bigcap_{i=0}^{\infty} \operatorname{Fix}\left(\mathrm{S}_{\mathrm{i}}\right) \bigcap \Omega \neq \phi$, where $\Omega$ is a fixed point set of the mapping G. For arbitrarily given $x_{0} \in C$, let $\left\{x_{n}\right\}$ be a sequence generated by $\mathrm{y}_{\mathrm{n}}=\alpha_{\mathrm{n}} \mathrm{f}\left(\mathrm{y}_{\mathrm{n}}\right)+\left(1-\alpha_{\mathrm{n}}\right) \Pi_{\mathrm{C}}\left(1-\mu_{1} \mathrm{~B}_{1}\right) \Pi_{\mathrm{C}}\left(1-\mu_{2} \mathrm{~B}_{2}\right) \mathrm{x}_{\mathrm{n}}$,

$\mathrm{x}_{\mathrm{n}+1}=\beta_{\mathrm{n}} \mathrm{x}_{\mathrm{n}}+\left(1-\beta_{\mathrm{n}}\right) \mathrm{S}_{\mathrm{n}} \mathrm{y}_{\mathrm{n}}, \mathrm{n} \geq 0$,

where $0<\mu_{\mathrm{i}}<\frac{\alpha_{\mathrm{i}}}{\mathrm{K}^{2}}$ for $\mathrm{i}=1,2$.

Let $\left\{\alpha_{n}\right\},\left\{\beta_{n}\right\}$ be two sequences in $(0,1)$ satisfying the following conditions:

i) $\lim _{n \rightarrow \infty} \alpha_{n}=0, \sum_{n=0}^{\infty} \alpha_{n}=\infty$,

ii) $0<\liminf _{\mathrm{n} \rightarrow \infty} \beta_{\mathrm{n}} \leq \lim \sup _{\mathrm{n} \rightarrow \infty} \beta_{\mathrm{n}}<1$,

Assume that $\sum_{\mathrm{n}=1}^{\infty} \sup _{\mathrm{x}} \in \mathrm{D}\left\|\mathrm{S}_{\mathrm{n}} \mathrm{x}-\mathrm{S}_{\mathrm{n}-1} \mathrm{x}\right\|<\infty$ for any bounded subset D of $\mathrm{C}$ and let $\mathrm{S}$ be a mapping of $\mathrm{C}$ into itself defined by $S x=\lim _{n \rightarrow \infty} S_{n} x$ for all $x \in C$ and suppose that $\operatorname{Fix}(S)=\bigcap_{i=0}^{\infty} \operatorname{Fix}\left(S_{i}\right)$. Then $\left\{x_{n}\right\}$ converges strongly to $q \in$ F, whivh solves the following VIP:

$<\mathrm{q}-\mathrm{f}(\mathrm{q}), \mathrm{J}(\mathrm{q}-\mathrm{p})>\leq 0, \forall \mathrm{p} \in \mathrm{F}$.

Theorem 3.2.13: [33] Let $\mathrm{C}$ be a nonempty closed convex subset of a uniformly convex Banach space $\mathrm{X}$ which has a uniformly Gateaux differentiable norm. Let $\Pi_{\mathrm{C}}$ be a sunny nonexpansive retraction from $\mathrm{X}$ onto $\mathrm{C}$. Let $\mathrm{B}_{\mathrm{i}}: \mathrm{C} \rightarrow \mathrm{X}$ be an $\lambda_{\mathrm{i}}$-strictly pseudocontractive and $\alpha_{\mathrm{i}}$-strongly accretive with $\alpha_{\mathrm{i}}+\lambda_{\mathrm{i}} \geq 1$ for $\mathrm{i}=1,2$. Let $\mathrm{f}: \mathrm{C} \rightarrow \mathrm{C}$ be a contraction with coefficient $\rho \in(0,1)$. Let $\left\{S_{n}\right\}_{n=0}^{\infty}$ be an infinite family of nonexpansive mappings of $\mathrm{C}$ into itself such that $\mathrm{F}=$ $\bigcap_{\mathrm{i}=0}^{\infty} \operatorname{Fix}\left(\mathrm{S}_{\mathrm{i}}\right) \bigcap \Omega \neq \phi$, where $\Omega$ is a fixed point set of the mapping G. For arbitrarily given $\mathrm{x}_{0} \in \mathrm{C}$, let $\left\{\mathrm{x}_{\mathrm{n}}\right\}$ be a sequence generated by $\mathrm{y}_{\mathrm{n}}=\alpha_{\mathrm{n}} \mathrm{x}_{\mathrm{n}}+\left(1-\alpha_{\mathrm{n}}\right) \Pi_{\mathrm{C}}\left(1-\mu_{1} \mathrm{~B}_{1}\right) \Pi_{\mathrm{C}}\left(1-\mu_{2} \mathrm{~B}_{2}\right) \mathrm{x}_{\mathrm{n}}$, $\mathrm{x}_{\mathrm{n}+1}=\beta_{\mathrm{n}} \mathrm{f}\left(\mathrm{x}_{\mathrm{n}}\right)+\left(1-\beta_{\mathrm{n}}\right) \mathrm{S}_{\mathrm{n}} \mathrm{y}_{\mathrm{n}}, \mathrm{n} \geq 0$,

where $1-\frac{\lambda_{i}}{1+\lambda_{i}}\left(1-\sqrt{\frac{1-\alpha_{i}}{\lambda_{i}}}\right) \leq \mu_{i} \leq 1$ for $\mathrm{i}=1,2$.

Let $\left\{\alpha_{n}\right\},\left\{\beta_{n}\right\}$ be two sequences in $(0,1)$ satisfying the following conditions:

i) $\quad 0<\liminf _{n \rightarrow \infty} \alpha_{n} \leq \lim \sup _{n \rightarrow \infty} \alpha_{n}<1$,

ii) $\lim _{n \rightarrow \infty} \beta_{n}=0, \sum_{n=0}^{\infty} \beta_{n}=\infty$,

iii) Either $\sum_{n=1}^{\infty}\left|\alpha_{n}-\alpha_{n-1}\right|<\infty$ or $\lim _{n \rightarrow \infty}\left|\alpha_{n}-\alpha_{n-1}\right| / \beta_{n}=0$.

iv) Either $\sum_{n=1}^{\infty}\left|\beta_{n}-\beta_{n-1}\right|<\infty$ or $\lim _{n \rightarrow \infty} \beta_{n-1} / \beta_{n}=1$. 
Assume that $\sum_{n=1}^{\infty} \sup _{x \in D}\left\|S_{n} x-S_{n-1} x\right\|<\infty$ for any bounded subset D of $C$ and let $S$ be a mapping of $C$ into itself defined $S x=\lim _{n \rightarrow \infty} S_{n} x$ for all $x \in C$ and suppose that $\operatorname{Fix}(S)=\bigcap_{i=0}^{\infty} \operatorname{Fix}\left(S_{i}\right)$. Then $\left\{x_{n}\right\}$ converges strongly to $q \in F$, whivh solves the following VIP:

$<\mathrm{q}-\mathrm{f}(\mathrm{q}), \mathrm{J}(\mathrm{q}-\mathrm{p})>\leq 0, \forall \mathrm{p} \in \mathrm{F}$.

Corollary (i). [33] Let $\mathrm{C}$ be a nonempty closed convex subset of a uniformly convex Banach space $\mathrm{X}$ which has a uniformly Gateaux differentiable norm. Let $\Pi_{\mathrm{C}}$ be a sunny nonexpansive retraction from $\mathrm{X}$ onto $\mathrm{C}$. Let $\mathrm{B}_{\mathrm{i}}$ : $\mathrm{C} \rightarrow \mathrm{X}$ be an $\lambda_{\mathrm{i}}$-strictly pseudocontractive and $\alpha_{\mathrm{i}}$-strongly accretive with $\alpha_{\mathrm{i}}+\lambda_{\mathrm{i}} \geq 1$ for $\mathrm{i}=1,2$. Let $\mathrm{f}: \mathrm{C} \rightarrow \mathrm{C}$ be a contraction with coefficient $\rho \in(0,1)$. Let $\mathrm{S}$ be a nonexpansive mapping of $\mathrm{C}$ into itself such that $\mathrm{F}=\operatorname{Fix}(\mathrm{S}) \cap \Omega \neq \phi$, where $\Omega$ is a fixed point set of the mapping $\mathrm{G}$. For arbitrarily given $\mathrm{x}_{0} \in \mathrm{C}$, let $\left\{\mathrm{x}_{\mathrm{n}}\right\}$ be a sequence generated by

$\mathrm{y}_{\mathrm{n}}=\alpha_{\mathrm{n}} \mathrm{x}_{\mathrm{n}}+\left(1-\alpha_{\mathrm{n}}\right) \Pi_{\mathrm{C}}\left(1-\mu_{1} \mathrm{~B}_{1}\right) \Pi_{\mathrm{C}}\left(1-\mu_{2} \mathrm{~B}_{2}\right) \mathrm{x}_{\mathrm{n}}$,

$\mathrm{x}_{\mathrm{n}+1}=\beta_{\mathrm{n}} \mathrm{f}\left(\mathrm{x}_{\mathrm{n}}\right)+\left(1-\beta_{\mathrm{n}}\right) \mathrm{Sy}_{\mathrm{n}}, \mathrm{n} \geq 0$,

where $1-\frac{\lambda_{i}}{1+\lambda_{i}}\left(1-\sqrt{\frac{1-\alpha_{i}}{\lambda_{i}}}\right) \leq \mu_{i} \leq 1$ for $\mathrm{i}=1,2$.

Let $\left\{\alpha_{n}\right\},\left\{\beta_{n}\right\}$ be two sequences in $(0,1)$ satisfying the following conditions:

i) $0<\liminf _{n \rightarrow \infty} \alpha_{n} \leq \lim \sup _{n \rightarrow \infty} \alpha_{n}<1$,

ii) $\lim _{n \rightarrow \infty} \beta_{n}=0, \sum_{n=0}^{\infty} \beta_{n}=\infty$,

iii) Either $\sum_{n=1}^{\infty}\left|\alpha_{n}-\alpha_{n-1}\right|<\infty$ or $\lim _{n \rightarrow \infty}\left|\alpha_{n}-\alpha_{n-1}\right| / \beta_{n}=0$.

iv) Either $\sum_{n=1}^{\infty}\left|\beta_{n}-\beta_{n-1}\right|<\infty$ or $\lim _{n \rightarrow \infty} \beta_{n-1} / \beta_{n}=1$.

Then $\left\{x_{n}\right\}$ converges strongly to $q \in F$, whivh solves the following VIP:

$<\mathrm{q}-\mathrm{f}(\mathrm{q}), \mathrm{J}(\mathrm{q}-\mathrm{p})>\leq 0, \forall \mathrm{p} \in \mathrm{F}$.

Also they gave an explicit iterative scheme in the setting of uniformly convex Banach spaces with a uniformly Gateaux differentiable norm as follows.

Theorem 3.2.14: [33] Let $C$ be a nonempty closed convex subset of a uniformly convex and 2-uniformly smooth Banach space $X$. Let $\Pi_{C}$ be a sunny nonexpansive retraction from $X$ onto $C$. Let $B_{i}: C \rightarrow X$ be a $\alpha_{i}$-inverse strongly accretive for $i=1$, 2. Let $f: C \rightarrow C$ be a contraction with coefficient $\rho \in(0,1)$. Let $\left\{\mathrm{S}_{\mathrm{n}}\right\}_{\mathrm{n}=0}^{\infty}$ be an infinite family of nonexpansive mappings of $C$ into itself such that $F=\bigcap_{i=0}^{\infty} \operatorname{Fix}\left(\mathrm{S}_{\mathrm{i}}\right) \bigcap \Omega \neq \phi$, where $\Omega$ is a fixed point set of the mapping

$G$. For arbitrarily given $x_{0} \in C$, let $\left\{x_{n}\right\}$ be a sequence generated by

$\mathrm{y}_{\mathrm{n}}=\alpha_{\mathrm{n}} \mathrm{f}\left(\mathrm{x}_{\mathrm{n}}\right)+\left(1-\alpha_{\mathrm{n}}\right) \mathrm{S}_{\mathrm{n}} \Pi_{\mathrm{C}}\left(1-\mu_{1} \mathrm{~B}_{1}\right) \Pi_{\mathrm{C}}\left(1-\mu_{2} \mathrm{~B}_{2}\right) \mathrm{x}_{\mathrm{n}}$,

$\mathrm{x}_{\mathrm{n}+1}=\beta_{\mathrm{n}} \mathrm{y}_{\mathrm{n}}+\left(1-\beta_{\mathrm{n}}\right) \mathrm{S}_{\mathrm{n}} \Pi_{\mathrm{C}}\left(1-\mu_{1} \mathrm{~B}_{1}\right) \Pi_{\mathrm{C}}\left(1-\mu_{2} \mathrm{~B}_{2}\right) \mathrm{y}_{\mathrm{n}} \mathrm{n} \geq 0$,

where $0<\mu_{\mathrm{i}}<\frac{\alpha_{\mathrm{i}}}{\mathrm{K}^{2}}$ for $\mathrm{i}=1,2$.

Let $\left\{\alpha_{n}\right\},\left\{\beta_{n}\right\}$ be two sequences in $(0,1]$ satisfying the following conditions:

i) $\lim _{\mathrm{n} \rightarrow \infty} \alpha_{\mathrm{n}}=0, \sum_{\mathrm{n}=0}^{\infty} \alpha_{\mathrm{n}}=\infty$,

ii) $\left\{\beta_{\mathrm{n}}\right\} \subset[\mathrm{a}, 1]$ for some $\mathrm{a} \in(0,1)$,

iii) Either $\sum_{n=1}^{\infty}\left|\alpha_{n}-\alpha_{n-1}\right|<\infty$ or $\lim _{n \rightarrow \infty} \alpha_{n-1} / \alpha_{n}=1$.

iv) Either $\sum_{n=1}^{\infty}\left|\beta_{n}-\beta_{n-1}\right|<\infty$ or $\lim _{n \rightarrow \infty}\left|\beta_{n}-\beta_{n-1}\right| / \alpha_{n}=0$.

Assume that $\sum_{\mathrm{n}=1}^{\infty} \sup _{\mathrm{x}} \in \mathrm{D}\left\|\mathrm{S}_{\mathrm{n}} \mathrm{x}-\mathrm{S}_{\mathrm{n}-1} \mathrm{x}\right\|<\infty$ for any bounded subset D of $\mathrm{C}$ and let $\mathrm{S}$ be a mapping of $\mathrm{C}$ into itself defined $S x=\lim _{n \rightarrow \infty} S_{n} x$ for all $x \in C$ and suppose that $\operatorname{Fix}(S)=\bigcap_{i=0}^{\infty} \operatorname{Fix}\left(S_{i}\right)$. Then $\left\{x_{n}\right\}$ converges strongly to $q \in F$, whivh solves the following VIP:

$<\mathrm{q}-\mathrm{f}(\mathrm{q}), \mathrm{J}(\mathrm{q}-\mathrm{p})>\leq 0, \forall \mathrm{p} \in \mathrm{F}$. 
Corollary (i): [33] Let $\mathrm{C}$ be a nonempty closed convex subset of a uniformly convex and 2-uniformly smooth Banach space $\mathrm{X}$. Let $\Pi_{\mathrm{C}}$ be a sunny nonexpansive retraction from $\mathrm{X}$ onto $\mathrm{C}$. Let $\mathrm{B}_{\mathrm{i}}: \mathrm{C} \rightarrow \mathrm{X}$ be an $\alpha_{\mathrm{i}}$-inverse strongly accretive for $\mathrm{i}=1,2$. Let $\mathrm{f}: \mathrm{C} \rightarrow \mathrm{C}$ be a contraction with coefficient $\rho \in(0,1)$. Let $\mathrm{S}$ be a nonexpansive mapping of $\mathrm{C}$ into itself such that $\mathrm{F}=\operatorname{Fix}(\mathrm{S}) \cap \Omega \neq \phi$, where $\Omega$ is a fixed point set of the mapping G. For arbitrarily given $\mathrm{x}_{0} \in \mathrm{C}$, let $\left\{\mathrm{x}_{\mathrm{n}}\right\}$ be a sequence generated by

$\mathrm{y}_{\mathrm{n}}=\alpha_{\mathrm{n}} \mathrm{f}\left(\mathrm{x}_{\mathrm{n}}\right)+\left(1-\alpha_{\mathrm{n}}\right) \mathrm{S} \Pi_{\mathrm{C}}\left(1-\mu_{1} \mathrm{~B}_{1}\right) \Pi_{\mathrm{C}}\left(1-\mu_{2} \mathrm{~B}_{2}\right) \mathrm{x}_{\mathrm{n}}$

$\mathrm{x}_{\mathrm{n}+1}=\beta_{\mathrm{n}} \mathrm{y}_{\mathrm{n}}+\left(1-\beta_{\mathrm{n}}\right) \mathrm{S} \Pi_{\mathrm{C}}\left(1-\mu_{1} \mathrm{~B}_{1}\right) \Pi_{\mathrm{C}}\left(1-\mu_{2} \mathrm{~B}_{2}\right) \mathrm{y}_{\mathrm{n}} \mathrm{n} \geq 0$,

where $0<\mu_{\mathrm{i}}<\frac{\alpha_{\mathrm{i}}}{\mathrm{K}^{2}}$ for $\mathrm{i}=1,2$.

Let $\left\{\alpha_{n}\right\},\left\{\beta_{n}\right\}$ be two sequences in $(0,1]$ satisfying the following conditions:

i) $\lim _{n \rightarrow \infty} \alpha_{n}=0, \sum_{n=0}^{\infty} \alpha_{n}=\infty$,

ii) $\left\{\beta_{\mathrm{n}}\right\} \subset[\mathrm{a}, 1]$ for some $\mathrm{a} \in(0,1)$,

iii) Either $\sum_{n=1}^{\infty}\left|\alpha_{n}-\alpha_{n-1}\right|<\infty$ or $\lim _{n \rightarrow \infty} \alpha_{n-1} / \alpha_{n}=1$.

iv) Either $\sum_{n=1}^{\infty}\left|\beta_{n}-\beta_{n-1}\right|<\infty$ or $\lim _{n \rightarrow \infty}\left|\beta_{n}-\beta_{n-1}\right| / \alpha_{n}=0$.

Then $\left\{x_{n}\right\}$ converges strongly to $q \in F$, whivh solves the following VIP:

$<\mathrm{q}-\mathrm{f}(\mathrm{q}), \mathrm{J}(\mathrm{q}-\mathrm{p})>\leq 0, \forall \mathrm{p} \in \mathrm{F}$.

Corollary (ii): [33] Let $\mathrm{C}$ be a nonempty closed convex subset of a real Hilbert space $\mathrm{H}$. Let $\mathrm{B}_{\mathrm{i}}$ : $\mathrm{C} \rightarrow \mathrm{H}$ be an $\alpha_{\mathrm{i}}$-inverse strongly monotone for $\mathrm{i}=1,2$. Let $\mathrm{f}: \mathrm{C} \rightarrow \mathrm{C}$ be a contraction with coefficient $\rho \in(0,1)$. Let $\left\{\mathrm{S}_{\mathrm{n}}\right\}_{\mathrm{n}=0}^{\infty}$ be an infinite family of nonexpansive mappings of $\mathrm{C}$ into itself such that $\mathrm{F}=\bigcap_{\mathrm{i}=0}^{\infty} \operatorname{Fix}\left(\mathrm{S}_{\mathrm{i}}\right) \bigcap \Omega \neq \phi$, where $\Omega$ is a fixed point set of the mapping $\mathrm{G}$. For arbitrarily given $\mathrm{x}_{0} \in \mathrm{C}$, let $\left\{\mathrm{x}_{\mathrm{n}}\right\}$ be a sequence generated by

$\mathrm{y}_{\mathrm{n}}=\alpha_{\mathrm{n}} \mathrm{f}\left(\mathrm{x}_{\mathrm{n}}\right)+\left(1-\alpha_{\mathrm{n}}\right) \mathrm{S}_{\mathrm{n}} \mathrm{P}_{\mathrm{C}}\left(1-\mu_{1} \mathrm{~B}_{1}\right) \Pi_{\mathrm{C}}\left(1-\mu_{2} \mathrm{~B}_{2}\right) \mathrm{x}_{\mathrm{n}}$,

$\mathrm{x}_{\mathrm{n}+1}=\beta_{\mathrm{n}} \mathrm{y}_{\mathrm{n}}+\left(1-\beta_{\mathrm{n}}\right) \mathrm{S}_{\mathrm{n}} \mathrm{P}_{\mathrm{C}}\left(1-\mu_{1} \mathrm{~B}_{1}\right) \Pi_{\mathrm{C}}\left(1-\mu_{2} \mathrm{~B}_{2}\right) \mathrm{y}_{\mathrm{n}} \mathrm{n} \geq 0$,

where $0<\mu_{\mathrm{i}}<2 \alpha_{\mathrm{i}}$ for $\mathrm{i}=1,2$.

Let $\left\{\alpha_{n}\right\},\left\{\beta_{n}\right\}$ be two sequences in $(0,1]$ satisfying the following conditions:

i) $\lim _{n \rightarrow \infty} \alpha_{n}=0, \sum_{n=0}^{\infty} \alpha_{n}=\infty$,

ii) $\left\{\beta_{\mathrm{n}}\right\} \subset[\mathrm{a}, 1]$ for some $\mathrm{a} \in(0,1)$,

iii) Either $\sum_{n=1}^{\infty}\left|\alpha_{n}-\alpha_{n-1}\right|<\infty$ or $\lim _{n \rightarrow \infty} \alpha_{n-1} / \alpha_{n}=1$.

iv) Either $\sum_{n=1}^{\infty}\left|\beta_{n}-\beta_{n-1}\right|<\infty$ or $\lim _{n \rightarrow \infty}\left|\beta_{n}-\beta_{n-1}\right| / \alpha_{n}=0$.

Assume that $\sum_{n=1}^{\infty} \sup _{x \in D}\left\|S_{n} x-S_{n-1} x\right\|<\infty$ for any bounded subset D of C and let $S$ be a mapping of $C$ into itself defined $S x=\lim _{n \rightarrow \infty} S_{n} x$ for all $x \in C$ and suppose that $\operatorname{Fix}(S)=\bigcap_{i=0}^{\infty} \operatorname{Fix}\left(S_{i}\right)$. Then $\left\{x_{n}\right\}$ converges strongly to $q \in F$, whivh solves the following VIP:

$<\mathrm{q}-\mathrm{f}(\mathrm{q}), \mathrm{J}(\mathrm{q}-\mathrm{p})>\leq 0, \forall \mathrm{p} \in \mathrm{F}$.

Corollary (iii): [33] Let $\mathrm{C}$ be a nonempty closed convex subset of a real Hilbert space $\mathrm{H}$. Let $\mathrm{B}_{\mathrm{i}}$ : $\mathrm{C} \rightarrow \mathrm{H}$ be an $\alpha_{\mathrm{i}^{-}}$ inverse strongly monotone for $\mathrm{i}=1,2$. Let $\mathrm{f}: \mathrm{C} \rightarrow \mathrm{C}$ be a contraction with coefficient $\rho \in(0,1)$. Let $\mathrm{S}$ be a nonexpansive mapping of $\mathrm{C}$ into itself such that $\mathrm{F}=\operatorname{Fix}(\mathrm{S}) \cap \Omega \neq \phi$, where $\Omega$ is a fixed point set of the mapping $\mathrm{G}$. For arbitrarily given $\mathrm{x}_{0} \in \mathrm{C}$, let $\left\{\mathrm{x}_{\mathrm{n}}\right\}$ be a sequence generated by

$\mathrm{y}_{\mathrm{n}}=\alpha_{\mathrm{n}} \mathrm{f}\left(\mathrm{x}_{\mathrm{n}}\right)+\left(1-\alpha_{\mathrm{n}}\right) \mathrm{SP}_{\mathrm{C}}\left(1-\mu_{1} \mathrm{~B}_{1}\right) \Pi_{\mathrm{C}}\left(1-\mu_{2} \mathrm{~B}_{2}\right) \mathrm{x}_{\mathrm{n}}$,

$\mathrm{x}_{\mathrm{n}+1}=\beta_{\mathrm{n}} \mathrm{y}_{\mathrm{n}}+\left(1-\beta_{\mathrm{n}}\right) \mathrm{SP}_{\mathrm{C}}\left(1-\mu_{1} \mathrm{~B}_{1}\right) \Pi_{\mathrm{C}}\left(1-\mu_{2} \mathrm{~B}_{2}\right) \mathrm{y}_{\mathrm{n}} \mathrm{n} \geq 0$,

where $0<\mu_{\mathrm{i}}<\frac{\alpha_{\mathrm{i}}}{\mathrm{K}^{2}}$ for $\mathrm{i}=1,2$.

Let $\left\{\alpha_{n}\right\},\left\{\beta_{n}\right\}$ be two sequences in $(0,1]$ satisfying the following conditions:

i) $\lim _{n \rightarrow \infty} \alpha_{n}=0, \sum_{n=0}^{\infty} \alpha_{n}=\infty$, 
ii) $\left\{\beta_{\mathrm{n}}\right\} \subset[\mathrm{a}, 1]$ for some $\mathrm{a} \in(0,1)$,

iii) Either $\sum_{n=1}^{\infty}\left|\alpha_{n}-\alpha_{n-1}\right|<\infty$ or $\lim _{n \rightarrow \infty} \alpha_{n-1} / \alpha_{n}=1$.

iv) Either $\sum_{n=1}^{\infty}\left|\beta_{n}-\beta_{n-1}\right|<\infty$ or $\lim _{n \rightarrow \infty}\left|\beta_{n}-\beta_{n-1}\right| / \alpha_{n}=0$.

Then $\left\{x_{n}\right\}$ converges strongly to $q \in F$, whivh solves the following VIP: $<\mathrm{q}-\mathrm{f}(\mathrm{q}), \mathrm{J}(\mathrm{q}-\mathrm{p})>\leq 0, \forall \mathrm{p} \in \mathrm{F}$.

Corollary (iv): [33] Let $\mathrm{C}$ be a nonempty closed convex subset of a real Hilbert space H. Let $\mathrm{T}$ : $\mathrm{C} \rightarrow \mathrm{C}$ be a pseudocontractive mapping and let $S$ be a nonexpansive mapping of $C$ into itself such that $F=\operatorname{Fix}(S) \cap$ Fix $(T) \neq \phi$. Let $\mathrm{f}: \mathrm{C} \rightarrow \mathrm{C}$ be a contraction with coefficient $\rho \in(0,1)$. For arbitrarily given $\mathrm{x}_{0} \in \mathrm{C}$, let $\left\{\mathrm{x}_{\mathrm{n}}\right\}$ be a sequence generated by $\left.y_{n}=\alpha_{n} f\left(x_{n}\right)+\left(1-\alpha_{n}\right) S\left((1-\lambda) x_{n}\right)+\lambda T x_{n}\right)$, $\left.\mathrm{x}_{\mathrm{n}+1}=\beta_{\mathrm{n}} \mathrm{y}_{\mathrm{n}}+\left(1-\beta_{\mathrm{n}}\right) \mathrm{S}\left((1-\lambda) \mathrm{y}_{\mathrm{n}}\right)+\lambda \mathrm{T} \mathrm{y}_{\mathrm{n}}\right), \mathrm{n} \geq 0$, where $0<\lambda<1-\mathrm{k}$. Let $\left\{\alpha_{\mathrm{n}}\right\},\left\{\beta_{\mathrm{n}}\right\}$ be two sequences in $(0,1]$ satisfying the following conditions:

i) $\lim _{n \rightarrow \infty} \alpha_{n}=0, \sum_{n=0}^{\infty} \alpha_{n}=\infty$,

ii) $\left\{\beta_{\mathrm{n}}\right\} \subset[\mathrm{a}, 1]$ for some $\mathrm{a} \in(0,1)$,

iii) Either $\sum_{n=1}^{\infty}\left|\alpha_{n}-\alpha_{n-1}\right|<\infty$ or $\lim _{n \rightarrow \infty} \alpha_{n-1} / \alpha_{n}=1$.

iv) Either $\sum_{n=1}^{\infty}\left|\beta_{n}-\beta_{n-1}\right|<\infty$ or $\lim _{n \rightarrow \infty}\left|\beta_{n}-\beta_{n-1}\right| / \alpha_{n}=0$.

Then $\left\{x_{n}\right\}$ converges strongly to $q \in F$, whivh solves the following VIP: $<\mathrm{q}-\mathrm{f}(\mathrm{q}), \mathrm{J}(\mathrm{q}-\mathrm{p})>\leq 0, \forall \mathrm{p} \in \operatorname{Fix}(\mathrm{S}) \cap \operatorname{Fix}(\mathrm{T})$.

Corollary (v): [33] Let $\mathrm{H}$ be a real Hilbert space. Let $\mathrm{A}$ be an $\alpha$-inverse-strongly monotone mapping of $\mathrm{H}$ into itself and let $S$ be a nonexpansive mapping of $C$ into itself such that $\operatorname{Fix}(S) \cap A^{-1} 0 \neq \phi$. Let $\mathrm{f}: \mathrm{H} \rightarrow \mathrm{H}$ be a contraction with coefficient $\rho \in(0,1)$. For arbitrarily given $x_{0} \in C$, let $\left\{x_{n}\right\}$ be a sequence generated by $y_{n}=\alpha_{n} f\left(x_{n}\right)+\left(1-\alpha_{n}\right) S\left(x_{n}-\lambda A x_{n}\right)$,

$\mathrm{x}_{\mathrm{n}+1}=\beta_{\mathrm{n}} \mathrm{y}_{\mathrm{n}}+\left(1-\beta_{\mathrm{n}}\right) \mathrm{S}\left(\mathrm{y}_{\mathrm{n}}-\lambda A \mathrm{y}_{\mathrm{n}}\right), \mathrm{n} \geq 0$,

where $0<\lambda<2 \alpha$. Let $\left\{\alpha_{\mathrm{n}}\right\},\left\{\beta_{\mathrm{n}}\right\}$ be two sequences in $(0,1]$ satisfying the following conditions:

i) $\lim _{n \rightarrow \infty} \alpha_{n}=0, \sum_{n=0}^{\infty} \alpha_{n}=\infty$,

ii) $\left\{\beta_{\mathrm{n}}\right\} \subset[\mathrm{a}, 1]$ for some $\mathrm{a} \in(0,1)$,

iii) Either $\sum_{n=1}^{\infty}\left|\alpha_{n}-\alpha_{n-1}\right|<\infty$ or $\lim _{n \rightarrow \infty} \alpha_{n-1} / \alpha_{n}=1$.

iv) Either $\sum_{n=1}^{\infty}\left|\beta_{n}-\beta_{n-1}\right|<\infty$ or $\lim _{n \rightarrow \infty}\left|\beta_{n}-\beta_{n-1}\right| / \alpha_{n}=0$.

Then $\left\{x_{n}\right\}$ converges strongly to $q \in \operatorname{Fix}(S) \cap A^{-1} 0$, whivh solves the following VIP: $<\mathrm{q}-\mathrm{f}(\mathrm{q}), \mathrm{q}-\mathrm{p}>\leq 0, \forall \mathrm{p} \in \operatorname{Fix}(\mathrm{S}) \cap \mathrm{A}^{-1} 0$.

In 2013, Kangtunyakarn [3] proved a strong convergence theorem for finding a common element of the set of solutions of a finite family of variational inequality problems and the set of fixed points of a nonexpansive mapping and an $\eta$ strictly pseudo-contractive mapping in uniformly convex and 2-uniformly smooth spaces.

Firstly, we give a definition.

Definition: Let $\mathrm{C}$ be a nonempty closed convex subset of a Banach space H. Let $\left\{\mathrm{T}_{\mathrm{i}}\right\}_{\mathrm{i}=1}^{\mathrm{N}}$ be finite family of nonexpansive mappings of $\mathrm{C}$ into itself and let $\lambda_{1}, \lambda_{2}, \ldots \ldots ., \lambda_{\mathrm{N}}$, be real numbers such that $0 \leq \lambda_{\mathrm{i}} \leq 1$ for every $\mathrm{i}=1,2$, $\ldots . ., \mathrm{N}$. Define a mapping $\mathrm{K}: \mathrm{C} \rightarrow \mathrm{C}$ as follows:

$U_{1}=\lambda_{1} \mathrm{~T}_{1}+\left(1-\lambda_{1}\right) \mathrm{I}$,

$\mathcal{U}_{2}=\lambda_{2} \mathrm{~T}_{2} \mathcal{U}_{1}+\left(1-\lambda_{2}\right) \mathcal{U}_{1}$,

$\mathcal{U}_{3}=\lambda_{3} \mathrm{~T}_{3} \mathcal{U}_{2}+\left(1-\lambda_{3}\right) \mathcal{U}_{2}$

$\mathcal{U}_{\mathrm{N}-1}=\lambda_{\mathrm{N}-1} \mathrm{~T}_{\mathrm{N}-1} \mathcal{U}_{\mathrm{N}-2}+\left(1-\lambda_{\mathrm{N}-1}\right) \mathcal{U}_{\mathrm{N}-2}$

$\mathrm{K}=\mathcal{U}_{\mathrm{N}}=\lambda_{\mathrm{N}} \mathrm{T}_{\mathrm{N}} \mathcal{U}_{\mathrm{N}-1}+\left(1-\lambda_{\mathrm{N}}\right) \mathcal{U}_{\mathrm{N}-1}$,

Such a mapping $K$ is called the $K$-mapping generated by $T_{1}, T_{2}, \ldots \ldots T_{N}$ and $\lambda_{1}, \lambda_{2}, \ldots \ldots, \lambda_{N}$. 
Theorem 3.2.15: [3] Let $C$ be a nonempty closed convex subset of a uniformly convex and 2-uniformly smooth Banach space $E$. Let $Q_{C}$ be a sunny nonexpansive retraction from $E$ onto $C$. For every $i=1,2, \ldots \ldots, N$, let $A_{i}: C \rightarrow E \alpha$-inverse strongly accretive mappings. Define a mapping $\mathrm{G}_{\mathrm{i}}: \mathrm{C} \rightarrow \mathrm{C}$ by $\mathrm{Q}_{\mathrm{C}}\left(\mathrm{I}-\lambda_{\mathrm{i}} \mathrm{A}_{\mathrm{i}}\right) \mathrm{x}=\mathrm{G}_{\mathrm{i}} \mathrm{x}$ for all $\mathrm{x} \in \mathrm{C}$ and $\mathrm{i}=1,2, \ldots \ldots, \mathrm{N}$, where $\lambda_{\mathrm{i}} \in\left(0, \frac{\alpha_{\mathrm{i}}}{\mathrm{K}^{2}}\right), \mathrm{K}$ is the 2-uniformly smooth constant of $\mathrm{E}$. Let $\mathrm{B}: \mathrm{C} \rightarrow \mathrm{C}$ be the K-mapping generated by $\mathrm{G}_{1}$, $\mathrm{G}_{2}, \ldots, \mathrm{G}_{\mathrm{N}}$ and $\rho_{1}, \rho_{2}, \ldots \ldots, \rho_{\mathrm{N}}$, where $\rho_{\mathrm{i}} \in(0,1), \forall \mathrm{i}=1,2, \ldots \ldots, \mathrm{N}-1$ and $\rho_{\mathrm{N}} \in(0,1]$. Let $\mathrm{T}: \mathrm{C} \rightarrow \mathrm{C}$ be a nonexpansive mapping and $\mathrm{S}: \mathrm{C} \rightarrow \mathrm{C}$ be an $\eta$-strictly pseudocontractive mapping with $\mathrm{F}=\mathrm{F}(\mathrm{S}) \cap \mathrm{F}(\mathrm{T}) \bigcap_{\mathrm{i}=1}^{\mathrm{N}} \mathrm{S}\left(\mathrm{C}, \mathrm{A}_{\mathrm{i}}\right)$ $\neq \phi$. Define a mapping $\mathrm{B}_{\mathrm{A}}: \mathrm{C} \rightarrow \mathrm{C}$ by $\mathrm{T}((1-\alpha) \mathrm{I}+\alpha \mathrm{S}) \mathrm{x}=\mathrm{B}_{\mathrm{A}} \mathrm{x}, \forall \mathrm{x} \in \mathrm{C}$ and $\alpha \in\left(0, \frac{\eta}{\mathrm{K}^{2}}\right)$. For arbitrarily given $\mathrm{x}_{1} \in \mathrm{C}$, let $\left\{x_{n}\right\}$ be a sequence generated by $\mathrm{x}_{\mathrm{n}+1}=\alpha_{\mathrm{n}} \mathrm{f}\left(\mathrm{x}_{\mathrm{n}}\right)+\beta_{\mathrm{n}} \mathrm{x}_{\mathrm{n}}+\gamma_{\mathrm{n}} \mathrm{Bx}_{\mathrm{n}}+\gamma_{\mathrm{n}} \mathrm{B}_{\mathrm{A}} \mathrm{x}_{\mathrm{n}}, \forall \mathrm{n} \geq 1$ where $\mathrm{f}: \mathrm{C} \rightarrow \mathrm{C}$ is a contractive mapping and $\left\{\alpha_{\mathrm{n}}\right\},\left\{\beta_{\mathrm{n}}\right\},\left\{\gamma_{\mathrm{n}}\right\},\left\{\delta_{\mathrm{n}}\right\} \subseteq[0,1], \alpha_{\mathrm{n}}+\beta_{\mathrm{n}}+\gamma_{\mathrm{n}}+\delta_{\mathrm{n}}=1$ and satisfy the following conditions:

i) $\lim _{\mathrm{n} \rightarrow \infty} \alpha_{\mathrm{n}}=0, \sum_{\mathrm{n}=0}^{\infty} \alpha_{\mathrm{n}}=\infty$,

ii) $\left\{\gamma_{\mathrm{n}}\right\},\left\{\delta_{\mathrm{n}}\right\} \subseteq[\mathrm{c}, \mathrm{d}] \subset(0,1)$, for some $\mathrm{c}, \mathrm{d}>0, \forall \mathrm{n} \geq 1$,

iii) $\sum_{n=1}^{\infty}\left|\beta_{n+1}-\beta_{n}\right|<\infty, \sum_{n=1}^{\infty}\left|\gamma_{n+1}-\gamma_{n}\right|<\infty, \sum_{n=1}^{\infty}\left|\delta_{n+1}-\delta_{n}\right|<\infty$

iv) $0<\liminf _{n \rightarrow \infty} \beta_{n} \leq \lim \sup _{n \rightarrow \infty} \beta_{n}<1$.

Then the sequence $\left\{x_{n}\right\}$ converges strongly to $q \in F$, whivh solves the following VIP:

$<\mathrm{q}-\mathrm{f}(\mathrm{q}), \mathrm{j}(\mathrm{q}-\mathrm{p})>\leq 0, \forall \mathrm{p} \in \mathrm{F}$.

In 2013, Atid Kangtunyakarn [2], introduced a new mapping, called $\mathrm{S}^{\mathrm{A}}$-mapping to modify the Halpern iterative scheme for finding a common element of two sets of solutions of variational inequality problem and the set of fixed points of a finite family of nonexpansive mappings and the set of fixed points of a finite family of strictly pseudocontrctive mappings in a uniformly convex and 2-uniformly smooth Banach space.

Firstly, we give a definition.

Definition: Let $\mathrm{C}$ be a nonempty closed convex subset of a Banach space H. Let $\left\{\mathrm{S}_{\mathrm{i}}\right\}_{\mathrm{i}=1}^{\mathrm{N}}$ and $\left\{\mathrm{T}_{\mathrm{i}}\right\}_{\mathrm{i}=1}^{\mathrm{N}}$ be two finite families of mappings of $C$ into itself. For each $j=1,2, \ldots \ldots, N$, let $\alpha_{j}=\left(\alpha_{1}{ }^{j}, \alpha_{2}{ }^{j}, \alpha_{3}{ }^{j}\right) \in I \times I \times I$, where $I \in[0,1]$ and $\alpha_{1}{ }^{\mathrm{j}}+\alpha_{2}{ }^{\mathrm{j}}+\alpha_{3}{ }^{\mathrm{j}}=1$. Define $\mathrm{S}^{\mathrm{A}}: \mathrm{C} \rightarrow \mathrm{C}$ as follows:

$\mathcal{U}_{0}=\mathrm{T}_{1}=\mathrm{I}$

$\mathcal{U}_{1}=\mathrm{T}_{1}\left(\alpha_{1}{ }^{1} \mathrm{~S}_{1} \mathcal{U}_{0}+\alpha_{2}{ }^{1} \mathcal{U}_{0}+\alpha_{3}{ }^{1} \mathrm{I}\right)$,

$\mathcal{U}_{2}=\mathrm{T}_{2}\left(\alpha_{1}^{2} \mathrm{~S}_{2} \mathcal{U}_{1}+\alpha_{2}^{2} \mathcal{U}_{1}+\alpha_{3}^{2} \mathrm{I}\right)$

$U_{3}=\mathrm{T}_{3}\left(\alpha_{1}^{3} \mathrm{~S}_{3} \mathcal{U}_{2}+\alpha_{2}{ }^{3} \mathcal{U}_{2}+\alpha_{3}{ }^{3} \mathrm{I}\right)$,

$\mathcal{U}_{\mathrm{N}-1}=\mathrm{T}_{\mathrm{N}-1}\left(\alpha_{1}^{\mathrm{N}-1} \mathrm{~S}_{\mathrm{N}-1} \mathcal{U}_{\mathrm{N}-2}+\alpha_{2}^{\mathrm{N}-1} \mathcal{U}_{\mathrm{N}-2}+\alpha_{3}^{\mathrm{N}-1} \mathrm{I}\right)$

$\mathrm{S}^{\mathrm{A}}=\mathcal{U}_{\mathrm{N}}=\mathrm{T}_{\mathrm{N}}\left(\alpha_{1}{ }^{\mathrm{N}} \mathrm{S}_{\mathrm{N}} \mathcal{U}_{\mathrm{N}-1}+\alpha_{2}{ }^{\mathrm{N}} \mathcal{U}_{\mathrm{N}-1}+\alpha_{3}{ }^{\mathrm{N}} \mathrm{I}\right)$,

This mapping is called the $S^{A}$-mapping generated by $S_{1}, S_{2}, \ldots ., S_{N}, T_{1}, T_{2}, \ldots \ldots T_{N}$ and $\alpha_{1}, \alpha_{2}, \ldots \ldots, \alpha_{N}$.

Theorem 3.2.16: [2] let $\mathrm{C}$ be a nonempty closed convex subset of a uniformly convex and 2-uniformly smooth Banach space $\mathrm{E}$. Let $\mathrm{Q}_{\mathrm{C}}$ be a sunny nonexpansive retraction from $\mathrm{E}$ onto $\mathrm{C}$. Let $\mathrm{A}, \mathrm{B}$ be $\alpha$ - and $\beta$-inverse strongly accretive mappings of $\mathrm{C}$ into $\mathrm{E}$, respectively. Let $\left\{\mathrm{S}_{\mathrm{i}}\right\}_{\mathrm{i}=1}^{\mathrm{N}}$ be a finite family of $\mathrm{k}_{\mathrm{i}}$-strict pseudocontractions of $\mathrm{C}$ into itself and let $\left\{\mathrm{T}_{\mathrm{i}}\right\}_{\mathrm{i}=1}^{\mathrm{N}}$ be a finite family of nonexpansive mappings of $\mathrm{C}$ into itself such that $\mathrm{F}=\bigcap_{\mathrm{i}=1}^{\mathrm{N}} \mathrm{F}\left(\mathrm{S}_{\mathrm{i}}\right) \bigcap_{\mathrm{i}=1}^{\mathrm{N}} \mathrm{F}\left(\mathrm{T}_{\mathrm{i}}\right) \cap \mathrm{S}(\mathrm{C}, \mathrm{A}) \cap$ $\mathrm{S}(\mathrm{C}, \mathrm{B}) \neq \phi$ and $\mathrm{k}=\min \left\{\mathrm{k}_{\mathrm{i}}: \mathrm{i}=1,2, \ldots \ldots, \mathrm{N}\right\}$ with $\mathrm{K}^{2} \leq \mathrm{k}$, where $\mathrm{K}$ is the 2-uniformly smooth constant of $\mathrm{E}$. Let $\alpha_{\mathrm{j}}=$ $\left(\alpha_{1}{ }^{j}, \alpha_{2}{ }^{j}, \alpha_{3}{ }^{j}\right) \in I \times I \times I$, where $I \in[0,1], \alpha_{1}{ }^{j}+\alpha_{2}{ }^{j}+\alpha_{3}{ }^{j}=1, \alpha_{1}{ }^{j} \in(0,1], \alpha_{2}{ }^{j} \in[0,1], \alpha_{3}{ }^{j} \in(0,1)$ for all $\mathrm{j}=1,2, \ldots \ldots, N$. Let $S^{A}$ be the $S^{A}$-mapping generated by $S_{1}, S_{2}, \ldots ., S_{N}, T_{1}, T_{2}, \ldots \ldots T_{N}$ and $\alpha_{1}, \alpha_{2}, \ldots ., \alpha_{N}$.

Let $\left\{x_{n}\right\}$ be the sequence generated by $x_{1}, u \in C$ and

$\mathrm{x}_{\mathrm{n}+1}=\alpha_{\mathrm{n}} \mathrm{u}+\beta_{\mathrm{n}} \mathrm{x}_{\mathrm{n}}+\gamma_{\mathrm{n}} \mathrm{Q}_{\mathrm{C}}(\mathrm{I}-\mathrm{aA}) \mathrm{x}_{\mathrm{n}}+\delta_{\mathrm{n}} \mathrm{Q}_{\mathrm{C}}(\mathrm{I}-\mathrm{bB}) \mathrm{x}_{\mathrm{n}}+\eta_{\mathrm{n}} \mathrm{S}^{\mathrm{A}} \mathrm{x}_{\mathrm{n}}, \mathrm{n} \geq 1$,

where $\left\{\alpha_{\mathrm{n}}\right\},\left\{\beta_{\mathrm{n}}\right\},\left\{\gamma_{\mathrm{n}}\right\},\left\{\delta_{\mathrm{n}}\right\},\left\{\eta_{\mathrm{n}}\right\} \in[0,1]$ and $\alpha_{\mathrm{n}}+\beta_{\mathrm{n}}+\gamma_{\mathrm{n}}+\delta_{\mathrm{n}}+\eta_{\mathrm{n}}=1$ and satisfy the following conditions:

i) $\lim _{n \rightarrow \infty} \alpha_{n}=0, \sum_{n=0}^{\infty} \alpha_{n}=\infty$,

ii) $\left\{\gamma_{\mathrm{n}}\right\},\left\{\delta_{\mathrm{n}}\right\},\left\{\eta_{\mathrm{n}}\right\} \subseteq[\mathrm{c}, \mathrm{d}] \subset(0,1)$, for some $\mathrm{c}, \mathrm{d}>0, \forall \mathrm{n} \geq 1$, 
iii) $\quad \sum_{n=1}^{\infty}\left|\alpha_{n+1}-\alpha_{n}\right|<\infty, \sum_{n=1}^{\infty}\left|\beta_{n+1}-\beta_{n}\right|<\infty, \sum_{n=1}^{\infty}\left|\gamma_{n+1}-\gamma_{n}\right|<\infty, \sum_{n=1}^{\infty}\left|\delta_{n+1}-\delta_{n}\right|<\infty \sum_{n=1}^{\infty}\left|\eta_{n+1}-\eta_{n}\right|<\infty$,

iv) $\quad 0<\liminf _{\mathrm{n} \rightarrow \infty} \beta_{\mathrm{n}} \leq \lim \sup _{\mathrm{n} \rightarrow \infty} \beta_{\mathrm{n}}<1$,

v) $\mathrm{a} \in\left(0, \frac{\alpha}{\mathrm{K}^{2}}\right)$ and $\mathrm{b} \in\left(0, \frac{\beta}{\mathrm{K}^{2}}\right)$.

Then $\left\{\mathrm{x}_{\mathrm{n}}\right\}$ converges strongly to $\mathrm{z}_{0}=\mathrm{Q}_{\mathrm{F}} \mathrm{u}$, where $\mathrm{Q}_{\mathrm{F}}$ is the sunny nonexpansive retraction of $\mathrm{C}$ onto $\mathrm{F}$.

\section{Acknowledgement}

The authors are extremely grateful to the referees and editors for their useful comments and suggestions which helped to improve this paper. The second author is funded by Council of Scientific and Industrial Research, India.

\section{References}

[1] A. Bunyawat and S. Suantal, Strong convergence theorems for variational inequalities and fixed points of a countable family of nonexpansive mappings, fixed point theory and applications 2011: 47 (2011). http://dx.doi.org/10.1186/1687-1812-2011-47.

[2] A. Kangtunyakarn, A new mapping for finding a common element of the sets of fixed points of two finite families of nonexpansive and strictly pseudo-contractive mappings and two sets of variational inequalities in uniformly convex and 2-smooth Banach spaces, Fixed Point Theory Appl. (2013).

[3] A. Kangtunyakarn, Iterative scheme for a nonexpansive mapping, an $\eta$-strictly pseudo-contractive mapping and variational inequality problems in a uniformly convex and 2-uniformly smooth Banach space, Fixed Point Theory Appl. (2013).

[4] A. Kangtunyakarn, An iterative algorithm to approximate a common element of the set of common fixed points for a finite family of strict pseudocontractions and of the set of solutions for a modified system of variational inequalities, Fixed Point Theory Appl. (2013). http://dx.doi.org/10.1186/1687-1812-2013-143.

[5] A. Moudafi, Viscosity approximation methods for fixed point problems, Journal of Mathematical Analysis and Applications 241(1) (2000) 4655. http://dx.doi.org/10.1006/jmaa.1999.6615.

[6] A. Nagurney, Network economics: a variational inequality approach, Kluwer Academic Publishers, Boston, 1993.

[7] C. Baiocchi, A. Capelo, Variational and Quasivariational Inequalities. Applications to Free-Boundary Problems. J. Wiley, New York, 1984.

[8] Ceng et al., An extragradient-like approximation method for variational inequalities and fixed point problems, fixed point theory and applications, 2011: 22. http://dx.doi.org/10.1186/1687-1812-2011-22.

[9] C. E. Chidume, N. Shahzad, H. Zegeye, Convergence theorems for mappings which are asymptotically nonexpansive in the intermediate sense, Numer Funct Anal Optim. 25, (2004) 239-257. http://dx.doi.org/10.1081/NFA-120039611.

[10] D. Kinderlehrer, G. Stampacchia, an Introduction to Variational Inequalities and their Applications, Academic Press, New York, 1980.

[11] D. R. Sahu, H. K. Xu, J. C.Yao, Asymptotically strict pseudocontractive mappings in the intermediate sense, Nonlinear Anal. 70, 3502-3511. http://dx.doi.org/10.1016/j.na.2008.07.007.

[12] F. E. Browder and W. V. Petryshyn, Construction of Fixed Points of non-linear mapping in Hilbert Space, Journal of Mathematics Analysis and Applications, Vol.20, (1967) 197-228. http://dx.doi.org/10.1016/0022-247X (67)90085-6.

[13] F. Liu, M. Z. Nashed, Regularization of Non-linear Ill- posed Variational inequalities and convergence rates,Set-valued Analysis 6 (1998) 313-344. http://dx.doi.org/10.1023/A:1008643727926.

[14] G. E. Kim, T. H. Kim, Mann and Ishikawa iterations with errors for non-Lipschitzian mappings in Banach spaces, Comput Math Appl. 42 (2001) 1565-1570. http://dx.doi.org/10.1016/S0898-1221 (01)00262-0.

[15] G. M. Korpelevich, The extragradient method for finding saddle points and other problems, Matecon. 12 (1976) 747-756.

[16] G. Stampaccha, Formes bilineaires coercitives sur les ensembles convexes, C. R. Acad. Sci. Paris 258(1964) 4413-4416.

[17] H. liduka and W. Takahashi, Strong convergence theorems for nonexpansive mappings and inverse strongly monotone mappings, Nonlinear Analysis: Theory, Methods and Applications 61(3) (2005) 341-350.

[18] H. Iiduka and W. Takahashi, Strong convergence theorems for nonexpansive nonself mappings and inverse strongly monotone mappings, J of Convex Analysis 11(1) (2004) 69-79.

[19] H. K. Xu, Viscosity approximation methods for nonexpansive mappings, Journal of Mathematical Analysis and Applications 298(1), (2004) 279-291. http://dx.doi.org/10.1016/j.jmaa.2004.04.059.

[20] H. Wang and Y. Song, An iteration scheme for nonexpansive mappings and variational inequalities, Bull. Korean Math. Soc. 48(5) (2011) 991-1002. http://dx.doi.org/10.4134/BKMS.2011.48.5.991.

[21] H. Zhou, Convergence theorems of fixed points for k-strict pseudocontraction in Hilbert spaces, Nonlinear Anal. 69(2008) 456-462. http://dx.doi.org/10.1016/j.na.2007.05.032.

[22] J. C. Jung, A new iteration method for nonexpansive mappings and monotone mappings in Hilbert spaces, J of inequalities and applications (2010) 16 pages.

[23] J. Chen, L. Zhang and T. Fan, Viscosity approximation methods for nonexpansive mappings and monotone mappings, Journal of Mathematical Analysis and Applications 334(2) (2007) 1450-1461. http://dx.doi.org/10.1016/j.jmaa.2006.12.088.

[24] J. Schu, Iterative construction of fixed points of asymptotically nonexpansive mapping, Journal of Mathematical Analysis and Applications 159 (1991) 407-413. http://dx.doi.org/10.1016/0022-247X (91)90245-U.

[25] K. Aoyama, H. liduka and W. Takahashi, Strong Convergence of Halpern's sequence for accretive operators in a Banach space, Panamer. Math. J. 17(2007) 75-89.

[26] K. Aoyama, H. Iiduka and W. Takahashi, Weak Convergence of an iterative sequence for accretive operators in a Banach spaces, Fixed Point Theory Appl. (2006) Art. ID 35390. http://dx.doi.org/10.1155/FPTA/2006/35390.

[27] K. Aoyama, Y. Kimura, W. Takahashi, M. Toyoda, Approximation of common fixed points of a countable family of nonexpansive mappings in a Banach space, Nonlinear Anal. 67 (2007) 2350-2360. http://dx.doi.org/10.1016/j.na.2006.08.032.

[28] K. Goebel, W. A. Kirk, A fixed point theorem for asymptotically nonexpansive mappings, Proc Am Math Soc 35(1) (1972) 171-174. http://dx.doi.org/10.1090/S0002-9939-1972-0298500-3.

[29] L. C.Ceng, A. Petrusel, C. Lee, M. M. Wong, Two extragradient approximation methods for variational inequalities and fixed point problems of strict pseudocontractions, Taiwanese j of Math 13 (2009) 607-632.

[30] L. C. Ceng, C. Y. Wang and J. C. Yao, Strong convergence theorems by a relaxed extragradient method for a general system of variational inequalities, Math. Methods Oper, Res. 67 (2008) 375-390. http://dx.doi.org/10.1007/s00186-007-0207-4. 
[31] L. C. Ceng, H. K. Xu, J. C. Yao, The viscosity approximation method for asymptotically nonexpansive mappings in Banach spaces, nonlinear anal., 69(4) (2008) 1402-1412.

[32] L. C. Ceng and J. C. Yao, extragradient-like approximation method for variational inequalities and fixed point problems, Appl. Math. Comput. 190(2007) 205-215. http://dx.doi.org/10.1016/j.amc.2007.01.021.

[33] L. C. Ceng, L. Abdul and Y. J. Chih, on solutions of a system of variational inequalities and fixed point problems in Banach spaces, Fixed Point Theory Appl. (2013).

[34] L. C. Ceng, N. C. Wong, J. C. Yao, Fixed point solutions of variational inequalities for a finite family of asymptotically nonexpansive mappings without common fixed point assumption, Comput Math Appl. 56 (2008) 2312-2322. http://dx.doi.org/10.1016/j.camwa.2008.05.002.

[35] L. C. Ceng, Q. H. Ansari, J. C. Yao, Strong and weak convergence theorems for asymptotically strict pseudocontraction mappings in the intermediate sense, J Nonlinear Convex Anal. 11(2) (2008) 283-308.

[36] L. C. Zeng, J. C. Yao, Strong convergence theorem by an extragradient method for fixed point problems and variational inequality problems, Taiwanese J Math, 10(5) (2006) 1293-1303.

[37] L. C. Zeng and J. C. Yao, extragradient-like approximation method for variational inequality problems and fixed point problems, Appl. Math. Comput, in press.

[38] M. A. Noor, Y. Yao, Three step iterations for variational inequalities and nonexpansive mappings, Appl. Math. Comput. 190(2007) 13121321. http://dx.doi.org/10.1016/j.amc.2007.02.013.

[39] M. A. Noor, Y. Yao, R. Chen, Y. C. Liou, An iterative method for fixed point problems and variational inequality problems, Mathematical communications 12(2007) 121-132.

[40] M. Pappalardo, M. Passacantando, Stability for equilibrium problems from variational inequalities to dynamical systems, J.O.T.A. 113 (2002).

[41] M. Shang, S. U. Yongfu, X. Qin, Three step iterations for nonexpansive mappings and inverse strongly monotone mappings, Jri Syst Sci and Complexity (2009) 333-344.

[42] N. Nadezhkina and W. Takahashi, Weak convergence theorem by an extragradient method for nonexpansive mappings and monotone Mappings, Journal of Optimization Theory and Applications 128 (2006) 191-201. http://dx.doi.org/10.1007/s10957-005-7564-z.

[43] N. Shahzad, A. Udomene, Fixed point solutions of variational inequalities for asymptotically nonexpansive mappings in Banach spaces, Nonlinear Analysis, 64(2006), 558-567. http://dx.doi.org/10.1016/j.na.2005.03.114.

[44] P. Kumam and P. Katchang, A viscosity of extragradient approximation method for finding equilibrium problems, variational inequalities and fixed point problems for nonexpansive mappings, Nonlinear Anal. 3(2009) 475-486.

[45] P. T. Harker, J. S. Pang, Finite dimensional variational inequalities and nonlinear complementarity problems: a survey of theory, algorithms and applications. Mathematical Programming 48 (1990) 161-220. http://dx.doi.org/10.1007/BF01582255.

[46] R. Chugh, R. Rani, a new iterative scheme for nonexpansive and inverse strongly monotone mappings, International J. of Math. Sci. and Engg. Appls. 8(1) (January, 2014) 189-205.

[47] R. E. Bruck, T. Kuczumow, S. Reich, Convergence of iterates of asymptotically nonexpansive mappings in Banach spaces with the uniform Opial property, Colloq Math, 65(1993) 169-179.

[48] R. P. Agarwal, D. O'Regan, D. R. Sahu, Iterative construction of fixed points of nearly asymptotically nonexpansive mappings, J Nonlinear Convex Anal. 8(1), (2007) 61-79.

[49] R. T. Rockafellar, Monotone operators and proximal point algorithm, SIAM Journal on Control and Optimization 14 (1976) 877-898. http://dx.doi.org/10.1137/0314056.

[50] R. T. Rockafellar, On the Maximality of Sums of nonlinear Monotone Operators," Transactions of the American Mathematical Society 149 (1970) 75-88. http://dx.doi.org/10.1090/S0002-9947-1970-0282272-5.

[51] R. Wangkeeree, U. Kamraksa, A general iterative method for solving the variational inequality problem and fixed point problem of an infinite family of nonexpansive mappings in Hilbert spaces, Fixed point theory and applications (2009), Article ID 369215, 23 pages.

[52] S.Matsushita and Kuroiwa, Approximation of fixed points of nonexpansive nonself mappings,Sci. Math. Jpn. 57(2003) 171-176.

[53] S. Y. Cho, Approximation of solutions of a generalized variational inequality problem based on iterative methods, Commun Korean Math. Soc. 25 (2010) 207-214. http://dx.doi.org/10.4134/CKMS.2010.25.2.207.

[54] T. H. Kim, H. K. Xu, Convergence of modified Mann's iteration method for asymptotically strict pseudocontractions, Nonlinear Anal. 68 (2008) 2828-2836. http://dx.doi.org/10.1016/j.na.2007.02.029.

[55] W. Takahashi, Non-linear functional Analysis, Yokohama Publisher, Yokohama Japan, 2000

[56] W. Takahashi, T. Tamura, Convergence Theorems for a pair of nonexpansive Mapping, Journal of Convex Analysis 5 (1998) $45-56$.

[57] W. Takahashi, M. Toyoda, Weak convergence theorems for nonexpansive mappings and monotone Mappings, Journal of Optimization Theory and Applications 118 (2003) 417-428. http://dx.doi.org/10.1023/A:1025407607560.

[58] X. Qin, S. M. Kang, S. U. Yongfu, M. Shang, Strong convergence of an iterative method for variational inequality problems and fixed point problems, Archivum Mathematicum(BRNO) Tomus 45 (2009) 147-158.

[59] X. Qin, Y. J. Cho and S. M. Kang, Convergence of an iterative algorithm for systems of variational inequalities and nonexpansive mappings with applications, J. Comput. Appl. Math. 233(2009) 231-240. http://dx.doi.org/10.1016/j.cam.2009.07.018.

[60] Y. Chen, H. He and R. Chen, Fixed point solutions of variational inequalities for asymptotically pseudocontractive mappings in Banach spaces, Applied Mathematical Sciences 1 (2007) 2735-2745.

[61] Y. C. Liou, Y. Yao, C. W. Tseng, H. T. Lin and P. X. Yang, Iterative algorithms approach to variational inequalities and fixed point problems, Abstract and applied analysis(2012) Article ID 949141, 15 pages.

[62] Y. Qing, S. Y. Cho, X. Qin, Convergence of iterative sequences for strict pseudocontractions and inverse strongly monotone mappings, Advanced modeling and optimization 13, 2(2011).

[63] Y. Yao and J. C. Yao On modified iterative method for nonexpansive mappings and monotone mappings, Appl. Math. Comput. 186(2007) 1551-1558. http://dx.doi.org/10.1016/j.amc.2006.08.062.

[64] Y. Yao, M. A. Noor, K. I. Noor and Y. C. Loiu, On an iterative algorithm for variational inequalities in Banach spaces, Mathematical communications, 16(2011) 95-104.

[65] Y. Yao and M. A. Noor, on viscosity iterative methods for variational inequalities, J. Math. Anal. Appl. 325(2007) 776-787. http://dx.doi.org/10.1016/j.jmaa.2006.01.091

[66] Y. Yao, M. Postolache, Iterative methods for pseudomonotone variational inequalities and fixed point problems, J Optim Theory Appl (2012)155: 273-287. http://dx.doi.org/10.1007/s10957-012-0055-0.

[67] Y. Yao, Y. C. Liou, J. C.Yao, An extragradient method for fixed point problems and variational inequality problems, J of inequalities and applications (2007) 12 pages.

[68] Z. Opial,Weak convergence of the sequence of successive Approximations of Nonexpensive Mappings, Bulletin of the American Mathematical Society 73 (1967) 591-597. http://dx.doi.org/10.1090/S0002-9904-1967-11761-0. 